UNIVERSIDADE DE SÃO PAULO

FACULDADE DE ECONOMIA, ADMINISTRAÇÃO E CONTABILIDADE DEPARTAMENTO DE ECONOMIA PROGRAMA DE PÓS-GRADUAÇÃO EM ECONOMIA

RISCO DOWNSIDE E COVAR NO MERCADO BRASILEIRO DE AÇÕES

Thiago Basso Alexandrino

Orientador: Prof. Dr. Joe Akira Yoshino

SÃO PAULO 
Prof. Dr. João Grandino Rodas

Reitor da Universidade de São Paulo

Prof. Dr. Reinaldo Guerreiro

Diretor da Faculdade de Economia, Administração e Contabilidade

Prof. a Dr. Joaquim José Martins Guilhoto

Chefe do Departamento de Economia

Prof. Dr. Márcio Issao Nakane

Coordenador do Programa de Pós-Graduação em Economia 


\title{
RISCO DOWNSIDE E COVAR NO MERCADO BRASILEIRO DE AÇÕES
}

\author{
Dissertação apresentada ao Departamento \\ de Economia da Faculdade de Economia, \\ Administração e Contabilidade da \\ Universidade de São Paulo como requisito \\ para obtenção do título de Mestre em \\ Ciências.
}

Orientador: Prof. Dr. Joe Akira Yoshino

\section{Versão Original}

\section{SÃo PAULO}


FICHA CATALOGRÁFICA

Elaborada pela Seção de Processamento Técnico do SBD/FEA/USP

Alexandrino, Thiago Basso

Risco Downside e CoVaR no mercado brasileiro de ações /

Thiago Basso Alexandrino. - São Paulo, 2013.

$76 \mathrm{p}$.

Dissertação (Mestrado) - Universidade de São Paulo, 2013.

Orientador: Joe Akira Yoshino.

1. Risco 2. Risco sistemático 3. Downside Risk 4. CoVaR 5. Mercado de capitais I. Universidade de São Paulo. Faculdade de Economia, Administração e Contabilidade. II. Título. 
Aos meus avós 
Agradeço a Deus pela saúde e pela vida, que me possibilitaram realizar esta dissertação.

Agradeço ao Professor Joe Akira Yoshino, meu orientador, por sempre me encorajar nas pesquisas com suas sábias palavras. Nunca me esquecerei do dia em que me disse que eu fazia parte da "família". Obrigado desde o primeiro dia em que estive na FEA. Ao Professor Marcelo Bianconi também ficam registrados os meus mais sinceros agradecimentos por estar sempre por perto, mesmo estando longe. Suas ideias e sugestões sobre o estudo foram de extrema importância para a conclusão da pesquisa. Ao Professor Bruno Giovannetti por fazer parte da banca de qualificação e por suas sugestões.

Agradeço aos meus pais, meus avós, à minha família inteira, porque esse é o maior bem que uma pessoa pode ter.

Meus amigos do colégio, da faculdade e do mestrado também possuem sua parcela de contribuição nesse processo de crescimento acadêmico e pessoal, pois sempre aprendemos com as experiências dos outros, além é claro, dos bons momentos vividos. Agradeço aos Professores da faculdade e do mestrado pelos conhecimentos transmitidos ao longo desses seis anos e meio de convivência.

Por fim, agradeço ao CNPq pelo apoio financeiro para estudar durante os dois anos iniciais do mestrado. 


\section{RESUMO}

Um dos objetivos deste estudo é testar modelos de precificação de ativos financeiros, especialmente o de risco downside de Ang et al. (2006), em todas as ações da Bovespa, para o período que se estende de janeiro de 1999 a julho de 2012. Para atingi-lo, aplica-se o método de regressões Fama e MacBeth (1973) com retornos um período à frente. A quase totalidade dos modelos testados é rejeitada, inclusive a existência de um eventual prêmio para o risco downside. A exceção é o modelo que inclui com o beta tradicional e o seu quadrado, o que permite rejeitar o CAPM devido a não linearidade no risco de mercado. A relação existente entre o beta e o retorno das ações seria positiva até beta igual a 0,642 e depois negativa. Outra meta desta dissertação é comparar as estimações condicionais às não condicionais do modelo CoVaR de Adrian e Brunnermeier (2011) para as 16 ações da Bovespa utilizadas por Almeida et al. (2012), que obtiveram apenas estimações não condicionais para o Brasil em um período semelhante. Os resultados daqui mostram uma baixa e não estatisticamente significante correlação com os de Almeida et al. (2012). Para este estudo, tem-se que as duas formas de calcular o CoVaR são similares para o teste de estresse, mas não para o risco sistêmico. 


\begin{abstract}
This research pursues as an objective to test cross-sectional returns of some asset pricing models, specially the downside risk suggested by Ang et al. (2006). To accomplish this goal, all the Brazilian Bovespa's stocks are used, from January 1999 to July 2012, in one month forward returns Fama-MacBeth regressions. Not only the downside risk model is rejected: almost all models, including the traditional CAPM and versions of the 3 factors Fama-French. A nonlinear CAPM (beta and beta squared) is the exception in the universe of tested models, which produces the best predictions and a positive relationship between betas and forward returns until beta equals 0,642, after this value, the relationship becomes negative. Another issue followed by this study is to compare conditional estimates of the CoVaR model of Adrian and Brunnermeier (2011) with the unconditional ones for the sixteen stock used by Almeida et al. (2012) unconditionally estimates. The results show low and not statistically significant correlation with Almeida's estimates. For the sample used here, comparing the conditional and the unconditional methodologies suggests a great similarity for the stress test, but not so close results for the systemic risk.
\end{abstract}




\section{SUMÁRIO}

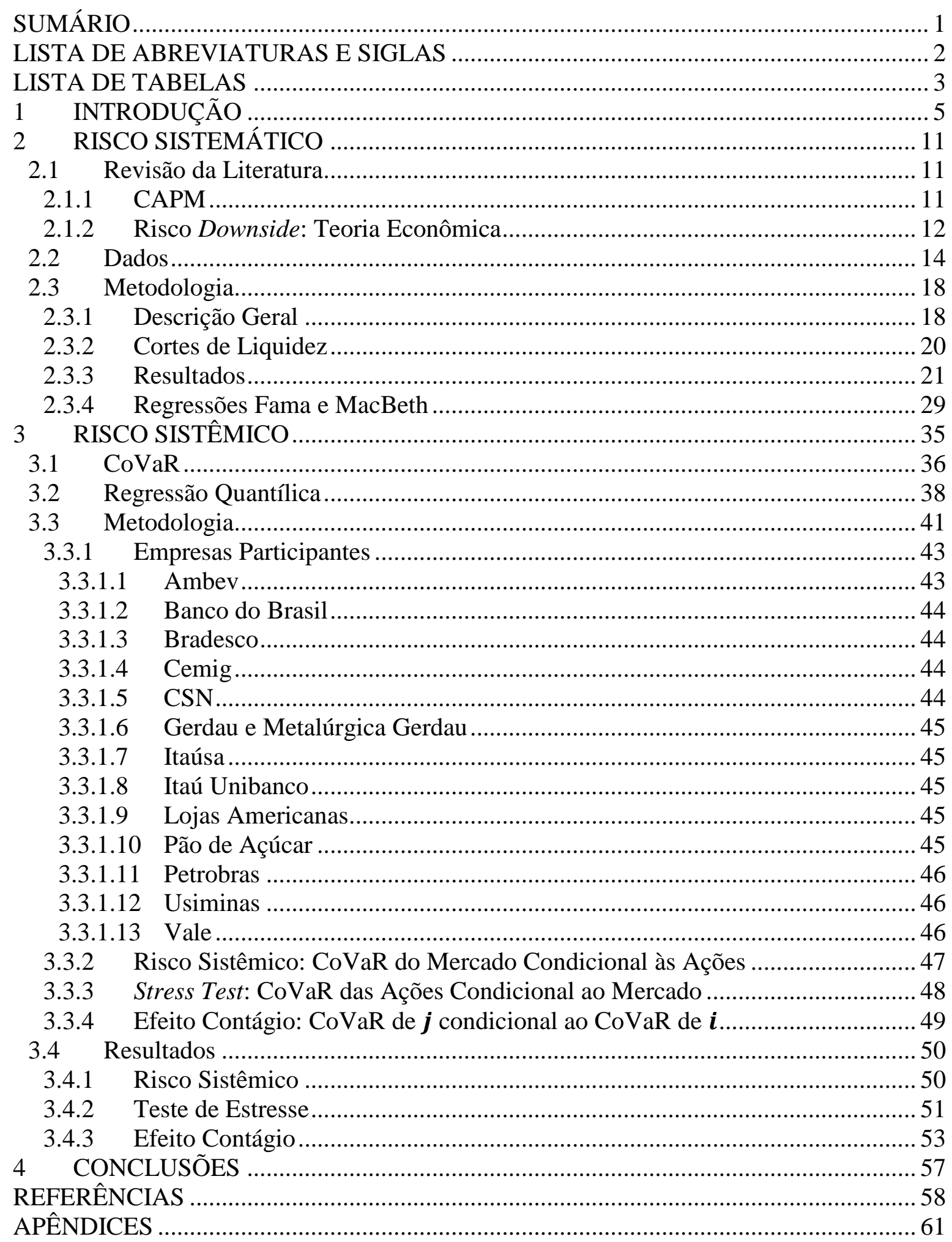




\section{LISTA DE ABREVIATURAS E SIGLAS}

CAPM: Capital Asset Pricing Model

B-M: Book-to-Market

Bovespa: Bolsa de Valores de São Paulo

EUA: Estados Unidos da América

CoVaR: Comovement Value at Risk

VaR: Value at Risk

LPM-CAPM: Lower Partial Moment

CDI: Certificado de Depósito Interbancário

Selic: Sistema Especial de Liquidação e de Custódia

Ibovespa: Índice Bovespa

VW: Value-Weighted

MQO: Mínimos Quadrados Ordinários

MDA: Mínimos Desvios Absolutos

T-bills: Treasury Bills

S\&P: Standard \& Poors

AMBV4: Ação Preferencial da Ambev

BBAS3: Ação Ordinária do Banco do Brasil

BBDC4: Ação Preferencial do Bradesco

CMIG4: Ação Preferencial da Cemig

CSNA3: Ação Ordinária da CSN

GGBR4: Ação Preferencial da Gerdau

GOAU4: Ação Preferencial da Metalúrgica Gerdau

ITSA4: Ação Preferencial da Itausa

ITUB4: Ação Preferencial do Itaú Unibanco

LAME4: Ação Preferencial das Lojas Americanas

PCAR4: Ação Preferencial do Pão de Açúcar

PETR3: Ação Ordinária da Petrobras

PETR4: Ação Preferencial da Petrobras

USIM5: Ação Preferencial A da Usiminas

VALE3: Ação Ordinária da Vale

VALE5: Ação Preferencial A da Vale 


\section{LISTA DE TABELAS}

Tabela 1 - Estatísticas Descritivas do Ibovespa, VW, CDI e Selic ................................. 17

Tabela 2 - Carteiras Formadas por Medidas de Risco Utilizando o Índice VW ............ 23

Tabela 3 - Carteiras Formadas por Medidas de Risco Utilizando o Ibovespa ............... 28

Tabela 4 - Regressões Fama-MacBeth com Intercepto VW ........................................ 33

Tabela 5 - Regressões Fama-MacBeth com Intercepto Ibovespa.................................. 34

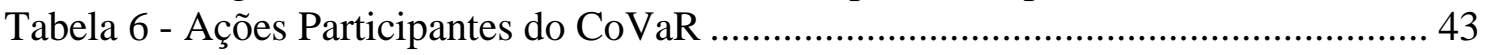

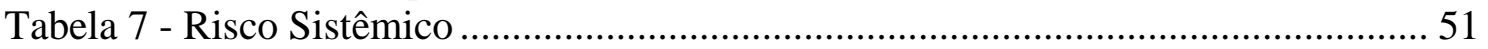

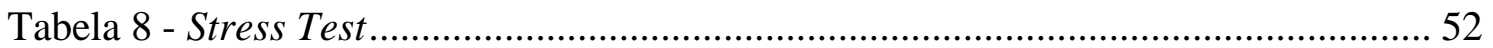

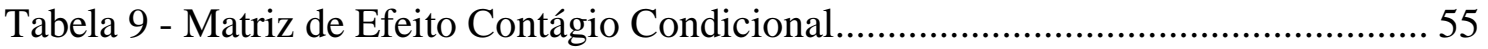

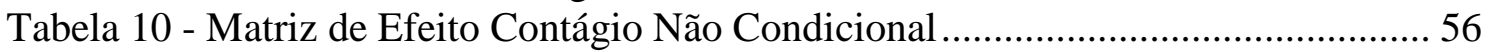

Tabela 11 - Testes de Raiz Unitária para as Variáveis Macroeconômicas Defasadas ... 61

Tabela 12 - Portfólios com Retornos em 60 Meses Anualizados.................................. 62

Tabela 13 - Portfólios Formados pelo Beta Downside com Retornos Mês à Frente Anualizados, em Diferentes Cortes de Liquidez ....................................... 63

Tabela 14 - Portfólios Formados pelo Beta Upside, com Retornos Mês à Frente Anualizados, em Diferentes Cortes de Liquidez ..................................... 65

Tabela 15 - Portfólios Formados pelo Beta, com Retornos Mês à Frente Anualizados, em Diferentes Cortes de Liquidez ......................................................... 67

Tabela 16 - Portfólios Formados pelo Beta Downside Relativo, com Retornos Mês à Frente Anualizados, em Diferentes Cortes de Liquidez .............................. 69 


\section{INTRODUÇÃO}

Uma das formas de se melhorar a precificação de ativos em relação ao modelo-padrão, Capital Asset Pricing Model (CAPM), é por meio de modelos que contemplem outras medidas de risco que não o de mercado. O desvio-padrão está presente no CAPM em razão do beta, implicando qualquer oscilação do retorno como arriscada e indesejada, mesmo aquelas acima da média. Essa hipótese remonta aos pressupostos desenvolvidos por Markowitz (1952) e é vista como uma das possíveis causas das falhas empíricas daquele modelo.

Medidas assimétricas de risco tem se mostrado boas alternativas ao desvio-padrão, como indicou Estrada (2002). A principal característica dessas medidas é tratar como risco apenas as variações consideradas indesejadas do retorno, ou seja, aquelas abaixo de um referencial - normalmente a média não condicional do retorno ou o retorno do ativo livre de risco. São chamadas assimétricas por capturarem características do terceiro momento da distribuição de retornos, a assimetria, e também do segundo momento. Encaixa-se nessa categoria o beta downside proposto por Ang et al. (2006), proveniente de um modelo teórico. Computa apenas as covariações nos instantes de tempo em que o excesso de retorno do mercado esteja abaixo de sua média no período, por isso é uma medida assimétrica. Por meio de testes cross-section dos retornos em vários modelos de precificação, os autores concluem que os resultados são condizentes com o previsto pelo modelo, especialmente para o beta downside e o beta downside relativo.

Note que variações para cima de um referencial também poderiam ser consideradas ruins, se a venda a descoberto não sofresse severas restrições legais e de liquidez. Em Ang et al. (2006), as realizações acima da média do excesso de retorno do mercado são descontos (oposto de risco), ou seja, ativos mais expostos ao beta upside teriam retornos esperados menores que os menos expostos. 
O presente estudo tem por objetivo testar o modelo de risco downside proposto por Ang et al. (2006), e outros modelos tradicionais, como o CAPM, e ainda modelos que incluam tamanho, book-to-market (B-M) para o mercado brasileiro de ações. Para isso serão utilizados dados de todas as ações da Bolsa de Valores de São Paulo (Bovespa), durante o período que se inicia em janeiro de 1999 e se estende até julho de 2012.

Como resultado, ao contrário do encontrado em Ang et al. (2006), a conclusão aponta a irrelevância do beta downside para explicar diferenças na cross-section dos retornos esperados para os papéis brasileiros no período. Apenas um dos modelos testados alcançou resultados satisfatórios em termos de significância estatística. Esse modelo possui como fatores de risco o beta tradicional e seu termo ao quadrado, indicando uma relação não linear entre risco de mercado e retorno, o que implica a rejeição do CAPM, como argumentam Fama e MacBeth (1973). Do ponto de vista estatístico, encontrou-se que: beta, beta downside, beta upside, tamanho, B-M e liquidez não são estatisticamente significantes. Apesar de não relevantes, tamanho e liquidez desempenharam seus papéis esperados: firmas menores retornaram, em média, mais que as maiores, assim como as ações menos líquidas acompanham um maior retorno esperado. Na direção contrária de seus papéis esperados, o beta e o beta downside tiveram predominantemente um papel de desconto, ao passo que o beta upside mostrou-se um risco na maioria das regressões.

Algumas explicações podem ser apontadas para os resultados encontrados por este trabalho não serem semelhantes aos de Ang et al. (2006). Primeiramente, as regressões Fama-MacBeth possuem apenas 102 meses, um número baixo decorrente das limitações impostas pelo mercado brasileiro (períodos de inflação alta ou instabilidade macroeconômica até o ano de 1999 são excluídos da amostra). Isso pode ter contribuído para a ausência de significância estatística. Por sua vez, o estudo norte-americano contava com dados mensais de 1962 até 2001, cerca de quatro vezes o tamanho desta amostra. 
Em segundo lugar, a média do excesso de retorno para o mercado brasileiro foi de apenas $1,64 \%$ ao ano no período analisado ${ }^{1}$, decorrente em grande parte da crise de 2008. Já Mehra e Prescott (1985) encontram o prêmio de risco da ordem de $6 \%$ ao ano para os EUA no período de 1889-1978, com alguns subperíodos de 10 anos de prêmio de risco bastante baixo, chegando a um mínimo de 0,18\% ao ano em 1929-1938.

Por fim, Ang et al. (2006) testam o modelo com os retornos contemporâneos às medidas de riscos. Já este trabalho utiliza retornos um mês à frente em relação às medidas de risco. Dessa forma, os resultados aqui encontrados são compatíveis com os de um investidor atuante durante o período da amostra. Considera-se isso um diferencial metodológico deste trabalho, já que as regressões ganham um componente preditivo, out-of-sample. O principal respaldo dessa metodologia é Fama e MacBeth (1973) e suas regressões homônimas também de caráter preditivo.

Além de estudar risco sistemático para o mercado brasileiro, esta dissertação busca compreender melhor medidas de risco sistêmico no mercado de ações brasileiro durante o mesmo período. Eventos financeiros ruins, como a crise de 2008, aumentaram consideravelmente o interesse de economistas, investidores e formuladores de políticas econômicas pelo estudo do risco sistêmico entre ativos. Hansen (2012) analisa os avanços já obtidos com algumas medidas de risco sistêmico, sumariza os desafios a serem superados, bem como salienta a importância do controle de risco sistêmico para um mercado financeiro e uma economia saudável.

Uma dessas medidas analisadas é o Comovement Value at Risk (CoVaR) definido em Adrian e Brunnermeier (2011). O CoVaR é o VaR (Value at Risk) de uma instituição $j$, condicional ao VaR de uma outra instituição $i$. Almeida et al. (2012) estimaram-no para 16 ações no Brasil, com o uso de VaRs tradicionais num primeiro estágio para, em seguida, obterem os CoVaRs. Essa é a chamada estimativa não condicional. Contudo existe outra possibilidade de estimá-lo, condicionando o $\mathrm{VaR}$ a variáveis macroeconômicas defasadas (variáveis-estado), para depois estimar o CoVaR

\footnotetext{
${ }^{1}$ Medido pelo índice de mercado ponderado pelo valor de mercado de todas as ações da bolsa brasileira e o CDI, construído pelos autores deste estudo. Quando obtido pelo Ibovespa e CDI, a média chega a $0,19 \%$ aa.
} 
condicional ao $\mathrm{VaR}$ da primeira instituição e às mesmas variáveis-estado. $\mathrm{O}$ modelo captura a transmissão do risco entre entidades do mercado financeiro em situações de crise, ao condicionar o VaR de uma instituição ao de outra.

Outro ponto interessante do CoVaR é a capacidade de capturar todas as possíveis formas de transmissão de risco, seja no sentido mercado para ação, ação para mercado ou ainda ação A para ação B, fazendo-o possuir um forte apelo prático no controle de risco de agentes financeiros.

Para a estimação, utilizou-se as mesmas 16 ações de Almeida et al. (2012), numa base de dados que cobre 74\% do período estudado por aqueles autores. Estima-se todos os três sentidos de transmissão de risco para o CoVaR: risco sistêmico (risco da ação influenciando o risco do mercado), teste de estresse (risco do mercado influenciando o risco da ação) e matriz de efeito contágio (risco de uma ação $j$ influenciando o risco de outra ação $i$ ). Os resultados apontam para uma alta e estatisticamente significante correlação entre as estimativas condicionais e não condicionais para o stress test de 0,93, mas para o risco sistêmico foi obtido uma correlação não estatisticamente significante de 0,41. Comparando com os resultados de Almeida et al. (2012), constatase uma baixa correlação $(0,23)$ entre as medidas do CoVaR dos dois estudos. Um fato interessante é a ação preferencial da Petrobras (PETR4) não desempenhar um papel tão importante para a transmissão de risco, em qualquer um dos sentidos, quanto apresentou naquele trabalho.

Quanto ao risco sistêmico o papel mais influente para o risco do mercado foi o preferencial da Metalúrgica Gerdau (GOAU4) na estimação condicional. Ao passo que na não condicional foi BBDC4. No teste de estresse a ação da AMBV4 foi, nas duas metodologias, o papel menos influenciado pelo mercado, resultado também obtido por Almeida et al. (2012). Na matriz de efeito contágio tanto na condicional, quanto na não condicional, a ação preferencial da Ambev apresentou-se como a mais resistente às situações ruins de seus pares. Somado a isso, ela também foi a menos influenciada pelo mercado no teste de estresse, fazendo-a a mais imune às situações ruins do mercado e de 
seus pares. Decisões de alocação de risco de uma carteira poderiam ser melhores tomadas a partir desse conhecimento. 


\section{RISCO SISTEMÁTICO}

\subsection{Revisão da Literatura}

\subsubsection{CAPM}

O CAPM é um modelo de equilíbrio geral de apreçamento de ativos financeiros, desenvolvido principalmente por Sharpe (1964) e Lintner (1965). O modelo tem como hipóteses principais: a função de utilidade dos indivíduos a ser maximizada depende apenas da média e do desvio-padrão dos retornos esperados (o primeiro item é um bem enquanto o segundo é um mal), os agentes são homogêneos e não exercem influência sobre o preço dos ativos, há uma taxa de juros livre de risco à qual os agentes podem emprestar e tomar emprestado. O modelo pode ser derivado sobre duas hipóteses: a distribuição de retornos é simétrica-estável, sendo a curva normal uma possibilidade, ou ainda quando a utilidade do investidor for quadrática. Em relação ao conjunto de premissas do CAPM, Lintner (1965) faz um interessante comentário: “os resultados oriundos do modelo proposto não deveriam nortear às práticas de negócio, porque as hipóteses do modelo ignoram muitos dos fatores importantes na vida real". Black (1972) deriva o modelo para o caso em que há restrições de se tomar emprestado à taxa livre de risco, mas não há sobre as vendas a descoberto.

De acordo com o CAPM, os agentes substituem maiores riscos por maiores retornos esperados, sendo o beta-CAPM a medida de risco relevante para o ativo. O desviopadrão exerce um papel importante, fato evidenciado pela presença de seu quadrado, $\operatorname{Var}\left(r_{m, t}^{e}\right)$, na fórmula do beta-CAPM de um ativo $i$ :

$$
\text { I) } \quad \beta_{i}=\frac{\operatorname{Cov}\left(r_{i, t}^{e}, r_{m, t}^{e}\right)}{\operatorname{Var}\left(r_{m, t}^{e}\right)}, i=1,2, \ldots, n
$$

Em que $r_{i, t}^{e}$ é o excesso de retorno do ativo $i$ em relação ao ativo livre de risco no mês $t$ e $r_{m, t}^{e}$ é o excesso de retorno da carteira de mercado em relação ao ativo livre de risco no mês $t$. Ações mais expostas às oscilações do mercado seriam mais arriscadas 
implicando um beta maior. Devido a esse maior risco, seu retorno esperado também deveria ser maior, compensando a maior exposição ao risco. A equação abaixo resume o modelo e vale para qualquer ativo $i$ :

II) $\quad E\left(r_{i, t}^{e}\right)=\beta_{i} E\left(r_{m, t}^{e}\right), i=1,2, \ldots, n$

\subsubsection{Risco Downside: Teoria Econômica}

Empiricamente as falhas do CAPM se acumulam ao longo dos anos, sendo FamaFrench (1992) uma importante referência a respeito. É de grande interesse obter melhores resultados empíricos, objetivo que pode ser alcançado por meio de hipóteses consideradas mais realistas. Com isso em mente, alguns autores passaram a considerar investidores com preferências assimétricas, portanto mais avessos às situações de queda do mercado. Routledge e Zin (2010) sugerem uma nova classe de preferências axiomatizadas chamada de "aversão generalizada ao desapontamento". Realizações muito ruins, que se encontram abaixo de um parâmetro definido com base no equivalente certeza da loteria, seriam penalizadas implicando maior desutilidade em relação à tradicional utilidade esperada.

Ang et al. (2006) apresentam um modelo no qual os agentes possuem utilidade com aversão ao desapontamento, um caso especial do modelo de Routledge e Zin (2010). O resultado também é uma maior aversão às perdas do que aos ganhos, gerando um prêmio ao risco downside ${ }^{2}$. Dessa forma, o risco proveniente do beta-CAPM não é uma estatística suficiente para explicar a relação risco $\times$ retorno de um ativo. Giovannetti (2011) considera um agente com utilidade quantílicas, que consiste na maximização do $\mathrm{VaR}$ de sua utilidade quando defrontado com alternativas diante do risco. $\mathrm{O}$ agente também pondera diferentemente cenários bons e ruins.

A medida de risco downside adotada Ang et al. (2006) é o beta downside, proposto por Bawa e Lindenberg (1977), ao desenvolverem um modelo mais geral que o CAPM,

\footnotetext{
${ }^{2}$ Os autores chegam a uma solução por meio de calibração, ressaltando que o modelo pode não ter solução para alguns valores de parâmetros.
} 
denominado LPM-CAPM (Lower Partial Moment - CAPM), sendo o primeiro um caso especial do último. $\mathrm{O}$ beta downside, $\beta_{i}^{-}$, é dado por:

III) $\quad \beta_{i}^{-}=\frac{\operatorname{Cov}\left(r_{i, t}^{e}, r_{m, t}^{e} \mid r_{m, t}^{e}<\mu_{m}^{e}\right)}{\operatorname{Var}\left(r_{m, t}^{e} \mid r_{m, t}^{e}<\mu_{m}^{e}\right)}$

A equação III) seria idêntica à I), se não fosse o condicionamento nas realizações tais que $r_{m, t}^{e}<\mu_{m}^{e}$ ( $\mu_{m}^{e}$ é a média do excesso de retorno do mercado no período de cômputo). Portanto, apenas as observações cujo excesso de retorno do mercado são inferiores à sua respectiva média são computadas no $\beta_{i}^{-}$, ao contrário do beta-CAPM, em que todas as observações entram no cálculo.

Analogamente, ao condicionar às observações cujo excesso de retorno do mercado é maior que sua própria média, obtém-se o beta upside $\left(\beta_{i}^{+}\right)$:

IV) $\quad \beta_{i}^{+}=\frac{\operatorname{Cov}\left(r_{i, t}^{e}, r_{m, t}^{e} \mid r_{m, t}^{e}>\mu_{m}^{e}\right)}{\operatorname{Var}\left(r_{m, t}^{e} \mid r_{m, t}^{e}>\mu_{m}^{e}\right)}$

Tudo o mais constante, um maior beta upside implica menores retornos esperados. Isso ocorre, porque as ações estariam mais expostas às oscilações positivas do mercado, uma boa característica. Portanto, o beta upside seria um desconto e não um prêmio de risco.

Estrada (2002) argumenta que uma medida de risco semelhante ao $\beta_{i}^{-}$também capturaria o componente de variação dos retornos, o chamado segundo momento, e a assimetria da distribuição (terceiro momento), uma vez que pondera distintamente as observações menores e maiores que um benchmark com pesos respectivamente um e zero:

V) $\quad \beta_{i}^{E s t r a d a}=\frac{\operatorname{Cov}\left(r_{i, t}^{e}, \operatorname{Min}\left(r_{m, t}^{e}, 0\right)\right)}{\operatorname{Var}\left(\operatorname{Min}\left(r_{m, t}^{e}, 0\right)\right)}$

Com sua própria medida de risco, esse autor obtém bons resultados para países emergentes em relação ao obtido com o CAPM. Como possível explicação argumenta 
que nesses países a distribuição de retornos seria mais assimétrica que nos países desenvolvidos. Isso deterioraria os resultados do CAPM, uma vez que distribuição simétrica é uma das possíveis hipóteses para a derivação do modelo.

Não há nenhum estudo que se propôs a testar o modelo de Ang et al. (2006) para o Brasil. Fortunato et al. (2010) testam o modelo de risco downside proposto por Estrada, que possui o mesmo fundamento assimétrico do beta downside, e chegam à conclusão de que não é apropriado ao mercado acionário brasileiro.

\subsection{Dados}

A periodicidade da amostra deste estudo é mensal, com dados de final de mês, abrangendo janeiro de 1999 a julho de 2012. Janeiro de 1999 é um mês marcante, porque houve um importante ponto de inflexão na história econômica do Brasil:o dólar tornou-se flutuante, afetando um dos principais preços da economia, a taxa de câmbio real por dólar. Acredita-se que essa seja uma mudança estrutural de grande relevância em relação ao período anterior, o que torna interessante o início da amostra em janeiro de 1999.

Os dados referentes às empresas foram obtidos pelo software Economática. A amostra abrange todas as ações negociadas em algum dia no período estudado. Isso inclui as ações disponíveis para o investidor no passado, mas que tenham saído da bolsa por algum motivo como: falência, fusão, venda, etc. Dessa forma, pode-se afirmar que por incluir todas as ações possíveis no período estudado, este estudo testará modelos para o mercado brasileiro de ações, o que não acontece com outros autores como: Garcia e Bonomo (2001) e Rostagno et al. (2004). Por outro lado, Machado e Medeiros (2011) é um bom exemplo de artigo que considera todas as ações da Bovespa.

Uma ação é incluída no universo de papéis considerado sempre que apresentar o primeiro registro de preço ajustado, inclusive para dividendos $\left(P A j_{t}\right)$. Dessa forma, no mês seguinte é possível calcular seu retorno contínuo mensal $\left(r_{t}\right)$, definido em VI). O 
único critério de exclusão do universo é a possível saída da Bovespa ${ }^{3}$, sendo o mês de saída seu último mês na amostra. Ao todo 946 ações integram esse universo e, dessas, 668 foram incluídas em algum momento do estudo, depois de respeitadas as regras de inclusão por volume ${ }^{4}$.

$$
\text { VI) } \quad r_{t}=\ln \left(\frac{P A j_{t}}{P A j_{t-1}}\right)
$$

A taxa de juros do Certificado de Depósito Interbancário (CDI) foi coletada pelo endereço eletrônico do Banco Central do Brasil ${ }^{5}$. Essa taxa será usada como proxy para a taxa de juros do ativo livre de risco do mercado brasileiro. Não há consenso em relação a qual ativo desempenharia melhor a função de "livre de risco" no mercado brasileiro. A vantagem do CDI em relação à taxa Selic, por exemplo, é que essa última é utilizada como instrumento de política monetária, contendo um viés político em sua determinação. Como pode ser visto na Tabela 1, não há diferenças significantes nas principais estatísticas descritivas dessas duas taxas.

A taxa de juros também é calculada de forma contínua. Em primeiro lugar, a taxa CDI anual é convertida em mensal $\left(R_{t}^{f}\right)$. Depois, o retorno discreto é transformado em contínuo:

VII) $\quad r_{t}^{f}=\ln \left(1+R_{t}^{f}\right)$

Já para a carteira eficiente de mercado há o tradicional Ibovespa, largamente utilizado como sua proxy nos estudos brasileiros. Improta (2012) utilizou além do Ibovespa um índice value-weighted (VW) de todas as ações de sua amostra. Isso é condizente com grande parte dos trabalhos norte-americanos. Aqui além do Ibovespa, também foi calculado um índice VW representativo de todo o mercado brasileiro de ações, ponderando os retornos contínuos de cada ação pela sua respectiva participação no valor

\footnotetext{
${ }^{3}$ A data exata da saída é informada pela Bovespa em seu site http://www.bmfbovespa.com.br

${ }^{4}$ Mais detalhes na Seção 2.3 Metodologia.

${ }^{5}$ http://www.bcb.gov.br/
} 
de mercado de todos os ativos da amostra ${ }^{6}$. Os pesos, ao contrário de Improta (2012), mas a exemplo do que ocorre com o Ibovespa, variam quadrimestralmente todos os meses de abril, agosto e dezembro valendo para os quatro meses seguintes. A exceção ocorre no início da amostra quando é utilizado o peso do mês de janeiro para os três meses seguintes (fevereiro, março e abril de 1999).

Os excessos de retornos de um ativo em relação ao ativo livre de risco são definidos como:

VIII) $\quad r_{t}^{e}=r_{t}-r_{t}^{f}$

Portanto, o excesso de retorno de um ativo qualquer em um dado mês, nada mais é o quanto esse ativo retorna a mais em relação ao ativo livre de risco.

As estatísticas descritivas do excesso de retorno do mercado em relação ao ativo livre de risco $\left(r_{m, t}^{e}\right)$ e das próprias taxas de juros do ativo livre de risco $\left(r_{t}^{f}\right)$ são apresentadas na Tabela 1, juntamente com o p-valor do teste de Jarque-Bera sobre uma eventual distribuição normal das variáveis. Como resultados, observa-se que não há diferenças significativas quando se utiliza o CDI ao invés da Selic e rejeita-se a normalidade das séries, o que no caso dos excessos de retorno do mercado pode vir a prejudicar a validação do modelo CAPM, uma vez que a normalidade do retorno de mercado pode ser uma de suas hipóteses.

\footnotetext{
6 Exceção foram as units, para as quais se utilizou o valor de mercado da empresa, devido à indisponibilidade dos dados de valor de mercado do ticker para essa categoria de ativos.
} 
Tabela 1 - Estatísticas Descritivas do Ibovespa, VW, CDI e Selic

\begin{tabular}{|c|c|c|c|c|c|c|}
\hline Variáveis & $r_{m, t}^{e}$ & $r_{m, t}^{e}$ & $r_{m, t}^{e}$ & $\boldsymbol{r}_{m, t}^{e}$ & $r_{t}^{f}$ & $r_{t}^{f}$ \\
\hline Utilizando & $\begin{array}{c}\text { Ibovespa e } \\
\text { CDI }\end{array}$ & $\begin{array}{c}\text { Ibovespa e } \\
\text { Selic }\end{array}$ & VW e CDI & VW e Selic & CDI & Selic \\
\hline $\begin{array}{l}\text { Num. de } \\
\text { Observações }\end{array}$ & 162 & 162 & 162 & 162 & 162 & 162 \\
\hline Média & $-0,01$ & $-0,02$ & 0,14 & 0,14 & 1,20 & 1,21 \\
\hline Mediana & 0,20 & 0,20 & 0,65 & 0,65 & 1,22 & 1,22 \\
\hline Desvio-Padrão & 7,84 & 7,84 & 6,45 & 6,45 & 0,37 & 0,38 \\
\hline Assimetria & $-0,39$ & $-0,39$ & $-0,54$ & $-0,54$ & 1,09 & 1,21 \\
\hline Curtose & 3,62 & 3,62 & 4,64 & 4,64 & 5,33 & 6,18 \\
\hline $\begin{array}{l}\text { Teste de } \\
\text { Normalidade (p- } \\
\text { valor) }\end{array}$ & $3,57 \%$ & $3,53 \%$ & $0 \%$ & $0 \%$ & $0 \%$ & $0 \%$ \\
\hline
\end{tabular}

O teste de normalidade Jarque-Bera possui como hipótese nula a distribuição normal dos dados. Logo, pvalores menores do que 5\% implicam rejeição da hipótese nula a um nível de significância de 5\%.

Abaixo, é apresentado o gráfico contendo os índices VW e o Ibovespa, normalizados em 1 no mês de fevereiro de 1999. A correlação entre eles é alta $(0,984)$, mostrando uma grande semelhança, apesar do VW consistentemente ser maior que o Ibovespa.

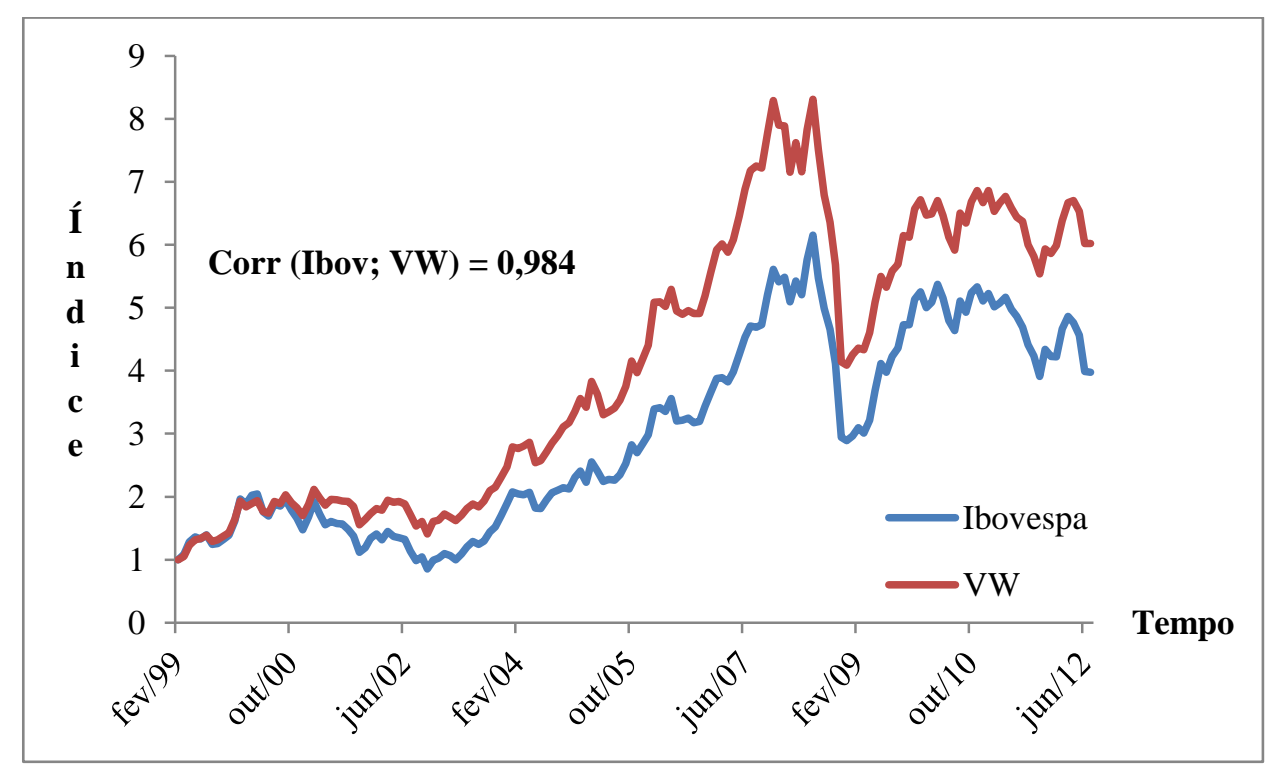

Figura 1 - Índices VW × Ibovespa 
Por fim, outras variáveis relevantes para o estudo são: valor de mercado da empresa e da classe, razão preço da ação sobre valor patrimonial por ação (cujo inverso multiplicativo é proxy para B-M) e volume financeiro movimentado pelo ticker.

\subsection{Metodologia}

\subsubsection{Descrição Geral}

Antes do teste propriamente dito do modelo de risco downside, é interessante verificar como se comportam os excessos de retorno de carteiras formadas a partir da classificação das ações quanto a algumas medidas de risco. Como indicador do desempenho dessas carteiras, Ang et al. (2006) utilizam o retorno contemporâneo às medidas de risco. Por outro lado, Fama e MacBeth (1973) utilizam o excesso de retorno um mês à frente no teste de seus modelos, tornando possível analisar a rentabilidade de um investidor que estruturasse suas operações baseadas nesses modelos. Neste estudo, foram realizadas as duas metodologias, mas a de retornos contemporâneos é apresentada apenas no Apêndice, devido ao forte apelo prático que o retorno um mês à frente oferece.

O cálculo das medidas de risco é feito mensalmente em uma janela móvel de 60 meses. Em seguida, dez carteiras são formadas e as ações ponderadas com pesos iguais. A seleção das ações para cada portfólio é feita de acordo com o decil da distribuição da medida de risco em questão, de tal forma que as ações cujas medidas de risco forem as 10\% menores estejam na mesma carteira (denominada P1). Depois, aquelas correspondentes ao próximo decil (maiores ou iguais a $10 \%$ e menores que $20 \%$ ) são agrupadas em outra carteira (P2) e assim sucessivamente. Qualquer ação da bolsa brasileira, em cada um dos meses da amostra, é elegível à formação das carteiras, desde que tenha um volume de negócio positivo em pelo menos 24 dos 60 meses $^{7}$ de cada uma das janelas móveis. Quando uma ação sai da Bovespa fica inelegível para a formação da carteira no mês da saída, mas nesse mês, seu excesso de retorno ainda é considerado na apuração dos resultados da carteira formada no mês anterior. A

\footnotetext{
${ }^{7}$ Fama e French (1992) utilizam esse critério de pelo menos 24 meses de presença em 60 meses possíveis.
} 
metodologia para a formação das carteiras descrita retrata fielmente as condições com as quais um investidor se defrontaria em cada um dos meses da amostra.

Como o período de cálculo das medidas de risco é de 60 meses, o investidor realizaria sua primeira escolha de carteiras ao final do mês de janeiro de 2004. A escolha vigeria para o mês de fevereiro de 2004, quando ao final desse mês, os excessos de retorno dos portfólios seriam apurados e a metodologia aplicada novamente. $\mathrm{O}$ último mês em que as carteiras são formadas é junho de 2012, com rentabilidade apurada referente a julho de 2012.

No Apêndice, são disponibilizados os resultados para os excessos de retornos contemporâneos, como em Ang et al. (2006). Lá as medidas de risco calculadas em janeiro de 2004, utilizando 60 meses de informação, são confrontadas com o excesso de retorno desse mesmo período. Dessa maneira, é impossível a aplicação dessa metodologia por um investidor, servindo apenas como possível teste do modelo.

As medidas de risco utilizadas para a formação das carteiras são: beta-CAPM, beta downside, beta upside, o beta downside relativo em relação ao beta-CAPM, de agora em diante apenas beta downside relativo, o beta upside relativo em relação ao beta-CAPM, de agora em diante apenas beta upside relativo, e por fim o beta upside menos o beta downside. O beta-CAPM é definido por I) e sua contrapartida amostral é:

IX) $\quad \beta_{i, t}=\frac{\sum_{t=1}^{T}\left(r_{i, t}^{e}-\overline{r_{l}^{e}}\right)\left(r_{m, t}^{e}-\overline{r_{m}^{e}}\right)}{\sum_{t=1}^{T}\left(r_{m, t}^{e}-\overline{r_{m}^{e}}\right)^{2}}$

Já os betas downside e upside são respectivamente:

$\mathrm{X}) \quad \beta_{i, t}^{-}=\frac{\sum_{r_{m, t}^{e}<\bar{r}_{m}}\left(r_{i, t}^{e}-\overline{r_{l}^{e}}\right)\left(r_{m, t}-\overline{r_{m}^{e}}\right)}{\sum_{r_{m, t}^{e}} \bar{r}_{m}\left(r_{m, t}^{e}-\bar{r}_{m}\right)^{2}}$

$\mathrm{XI} \quad \beta_{i, t}^{+}=\frac{\sum_{r_{m, t}^{e}>\bar{r}_{m}}\left(r_{i, t}^{e}-\overline{r_{l}^{e}}\right)\left(r_{m, t}^{e}-\overline{r_{m}^{e}}\right)}{\sum_{r_{m, t}^{e}}>_{\bar{r}_{m}}\left(r_{m, t}^{e} \overline{r_{m}^{e}}\right)^{2}}$ 
Finalmente, as medidas relativas: o beta downside relativo é a diferença entre o beta downside e o beta-CAPM $\left(\beta_{i, t}^{-}-\beta_{i, t}\right)$. Por sua vez, o beta upside relativo é dado por $\left(\beta_{i, t}^{+}-\beta_{i, t}\right)$ e por fim, a última medida presente em Ang et al. (2006) é $\left(\beta_{i, t}^{+}-\beta_{i, t}^{-}\right)$. Será visto mais adiante que essas três medidas podem sempre ser resumidas por qualquer uma dentre elas.

\subsubsection{Cortes de Liquidez}

Muitos estudos para o mercado brasileiro de ações que testam modelos de apreçamento, principalmente o CAPM e o de Estrada (2002), escolhem suas amostras baseadas na composição do Ibovespa ou em outros critérios mais subjetivos de liquidez ${ }^{8}$. Para tornar possível a comparação entre os demais estudos e este, aplica-se a metodologia da seção anterior a diferentes níveis de liquidez (por exemplo, a 90\% das ações mais líquidas), sendo primeiramente respeitados os critérios de inclusão e exclusão definidos na seção 2.3.1, para depois restringir a amostra a certo nível de liquidez.

A liquidez é um conceito amplo na literatura econômica. Sarr e Lybek (2002) apontam cinco características que um mercado líquido exibe. A primeira delas, tightness, referese a baixos custos de transação, que pode ser medido pelo bid-ask spread. A segunda (immediacy) refere-se à velocidade com que as operações são realizadas: quanto mais rápido o negócio se concretizar, mais líquido será o mercado. Depth, a terceira característica, é a existência de grandes e numerosas ordens ao redor do preço atual de mercado. O quarto atributo, breadth, é o baixo impacto que essas ordens grandes e numerosas exercem sobre o preço do ativo em questão. Por fim, o último aspecto de um mercado líquido é resiliency: a capacidade rápida com que novas ordens surjam a fim de corrigir eventuais desvios do preço em relação aos seus fundamentos.

Com o conhecimento dessas características de um mercado líquido, este estudo considerará duas medidas de liquidez, por isso nem todos os atributos descritos por Sarr

\footnotetext{
${ }^{8}$ O Ibovespa é composto por critérios de liquidez e negociabilidade. A grande parte dos estudos selecionam as ações mais líquidas da bolsa.
} 
e Lybek (2002) serão contemplados. A primeira medida de liquidez é sugerida por Amihud (2002):

$$
\text { XII) } \quad L i q_{i, t}^{A}=\frac{1}{T} \sum_{t=1}^{T}\left(\frac{\left|r_{i, t}^{e}\right|}{\operatorname{Volume}_{i, t}}\right)
$$

É uma média, em 60 meses, da razão do módulo do retorno sobre o volume financeiro do respectivo mês. Com isso, quanto menor esse valor, mais líquida será a ação. $\mathrm{O}$ autor interpreta-a como a resposta do preço associada a $\mathrm{R} \$ 1,00$ negociado. Portanto, uma ação líquida não apresenta grandes variações de preços, dado um volume financeiro negociado.

A segunda medida de liquidez é utilizada em Bianconi e Yoshino (2012a) e quanto maior seu valor, maior a liquidez. O desvio padrão é calculado em intervalo de 60 meses e o volume é referente ao último mês utilizado no cálculo do desvio-padrão:

$$
\text { XIII) } \quad \operatorname{Liq}_{i, T}^{B Y}=\frac{\text { olume }_{i, T}}{\left[\left(\frac{1}{T-1}\right)\left(\sum_{t=1}^{T}\left(r_{i, t}^{e}-\overline{r_{l}^{e}}\right)^{2}\right)\right]^{1 / 2}}
$$

A partir dessas medidas de liquidez e da amostra, são feitos cortes em diferentes níveis de liquidez, em cada um dos meses. Com $L i q_{i, t}^{A}$ e $L i q_{i, t}^{B Y}$ as ações são ordenadas das menos líquidas para as mais líquidas, de tal forma que a amostra seja dividida em diversos níveis de liquidez. Isso é equivalente a um investidor ou pesquisador escolher sua carteira apenas as $x \%$ ações mais líquidas da Bovespa, para $x=10,25,40,50,60$, 75,90 .

\subsubsection{Resultados}

A Tabela 2 mostra os resultados para a média anualizada dos excessos de retornos mensais um mês à frente e as médias das medidas de risco para o período de fevereiro de 2004 a julho de 2012 para cada uma das carteiras. Os portfólios formados pelos betas tradicionais não seguem o previsto pela teoria econômica: maiores betas estariam associados a um maior retorno. Pelo contrário, a carteira de maior beta possui a menor 
média de excesso de retorno. Não parece existir algum padrão claro entre os diversos níveis de risco e seus respectivos excessos de retorno.

Dessa forma, o modelo CAPM parece não ser adequado para descrever a cross-section dos retornos realizados nesta amostra, fato a ser comprovado nas regressões Fama e Macbeth. A Tabela 15 localizada no Apêndice apresenta os resultados para os diferentes níveis de liquidez e a situação não se altera: as carteiras de maiores betas são associadas às médias de excesso de retorno negativas e apresentam os piores desempenhos entre os demais portfólios. Contudo, apenas as diferenças entre P10 e P1 dos cortes de 40\% e $90 \%$ são estatisticamente significantes a $5 \%$ bicaudal.

Apesar disso, um fato já documentado na literatura de retornos em cross-section, como em Acharya e Pedersen (2005) e Amihud (2002), surge: um possível prêmio para a falta de liquidez dos ativos que será testado com as regressões Fama e MacBeth. Na penúltima coluna (P10), o excesso de retorno aumenta dos cortes de ativos mais líquidos (primeira linha) para o corte contendo ativos menos líquidos também (última linha do Painel $A$ ). A maior parte das outras colunas repete esse padrão, apesar de não ser linear entre as carteiras. Outra característica advinda da Tabela 15 é notada no Painel $B$ : as ações mais líquidas (10\% mais líquidas) possuem betas sistematicamente maiores que as ações menos líquidas (amostra inteira), resultando numa diferença aproximada de 0,3 nos betas. Portanto, um investidor poderia receber mais rendimento escolhendo ações de baixo beta e baixa liquidez. 
Tabela 2 - Carteiras Formadas por Medidas de Risco Utilizando o Índice VW PAINEL A: Portfólios formados pelo $\beta_{i, t}$ (beta)

\begin{tabular}{|c|c|c|c|c|c|c|c|c|c|c|c|}
\hline Portfólios & $\begin{array}{l}\text { 1: } \beta_{p, t} \\
\text { baixo }\end{array}$ & 2 & 3 & 4 & 5 & 6 & 7 & 8 & 9 & $\begin{array}{l}\text { 10: } \beta_{p, t} \\
\text { alto }\end{array}$ & $\begin{array}{l}\text { Alto menos } \\
\text { baixo }\end{array}$ \\
\hline$r_{p, t+1}^{e}$ & 2,67 & 0,54 & $-1,96$ & 3,62 & 5,32 & 4,47 & 0,37 & 3,18 & $-0,72$ & $-2,65$ & $-5,32(-0,74)$ \\
\hline $\boldsymbol{\beta}_{p, t}$ & $-0,12$ & 0,17 & 0,31 & 0,44 & 0,56 & 0,69 & 0,82 & 0,97 & 1,16 & 1,53 & 1,65 \\
\hline$\beta_{i, t}^{+}$ & $-0,17$ & 0,15 & 0,28 & 0,39 & 0,52 & 0,64 & 0,75 & 0,92 & 1,07 & 1,40 & 1,57 \\
\hline$\beta_{p, t}^{-}$ & $-0,10$ & 0,18 & 0,34 & 0,47 & 0,59 & 0,72 & 0,86 & 1,00 & 1,21 & 1,61 & 1,71 \\
\hline $\boldsymbol{\beta}_{i, t}^{-}-\beta_{i, t}$ & 0,03 & 0,01 & 0,02 & 0,03 & 0,02 & 0,03 & 0,04 & 0,03 & 0,05 & 0,08 & 0,06 \\
\hline \multicolumn{12}{|c|}{ PAINEL B: Portfólios formados pelo $\beta_{i, t}^{-}$(beta downside) } \\
\hline Portfólios & $\begin{array}{l}\text { 1: } \boldsymbol{\beta}_{p, t} \\
\text { baixo }\end{array}$ & 2 & 3 & 4 & 5 & 6 & 7 & 8 & 9 & $\begin{array}{l}\text { 10: } \beta_{p, t} \\
\text { alto }\end{array}$ & $\begin{array}{l}\text { Alto menos } \\
\text { baixo (Estat. t) }\end{array}$ \\
\hline$r_{p, t+1}^{e}$ & 2,96 & 2,50 & $-2,48$ & 3,78 & 7,07 & 1,86 & 2,29 & 0,08 & $-3,03$ & $-0,28$ & $-3,23(-0,45)$ \\
\hline $\boldsymbol{\beta}_{p, t}$ & $-0,08$ & 0,19 & 0,34 & 0,45 & 0,57 & 0,69 & 0,82 & 0,96 & 1,14 & 1,47 & 1,55 \\
\hline $\boldsymbol{\beta}_{i, t}^{+}$ & 0,02 & 0,23 & 0,36 & 0,43 & 0,54 & 0,63 & 0,74 & 0,85 & 0,99 & 1,17 & 1,15 \\
\hline$\beta_{p, t}^{-}$ & $-0,15$ & 0,16 & 0,31 & 0,45 & 0,58 & 0,72 & 0,86 & 1,03 & 1,23 & 1,68 & 1,82 \\
\hline $\boldsymbol{\beta}_{i, t}^{-}-\boldsymbol{\beta}_{i, t}$ & $-0,07$ & $-0,03$ & $-0,02$ & 0,00 & 0,02 & 0,03 & 0,05 & 0,07 & 0,09 & 0,20 & 0,27 \\
\hline \multicolumn{12}{|c|}{ PAINEL C: Portfólios formados pelo $\beta_{i, t}^{+}$(beta upside) } \\
\hline Portfólios & $\begin{array}{l}\text { 1: } \beta_{p, t} \\
\text { baixo }\end{array}$ & 2 & 3 & 4 & 5 & 6 & 7 & 8 & 9 & $\begin{array}{l}10: \beta_{p, t} \\
\text { alto }\end{array}$ & $\begin{array}{l}\text { Alto menos } \\
\text { baixo }\end{array}$ \\
\hline$r_{p, t+1}^{e}$ & 2,82 & $-2,50$ & 2,68 & 2,59 & $-0,78$ & 6,10 & 4,36 & 1,67 & 3,07 & $-5,15$ & $-7,97(-1,14)$ \\
\hline $\boldsymbol{\beta}_{p, t}$ & $-0,01$ & 0,22 & 0,34 & 0,45 & 0,58 & 0,69 & 0,79 & 0,94 & 1,12 & 1,42 & 1,43 \\
\hline$\overline{\beta_{i, t}^{+}}$ & $-0,28$ & 0,09 & 0,25 & 0,38 & 0,50 & 0,63 & 0,78 & 0,94 & 1,15 & 1,52 & 1,80 \\
\hline$\beta_{p, t}^{-}$ & 0,17 & 0,31 & 0,40 & 0,49 & 0,63 & 0,72 & 0,80 & 0,93 & 1,09 & 1,35 & 1,17 \\
\hline$\beta_{i, t}^{-}-\beta_{i, t}$ & 0,18 & 0,09 & 0,06 & 0,04 & 0,05 & 0,03 & 0,00 & $-0,01$ & $-0,03$ & $-0,07$ & $-0,25$ \\
\hline \multicolumn{12}{|c|}{ PAINEL D: Portfólios formados pelo $\beta_{i, t}^{-}-\beta_{i, t}$ (beta downside relativo) } \\
\hline Portfólios & $\begin{array}{l}\text { 1: } \beta_{p, t} \\
\text { baixo }\end{array}$ & 2 & 3 & 4 & 5 & 6 & 7 & 8 & 9 & $\begin{array}{l}\text { 10: } \beta_{p, t} \\
\text { alto }\end{array}$ & $\begin{array}{l}\text { Alto menos } \\
\text { baixo (Estat. t) }\end{array}$ \\
\hline$r_{p, t+1}^{e}$ & $-0,81$ & 5,02 & 3,10 & $-0,71$ & 6,45 & $-1,20$ & 0,00 & 3,04 & 3,29 & $-3,34$ & $-2,53(-0,45)$ \\
\hline$\beta_{p, t}$ & 0,65 & 0,56 & 0,58 & 0,63 & 0,63 & 0,62 & 0,64 & 0,66 & 0,74 & 0,82 & 0,17 \\
\hline $\boldsymbol{\beta}_{i, t}^{+}$ & 1,02 & 0,73 & 0,68 & 0,67 & 0,62 & 0,55 & 0,52 & 0,47 & 0,45 & 0,27 & $-0,75$ \\
\hline$\beta_{p, t}^{-}$ & 0,39 & 0,44 & 0,52 & 0,61 & 0,64 & 0,66 & 0,72 & 0,78 & 0,93 & 1,20 & 0,81 \\
\hline $\boldsymbol{\beta}_{i, t}^{-}-\boldsymbol{\beta}_{i, t}$ & $-0,26$ & $-0,13$ & $-0,07$ & $-0,03$ & 0,01 & 0,04 & 0,08 & 0,12 & 0,19 & 0,38 & 0,64 \\
\hline
\end{tabular}


cont. Tabela 2 - Carteiras Formadas por Medidas de Risco Utilizando o Índice VW

PAINEL E: Portfólios formados pelo $\beta_{i, t}^{+}-\beta_{i, t}$ (beta upside relativo)

\begin{tabular}{|c|c|c|c|c|c|c|c|c|c|c|c|}
\hline Portfólios & $\begin{array}{l}\text { 1: } \beta_{p, t} \\
\text { baixo }\end{array}$ & 2 & 3 & 4 & 5 & 6 & 7 & 8 & 9 & $\begin{array}{l}10: \beta_{p, t} \\
\text { alto }\end{array}$ & $\begin{array}{l}\text { Alto menos } \\
\text { baixo (Estat. } t)\end{array}$ \\
\hline$r_{p, t+1}^{e}$ & $-3,17$ & 3,36 & 2,57 & 0,28 & $-1,08$ & 6,27 & $-0,52$ & 2,72 & 5,25 & $-0,81$ & $2,36(0,42)$ \\
\hline $\boldsymbol{\beta}_{p, t}$ & 0,82 & 0,74 & 0,66 & 0,64 & 0,62 & 0,63 & 0,63 & 0,58 & 0,56 & 0,65 & $-0,17$ \\
\hline$\beta_{i, t}^{+}$ & 0,27 & 0,45 & 0,47 & 0,52 & 0,55 & 0,62 & 0,67 & 0,68 & 0,73 & 1,02 & 0,75 \\
\hline $\boldsymbol{\beta}_{p, t}^{-}$ & 1,20 & 0,93 & 0,78 & 0,72 & 0,66 & 0,64 & 0,61 & 0,51 & 0,44 & 0,39 & $-0,81$ \\
\hline $\boldsymbol{\beta}_{i, t}^{-}-\beta_{i, t}$ & 0,38 & 0,19 & 0,12 & 0,08 & 0,04 & 0,01 & $\begin{array}{c}-0,03 \\
\end{array}$ & $-0,07$ & $-0,13$ & $-0,26$ & $-0,64$ \\
\hline \multicolumn{12}{|c|}{ PAINEL F: Portfólios formados pelo $\beta_{i, t}^{+}-\beta_{i, t}^{-}$(beta upside menos beta downside) } \\
\hline Portfólios & $\begin{array}{l}\text { 1: } \beta_{p, t} \\
\text { baixo }\end{array}$ & 2 & 3 & 4 & 5 & 6 & 7 & 8 & 9 & $\begin{array}{l}10: \beta_{p, t} \\
\text { alto }\end{array}$ & $\begin{array}{l}\text { Alto menos } \\
\text { baixo (Estat. t) }\end{array}$ \\
\hline$r_{p, t+1}^{e}$ & $-3,17$ & 3,36 & 2,57 & 0,28 & $-1,08$ & 6,27 & $-0,52$ & 2,73 & 5,34 & $-0,91$ & $2,26(0,40)$ \\
\hline $\boldsymbol{\beta}_{p, t}$ & 0,82 & 0,74 & 0,66 & 0,64 & 0,62 & 0,63 & 0,63 & 0,58 & 0,56 & 0,65 & $-0,17$ \\
\hline $\boldsymbol{\beta}_{i, t}^{+}$ & 0,27 & 0,45 & 0,47 & 0,52 & 0,55 & 0,62 & 0,67 & 0,68 & 0,73 & 1,02 & 0,75 \\
\hline $\boldsymbol{\beta}_{p, t}^{-}$ & 1,20 & 0,93 & 0,78 & 0,72 & 0,66 & 0,64 & 0,61 & 0,51 & 0,44 & 0,39 & $-0,81$ \\
\hline$\beta_{i, t}^{-}-\beta_{i, t}$ & 0,38 & 0,19 & 0,12 & 0,08 & 0,04 & 0,01 & $-0,03$ & $-0,07$ & $-0,13$ & $-0,26$ & $-0,64$ \\
\hline
\end{tabular}

De volta à Tabela 2, a situação não muda com os portfólios formados a partir do beta downside. Visto que o beta downside é entendido como um fator de risco, quanto maior essa medida, maior deveria ser retorno esperado. No entanto, os resultados indicam que a diferença entre os excessos de retorno do portfólio de maior beta downside em relação ao de menor é de $-3,23 \%$ ao ano, ou seja, oposto do previsto pela teoria. Contudo essa relação não é linear ao longo dos diferentes portfólios, nem estatisticamente significante. Como mostra a Tabela 13 do Apêndice, em alguns dos cortes de liquidez a diferença é estatisticamente significante, como nas $25 \%$ mais líquidas, chegando a 18,57. Dessa forma, um investidor que escolhesse analisar apenas as $25 \%$ ações mais líquidas da Bovespa, aplicando de maneira oposta à do CAPM: comprando a de menor beta estaria com um risco mais baixo e obtendo em média 18,57\% a mais em relação ao investidor que comprou a carteira de maior risco. 
Abaixo, a Figura 2 mostra como $\beta_{i, t}, \beta_{i, t}^{-}$e $\beta_{i, t}^{+}$se movem conjuntamente nas carteiras formadas a partir do beta downside:

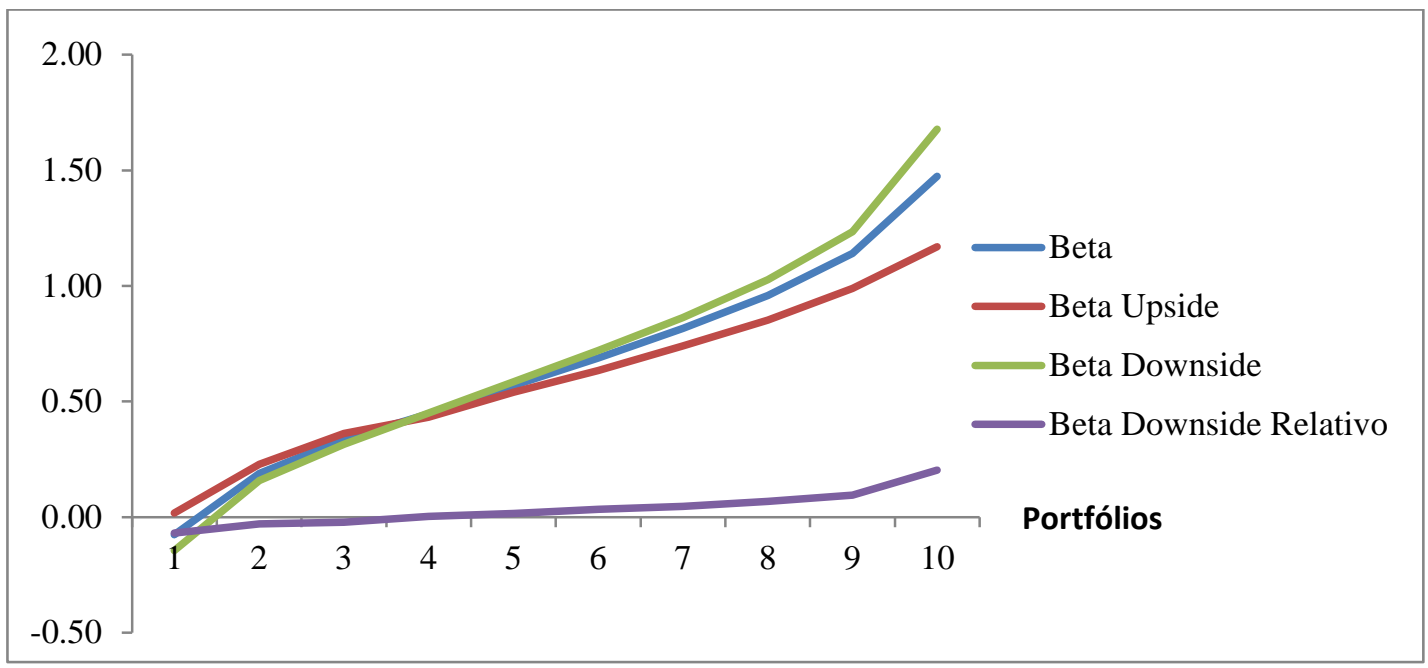

Figura 2 - Medidas de Risco dos Portfólios Formados a Partir do Beta Downside

Analisando os resultados referentes ao beta upside na Tabela 2, percebe-se uma significativa melhora em relação ao beta tradicional e ao beta downside. A diferença entre os excessos de retorno de P10 (menor risco) e P1 (maior risco) é de -7,97\%, mas não estatisticamente significante. Qualitativamente esse resultado está de acordo com o previsto pelo modelo de Ang et al. (2006), já que o $\beta_{i, t}^{+}$seria um fator de desconto. À medida que ações mais expostas (P10) ao mercado estar em uma boa situação $\left(r_{m, t}>\right.$ $\bar{r}_{m}$ ) deveriam pagar, em média, menos que as ações menos expostas às boas situações (P1). Esse resultado é robusto aos cortes de liquidez, como pode ser visto na Tabela 14 do Apêndice, sendo significante (estatística t maior que 1,96) em dois desses cortes.

No entanto, isso não deve ser comemorado, uma vez que o beta upside é altamente relacionado com o beta tradicional e com o beta downside, como mostra a Figura 2. Um dos três betas será uma combinação linear dos outros dois, pois um excesso de retorno de mercado ou é negativo, ou é positivo. Portfólios formados a partir do beta upside podem estar refletindo apenas sua alta correlação com o beta tradicional, não necessariamente seu real efeito de desconto. 
Como sugerido por Ang et al. (2006), o melhor indicador de sucesso entre as medidas assimétricas de risco é o beta downside relativo, uma vez que é dado pela diferença entre os betas downside e o tradicional, capturando o efeito assimétrico líquido. Nessas carteiras formadas a partir do $\beta_{i, t}^{-}-\beta_{i, t}$, como pode ser observado no Painel $D$ da Tabela 2 e na Figura 3, é possível ver esse resultado: o beta tradicional não apresenta um padrão de crescimento semelhante ao dos Painéis $A, B$ ou $C$ da Tabela 2, mas um comportamento mais flat, já o beta upside se mostra decrescente e dessa forma seu principal efeito é de desconto, ao contrário de $\beta_{i, t}^{-}$que é crescente (risco).

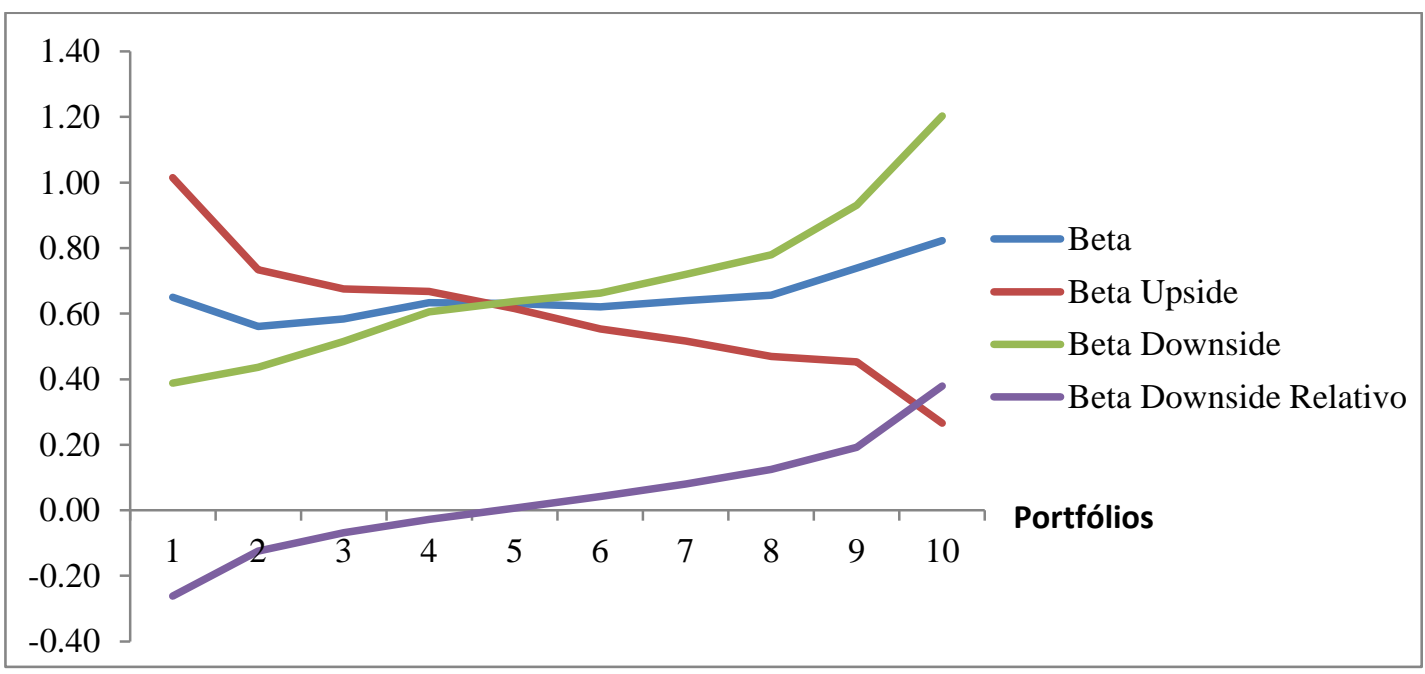

Figura 3 - Medidas de Risco dos Portfólios Formados a Partir do Beta Downside Relativo

Outra possibilidade de formação de carteiras é o beta upside relativo, análogo ao $\left(\beta_{i, t}^{-}-\beta_{i, t}\right)$, mas para as boas situações de mercado. Contudo, como pode ser observado nos Painéis $D$ e $E$ da Tabela 2, chegou-se ao resultado de que classificar ativos pelo $\left(\beta_{i, t}^{-}-\beta_{i, t}\right)$ ou pelo $\left(\beta_{i, t}^{+}-\beta_{i, t}\right)$ implica resultados quantitativos muito próximos entre as duas abordagens, exceção à ordem contrária dos portfólios: $\mathrm{P} 1 \mathrm{em}\left(\beta_{i, t}^{-}-\beta_{i, t}\right)$ torna-se $\mathrm{P} 10$ em $\left(\beta_{i, t}^{+}-\beta_{i, t}\right), \mathrm{P} 2$ em $\left(\beta_{i, t}^{-}-\beta_{i, t}\right)$ torna-se P9 em $\left(\beta_{i, t}^{+}-\beta_{i, t}\right)$. Similarmente, Ang et al. (2006) também chegaram a resultados muito próximos nesse sentido.

Outra comparação, agora entre os Painéis $E$ e $F$, permite concluir a existência da mesma semelhança entre $\left(\beta_{i, t}^{+}-\beta_{i, t}\right)$ e $\left(\beta_{i, t}^{+}-\beta_{i, t}^{-}\right)$. Ang et al. (2006) também chegaram a resultados muito próximos nesse sentido. Como o $\left(\beta_{i, t}^{-}-\beta_{i, t}\right)$ sintetiza os efeitos de 
$\left(\beta_{i, t}^{+}-\beta_{i, t}\right)$ e $\left(\beta_{i, t}^{+}-\beta_{i, t}^{-}\right)$, nas tabelas seguintes serão apresentados apenas os resultados referentes ao beta downside relativo.

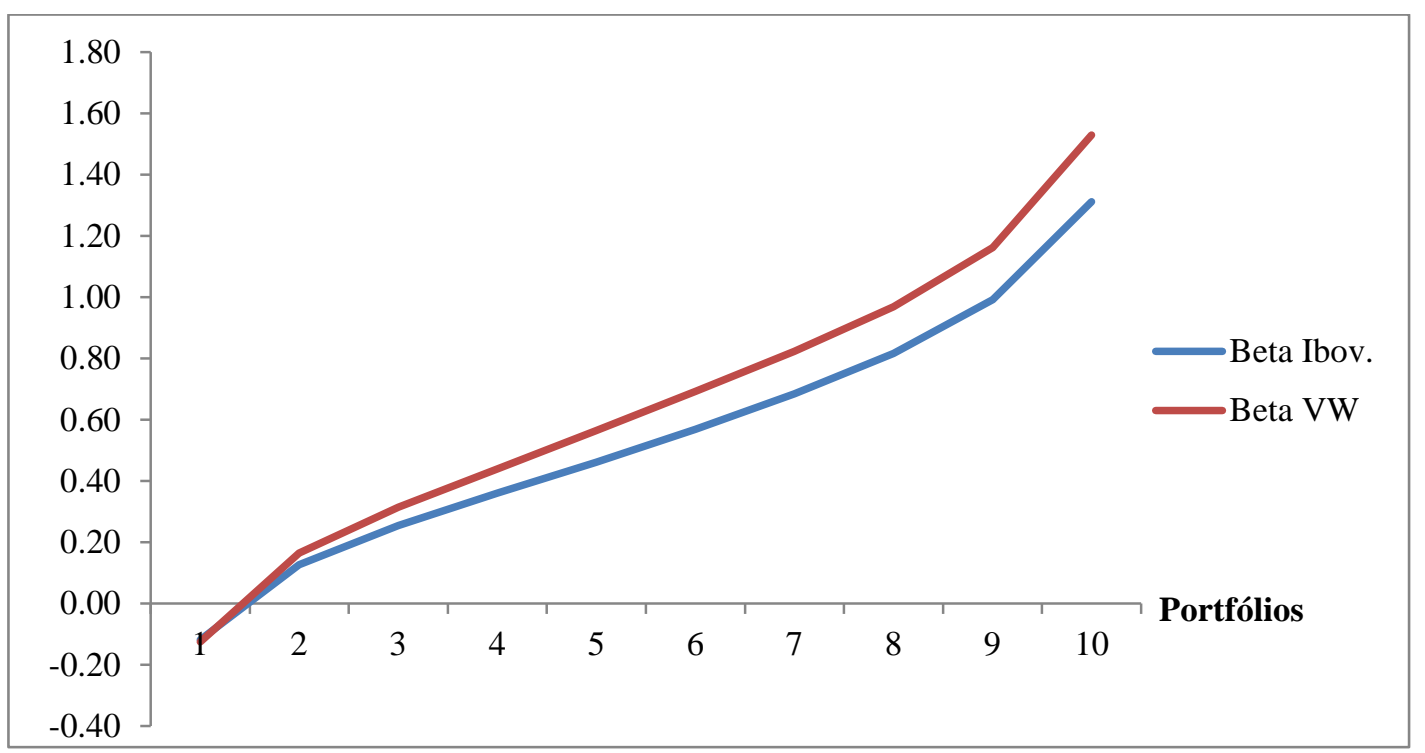

Figura 4 - Betas Ibovespa × VW em Portfólios Formados pelo Beta Tradicional

A Tabela 3 apresenta resultados semelhantes aos da Tabela 2, ou seja, a média anualizada dos excessos de retornos mensais um mês à frente e as médias das medidas de risco para o período de fevereiro de 2004 a julho de 2012. A diferença entre as duas é que agora o Ibovespa serve como proxy para o portfólio de mercado, como comparação dos dois índices de mercado, mas não há mudanças drásticas provocadas. Isso era esperado devido à alta correlação entre os índices, da ordem de 98,5\% (Figura 1). Constata-se, apesar disso, que os betas (tanto os tradicionais, quanto os assimétricos) em relação ao Ibovespa são, em média, menores que os calculados com o índice VW. A Figura 4 mostra essa relação entre os betas dos dois índices de mercado nos portfólios formados a partir do beta tradicional. 
Tabela 3 - Carteiras Formadas por Medidas de Risco Utilizando o Ibovespa

\begin{tabular}{|c|c|c|c|c|c|c|c|c|c|c|c|}
\hline \multicolumn{12}{|c|}{ PAINEL A: Portfólios formados pelo $\beta_{i, t}$} \\
\hline Portfólios & $\begin{array}{l}\text { 1: } \beta_{p, t} \\
\text { baixo }\end{array}$ & 2 & 3 & 4 & 5 & 6 & 7 & 8 & 9 & $\begin{array}{l}10: \beta_{p, t} \\
\text { alto }\end{array}$ & $\begin{array}{l}\text { Alto menos } \\
\text { baixo (Estat. } t)\end{array}$ \\
\hline$r_{p, t+1}^{e}$ & 1,71 & 1,76 & $-3,60$ & 5,07 & 2,93 & 0,58 & 4,91 & 4,76 & $-0,06$ & $-3,28$ & $-4,98(-0,67)$ \\
\hline $\boldsymbol{\beta}_{p, t}$ & $-0,12$ & 0,13 & 0,26 & 0,36 & 0,46 & 0,57 & 0,68 & 0,82 & 0,99 & 1,31 & 1,43 \\
\hline $\boldsymbol{\beta}_{i, t}^{+}$ & $-0,18$ & 0,08 & 0,20 & 0,31 & 0,41 & 0,50 & 0,60 & 0,75 & 0,89 & 1,20 & 1,37 \\
\hline $\boldsymbol{\beta}_{p, t}^{-}$ & $-0,07$ & 0,16 & 0,29 & 0,39 & 0,50 & 0,62 & 0,74 & 0,86 & 1,06 & 1,39 & 1,47 \\
\hline $\boldsymbol{\beta}_{i, t}^{-}-\beta_{i, t}$ & 0,04 & 0,04 & 0,04 & 0,03 & 0,04 & 0,05 & 0,06 & 0,05 & 0,06 & 0,08 & 0,04 \\
\hline \multicolumn{12}{|c|}{ PAINEL B: Portfólios formados pelo $\beta_{i, t}^{-}$} \\
\hline Portfólios & $\begin{array}{l}\text { 1: } \beta_{p, t} \\
\text { baixo }\end{array}$ & 2 & 3 & 4 & 5 & 6 & 7 & 8 & 9 & $\begin{array}{l}10: \beta_{p, t} \\
\text { alto }\end{array}$ & $\begin{array}{l}\text { Alto menos } \\
\text { baixo (Estat. } t)\end{array}$ \\
\hline$r_{p, t+1}^{e}$ & 2,90 & 2,20 & $-2,63$ & 1,93 & 5,99 & 3,36 & 1,81 & 0,88 & $-0,38$ & $-1,32$ & $-4,22(-0,61)$ \\
\hline $\boldsymbol{\beta}_{p, t}$ & $-0,08$ & 0,15 & 0,27 & 0,37 & 0,46 & 0,57 & 0,68 & 0,80 & 0,98 & 1,26 & 1,34 \\
\hline$\beta_{i, t}^{+}$ & $-0,03$ & 0,15 & 0,26 & 0,33 & 0,41 & 0,50 & 0,58 & 0,69 & 0,85 & 1,01 & 1,03 \\
\hline$\beta_{p, t}^{-}$ & $-0,12$ & 0,14 & 0,28 & 0,39 & 0,50 & 0,62 & 0,74 & 0,88 & 1,07 & 1,45 & 1,57 \\
\hline$\beta_{i, t}^{-}-\beta_{i, t}$ & $-0,04$ & 0,00 & 0,01 & 0,02 & 0,04 & 0,05 & 0,06 & 0,08 & 0,09 & 0,18 & 0,22 \\
\hline \multicolumn{12}{|c|}{ PAINEL C: Portfólios formados pelo $\beta_{i, t}^{+}$} \\
\hline Portfólios & $\begin{array}{l}\text { 1: } \beta_{p, t} \\
\text { baixo }\end{array}$ & 2 & 3 & 4 & 5 & 6 & 7 & 8 & 9 & $\begin{array}{l}10: \beta_{p, t} \\
\text { alto }\end{array}$ & $\begin{array}{lr}\text { Alto menos } \\
\text { baixo (Estat. t) }\end{array}$ \\
\hline$r_{p, t+1}^{e}$ & 0,57 & $-0,98$ & 2,47 & 3,00 & 2,34 & $-0,24$ & 2,01 & 7,61 & 4,37 & $-6,36$ & $-6,93(-0,97)$ \\
\hline $\boldsymbol{\beta}_{p, t}$ & $-0,03$ & 0,17 & 0,27 & 0,37 & 0,47 & 0,57 & 0,66 & 0,79 & 0,96 & 1,23 & 1,26 \\
\hline $\boldsymbol{\beta}_{i, t}^{+}$ & $-0,27$ & 0,04 & 0,18 & 0,29 & 0,40 & 0,51 & 0,62 & 0,77 & 0,95 & 1,27 & 1,54 \\
\hline $\boldsymbol{\beta}_{p, t}^{-}$ & 0,14 & 0,26 & 0,33 & 0,43 & 0,53 & 0,61 & 0,68 & 0,80 & 0,96 & 1,20 & 1,06 \\
\hline $\boldsymbol{\beta}_{i, t}^{-}-\boldsymbol{\beta}_{i, t}$ & 0,17 & 0,09 & 0,06 & 0,06 & 0,05 & 0,04 & 0,02 & 0,01 & 0,00 & $-0,03$ & $-0,20$ \\
\hline \multicolumn{12}{|c|}{ PAINEL D: Portfólios formados pelo $\beta_{i, t}^{-}-\beta_{i, t}$} \\
\hline Portfólios & $\begin{array}{l}\text { 1: } \beta_{p, t} \\
\text { baixo }\end{array}$ & 2 & 3 & 4 & 5 & 6 & 7 & 8 & 9 & $\begin{array}{l}10: \beta_{p, t} \\
\text { alto }\end{array}$ & $\begin{array}{lr}\text { Alto menos } \\
\text { baixo (Estat. t) }\end{array}$ \\
\hline$r_{p, t+1}^{e}$ & 1,28 & 2,93 & 3,59 & 2,45 & 1,03 & 1,37 & 2,04 & 1,79 & 1,47 & $-3,14$ & $-4,42(-0,73)$ \\
\hline $\boldsymbol{\beta}_{p, t}$ & 0,54 & 0,47 & 0,49 & 0,51 & 0,53 & 0,53 & 0,56 & 0,56 & 0,61 & 0,65 & 0,11 \\
\hline$\beta_{i, t}^{+}$ & 0,79 & 0,58 & 0,54 & 0,52 & 0,49 & 0,45 & 0,45 & 0,39 & 0,36 & 0,18 & $\begin{array}{l}-0,61 \\
\end{array}$ \\
\hline $\boldsymbol{\beta}_{p, t}^{-}$ & 0,35 & 0,38 & 0,45 & 0,50 & 0,55 & 0,58 & 0,65 & 0,69 & 0,79 & 0,99 & 0,64 \\
\hline $\boldsymbol{\beta}_{i, t}^{-}-\beta_{i, t}$ & $-0,19$ & $-0,08$ & $-0,04$ & $-0,01$ & 0,02 & 0,05 & 0,08 & 0,12 & 0,18 & 0,34 & 0,53 \\
\hline
\end{tabular}




\subsubsection{Regressões Fama e MacBeth}

Apesar de sugerirem a falha tanto do CAPM, quanto do modelo de risco downside, os resultados apresentados na seção anterior não isolam o efeito de uma medida de risco da outra. Fornecem apenas indicativos do que as variáveis podem ser: risco ou desconto. Por exemplo, pela seção anterior os padrões decrescentes do retorno em relação ao risco fazem com que o beta, o beta downside e o beta upside tenham como esperado um papel de desconto. O mesmo acontece com a liquidez, uma vez que ações menos líquidas retornam, em média, menos que as mais líquidas.

O teste dos efeitos de cada variável apurados de forma isolada são realizados por meio das regressões Fama e MacBeth (1973), cuja variável dependente é o excesso de retorno um mês à frente. Algebricamente, um modelo com $n$ variáveis de risco se resume a:

$$
\text { XIV) } \quad r_{i, t+1}^{e}=\lambda_{0, t}+\lambda_{1, t} v_{i, t}^{1}+\cdots+\lambda_{n, 0} v_{i, t}^{n}+\epsilon_{i, t}, \quad t=1,2, \ldots, T
$$

As regressões foram realizadas no âmbito de todas as ações $i$ da amostra (668 ações), ou seja, sem os cortes de liquidez, o tamanho da amostra é de 102 meses, todos "out-ofsample". A equação XIV) abarca vários modelos de risco, como o tradicional CAPM, os propostos por Ang et al. (2006), versões do 3 fatores de Fama-French e modelos com medidas de liquidez.

Entende-se por tamanho o logaritmo natural do valor de mercado da empresa, por B-M (book-to-market) o quociente valor patrimonial por ação sobre o preço da ação. As medidas de liquidez e o beta e seus derivados já foram explicados ao longo do texto. É importante ressaltar que todas as variáveis utilizadas nas regressões já são conhecidas no instante $t$ e todas, com exceção de B-M, possuem defasagem de um mês em relação ao excesso de retorno. B-M possui defasagem de seis meses, algo conservador a fim de garantir seu conhecimento na data $t$, como sugerido por Fama e French (1993).

Pela equação XIV) são obtidas 102 estimativas dos coeficientes $\lambda$. A Tabela 4 apresenta as médias temporais de cada coeficiente das várias medidas de risco com sua estatística $t$ entre colchetes. Portanto para uma variável 1 qualquer, são obtidas a média $\left(\lambda_{1}\right)$, a variância $\left(\sigma_{1}^{2}\right)$ e a estatística $t$ dessa variável: 


$$
\begin{array}{cl}
\text { XV) } & \lambda_{1}=\frac{\sum_{t=1}^{T} \lambda_{1, t}}{T} \\
\text { XVI }) & \sigma_{1}^{2}=\frac{\sum_{t=1}^{T}\left(\lambda_{1, t}-\lambda_{1}\right)^{2}}{T} \\
\text { XVII) } & \text { Estat. } t_{1}=\frac{\lambda_{1}}{\sigma / \sqrt{T}}
\end{array}
$$

Em todos os modelos não há nenhuma variável com significância estatística, com exceção do modelo (14). Nesse modelo as duas variáveis explicativas são o beta tradicional e seu termo ao quadrado, sendo esse último significante a $10 \%$. Muito provavelmente essa não significância estatística de quase todos os modelos seja devido aos padrões encontrados na seção anterior, quando em relação aos vários tipos de beta, a significância estatística também não foi encontrada. Por exemplo, no modelo (1), o CAPM, a direção do sinal do beta é condizente com os resultados da Tabela 2, já que nesta quanto maior o beta, menor foi o retorno esperado. Já no modelo (2), de riscos assimétricos, o beta upside possui sinal contrário ao da Tabela 2, mas o beta downside possui o mesmo sinal. Isso confirma os resultados da Figura 4, que ilustra os efeitos isolados do beta downside e upside, por meio dos portfólios formados a partir do beta downside relativo.

De acordo com Banz (1981), quanto maior o tamanho da empresa, menor o retorno esperado de sua ação. Fama e French (1992) concluem que book-to-market possui uma relação inversa. $\mathrm{Na}$ Tabela 4, ambas as variáveis possuem essas relações condizentes com os dois trabalhos citados. A liquidez da ação parece exercer um efeito negativo sobre seu retorno esperado. Embora não exista a significância estatística para nenhuma das citadas variáveis, acredita-se que essa ausência possa ser ocasionada pelo tamanho da amostra proporcionada pelo mercado brasileiro (102 meses) ser bastante limitado comparativamente ao que se obtém com dados norte-americanos.

As duas últimas linhas da Tabela 4 mostram o que a inclusão de termos de ordem mais elevada do beta tradicional ocasiona. O prêmio de mercado é positivo apenas nesses dois casos e ainda possui estatísticas $t$ elevadas, se comparadas aos outros modelos. Também, o termo ao quadrado é negativo em (14) e (15) e estatisticamente significante em (14), ao passo que o termo cúbico não aparenta ser relevante. Esses resultados sugerem a não linearidade do risco de mercado sobre o retorno das ações, sendo o 
retorno positivamente relacionado com o beta tradicional até 0,642 e depois desse valor, a relação torna-se negativa. Fama e MacBeth (1973) testaram essa possibilidade, mas rejeitaram-na em favor da linearidade no risco de mercado.

A Figura 5 abaixo exibe o excesso de retorno médio um mês à frente de portfólios formados a partir do beta tradicional, cujos valores foram extraídos do Painel A da Tabela 2, bem como suas tendências polinomiais de $2^{\circ}$ e $3^{\circ}$ graus. Nela é possível visualizar a razão da não linearidade no risco de mercado: os excessos de retorno médios não são monotônicos.

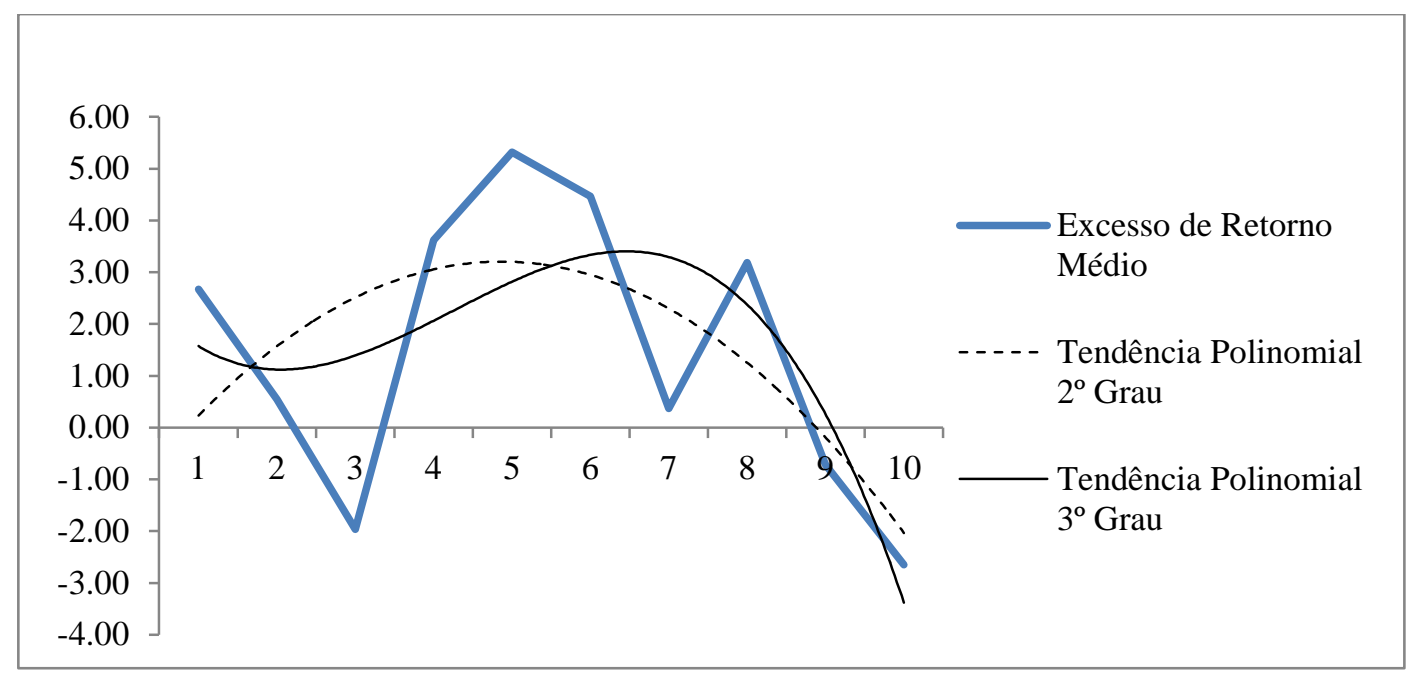

Figura 5 - Características de Grau Maior do Excesso de Retorno Médio

O prêmio médio do excesso de retorno das ações previsto pelos modelos, obtido pela multiplicação dos coeficientes da Tabela 4 pelas respectivas médias das medidas de risco, é apresentado na última coluna da Tabela 4. Para comparação, a média do excesso de retorno das ações observado no período é de é 1,143 (em porcentagem ao ano). Quanto mais negativo o valor previsto pelo modelo, mais positivo será o intercepto a fim corrigir o erro de precificação. Os interceptos dos modelos (14) e (15) são os únicos negativos em toda a tabela, pois também são os únicos a apresentarem previsão positiva, respectivamente 0,891 e 1,940, valores relativamente próximos à média amostral $(1,143)$, o que sugere a melhor adequação dos modelos não lineares ao mercado brasileiro no período estudado.

Já na Tabela 5, são realizadas as regressões Fama e MacBeth utilizando o Ibovespa como índice de mercado. No entanto, os resultados não se alteram do ponto de vista 
qualitativo: a significância estatística não aparece novamente nos 13 primeiros modelos. Observa-se que via de regra as estatísticas $t$ aumentam em seu valor absoluto e ocorrem algumas mudanças de sinais entre uma tabela e outra, como nos modelos 6, 7, 9, 10 e 11. Mais uma vez o termo quadrático é negativo e significante em (14), com estatística $t$ igual a -2,23. O prêmio de mercado se torna ainda mais positivo e sua $t$ é de 1,47 e a inclusão do termo cúbico é desnecessária e atrapalha a significância do termo quadrático.

Outro fato em comum entre as duas tabelas é a significância estatística dos $R$-quadrado ajustados, apesar de serem baixos. Com o índice VW, o CAPM possui essa estatística em 1,2\%, o Fama-French em 4,4\% e o modelo 10 apresenta o maior $R$-quadrado ajustado $(5,4 \%)$ e suas medidas de risco são: beta upside, beta downside, tamanho, B-M e a medida de liquidez proposta por Amihud. Comparando os $R$-quadrado ajustados com os de Fama e MacBeth (1973) que também utilizam regressões preditivas, cerca de $30 \%$, percebe-se o que os $R$-quadrados ajustados encontrados neste trabalho são baixos. 
Tabela 4 - Regressões Fama-MacBeth com Intercepto VW

\begin{tabular}{|c|c|c|c|c|c|c|c|c|c|c|c|c|c|c|}
\hline Modelos & Intercepto & $\boldsymbol{\beta}_{p, t}$ & $\beta_{p, t}^{2}$ & $\beta_{p, t}^{3}$ & $\beta_{i, t}^{+}$ & $\beta_{p, t}^{-}$ & $\beta_{i, t}^{-}-\beta_{i, t}$ & $\beta_{i, t}^{+}-\beta_{i, t}$ & Tamanho & $\mathbf{B M}$ & Liq. DM & $\begin{array}{c}\text { Liq. } \\
\text { Amihud }\end{array}$ & $\begin{array}{c}\text { R2 } \\
\text { ajust. }\end{array}$ & Previsão \\
\hline (1) & $\begin{array}{l}2,152 \\
{[0,43]}\end{array}$ & $\begin{array}{l}-1,598 \\
{[-0,36]}\end{array}$ & & & & & & & & & & & $\begin{array}{l}0,012 \\
{[7,01]}\end{array}$ & $-1,056$ \\
\hline (2) & $\begin{array}{l}2,415 \\
{[0,49]}\end{array}$ & & & & $\begin{array}{l}0,613 \\
{[0,17]} \\
\end{array}$ & $\begin{array}{l}-2,475 \\
{[-0,67]} \\
\end{array}$ & & & & & & & $\begin{array}{c}0,018 \\
{[8,30]}\end{array}$ & $-1,358$ \\
\hline (3) & $\begin{array}{l}4,348 \\
{[0,24]}\end{array}$ & $\begin{array}{l}-1,704 \\
{[-0,40]}\end{array}$ & & & & & & & $\begin{array}{c}-0,0985 \\
{[-0,09]}\end{array}$ & $\begin{array}{l}0,016 \\
{[0,28]}\end{array}$ & & & $\begin{array}{l}0,044 \\
{[7,09]}\end{array}$ & $-2,516$ \\
\hline (4) & $\begin{array}{l}5,765 \\
{[0,33]}\end{array}$ & $\begin{array}{l}-1,939 \\
{[-0,46]}\end{array}$ & & & & & & & $\begin{array}{l}-0,175 \\
{[-0,16]}\end{array}$ & $\begin{array}{l}0,016 \\
{[0,27]}\end{array}$ & & $\begin{array}{l}-4,572 \\
{[-0,64]}\end{array}$ & $\begin{array}{l}0,050 \\
{[8,09]}\end{array}$ & $-4,068$ \\
\hline (5) & $\begin{array}{l}2,581 \\
{[0,14]}\end{array}$ & $\begin{array}{l}-1,693 \\
{[-0,40]}\end{array}$ & & & & & & & $\begin{array}{l}0,040 \\
{[0,03]}\end{array}$ & $\begin{array}{c}0,017 \\
{[0,29]}\end{array}$ & $\begin{array}{c}-8,41 \times \mathrm{e}^{\wedge}-8 \\
{[-0,40]}\end{array}$ & & $\begin{array}{l}0,044 \\
{[7,11]}\end{array}$ & $-0,770$ \\
\hline (6) & $\begin{array}{l}6,325 \\
{[0,36]}\end{array}$ & & & & & & $\begin{array}{l}0,001 \\
{[0,00]}\end{array}$ & & $\begin{array}{l}-0,311 \\
{[-0,27]}\end{array}$ & $\begin{array}{l}0,010 \\
{[0,17]}\end{array}$ & & & $\begin{array}{l}0,037 \\
{[6,00]}\end{array}$ & $-4,240$ \\
\hline (7) & $\begin{array}{l}7,518 \\
{[0,43]}\end{array}$ & & & & & & $\begin{array}{l}0,436 \\
{[0,06]}\end{array}$ & & $\begin{array}{l}-0,386 \\
{[-0,34]}\end{array}$ & $\begin{array}{l}0,011 \\
{[0,17]}\end{array}$ & & $\begin{array}{l}-3,194 \\
{[-0,45]}\end{array}$ & $\begin{array}{l}0,043 \\
{[7,01]}\end{array}$ & $-5,494$ \\
\hline (8) & $\begin{array}{l}4,585 \\
{[0,24]}\end{array}$ & & & & & & $\begin{array}{l}-0,231 \\
{[-0,03]}\end{array}$ & & $\begin{array}{l}-0,169 \\
{[-0,14]}\end{array}$ & $\begin{array}{l}0,010 \\
{[0,17]}\end{array}$ & $\begin{array}{c}-1,11 \times \mathrm{e}^{\wedge}-7 \\
{[-0,52]}\end{array}$ & & $\begin{array}{l}0,037 \\
{[6,02]}\end{array}$ & $-2,500$ \\
\hline (9) & $\begin{array}{l}4,510 \\
{[0,26]}\end{array}$ & & & & $\begin{array}{l}-0,542 \\
{[-0,16]}\end{array}$ & $\begin{array}{l}-1,478 \\
{[-0,35]}\end{array}$ & & & $\begin{array}{l}-0,095 \\
{[-0,08]}\end{array}$ & $\begin{array}{c}0,018 \\
{[0,31]}\end{array}$ & & & $\begin{array}{l}0,047 \\
{[7,60]}\end{array}$ & $-2,706$ \\
\hline (10) & $\begin{array}{l}5,746 \\
{[0,33]}\end{array}$ & & & & $\begin{array}{l}-0,855 \\
{[-0,25]}\end{array}$ & $\begin{array}{l}-1,395 \\
{[-0,32]}\end{array}$ & & & $\begin{array}{l}-0,161 \\
{[-0,15]}\end{array}$ & $\begin{array}{l}0,019 \\
{[0,32]}\end{array}$ & & $\begin{array}{l}-3,916 \\
{[-0,55]}\end{array}$ & $\begin{array}{l}0,054 \\
{[8,63]}\end{array}$ & $-4,042$ \\
\hline (11) & $\begin{array}{l}2,909 \\
{[0,16]}\end{array}$ & & & & $\begin{array}{l}-0,456 \\
{[-0,13]}\end{array}$ & $\begin{array}{l}-1,539 \\
{[-0,36]}\end{array}$ & & & $\begin{array}{l}0,031 \\
{[0,03]}\end{array}$ & $\begin{array}{l}0,019 \\
{[0,32]}\end{array}$ & $\begin{array}{c}-7,7 \times \mathrm{e}^{\wedge}-8 \\
{[-0,36]}\end{array}$ & & $\begin{array}{l}0,048 \\
{[7,62]}\end{array}$ & $-1,116$ \\
\hline (12) & $\begin{array}{l}1,490 \\
{[0,26]}\end{array}$ & & & & & & $\begin{array}{l}-2,224 \\
{[-0,26]}\end{array}$ & & & & & & $\begin{array}{l}0,005 \\
{[5,64]}\end{array}$ & $-0,081$ \\
\hline (13) & $\begin{array}{l}1,490 \\
{[0,26]}\end{array}$ & & & & & & & $\begin{array}{l}2,507 \\
{[0,42]}\end{array}$ & & & & & $\begin{array}{l}0,005 \\
{[5,64]}\end{array}$ & $-0,153$ \\
\hline (14) & $\begin{array}{l}-0,027 \\
{[-0,01]}\end{array}$ & $\begin{array}{c}6,864 \\
{[1,03]}\end{array}$ & $\begin{array}{l}-5,342 \\
{[-1,69]}\end{array}$ & & & & & & & & & & $\begin{array}{l}0,014 \\
{[7,22]}\end{array}$ & 0,891 \\
\hline (15) & $\begin{array}{l}-1,132 \\
{[-0,23]}\end{array}$ & $\begin{array}{l}10,722 \\
{[1,44]}\end{array}$ & $\begin{array}{l}-7,107 \\
{[-0,70]}\end{array}$ & $\begin{array}{l}-0,370 \\
{[-0,09]}\end{array}$ & & & & & & & & & $\begin{array}{l}0,019 \\
{[6,32]}\end{array}$ & 1,940 \\
\hline
\end{tabular}


Tabela 5 - Regressões Fama-MacBeth com Intercepto Ibovespa

\begin{tabular}{|c|c|c|c|c|c|c|c|c|c|c|c|c|c|c|}
\hline Modelos & Intercepto & $\boldsymbol{\beta}_{p, t}$ & $\beta_{p, t}^{2}$ & $\beta_{p, t}^{3}$ & $\beta_{i, t}^{+}$ & $\beta_{p, t}^{-}$ & $\beta_{i, t}^{-}-\beta_{i, t}$ & $\beta_{i, t}^{+}-\beta_{i, t}$ & Tamanho & BM & Liq. DM & $\begin{array}{c}\text { Liq. } \\
\text { Amihud }\end{array}$ & $\begin{array}{c}\text { R2 } \\
\text { ajust. }\end{array}$ & Previsão \\
\hline (1) & $\begin{array}{l}1,610 \\
{[0,31]}\end{array}$ & $\begin{array}{l}-1,287 \\
{[-0,25]}\end{array}$ & & & & & & & & & & & $\begin{array}{c}0,012 \\
{[6,86]}\end{array}$ & $-0,713$ \\
\hline (2) & $\begin{array}{l}2,035 \\
{[0,40]}\end{array}$ & & & & $\begin{array}{l}2,366 \\
{[0,45]}\end{array}$ & $\begin{array}{l}-4,028 \\
{[-0,76]}\end{array}$ & & & & & & & $\begin{array}{l}0,018 \\
{[8,49]}\end{array}$ & $-1,295$ \\
\hline (3) & $\begin{array}{l}5,062 \\
{[0,28]}\end{array}$ & $\begin{array}{l}-0,983 \\
{[-0,21]}\end{array}$ & & & & & & & $\begin{array}{l}-0,204 \\
{[-0,18]}\end{array}$ & $\begin{array}{l}0,015 \\
{[0,25]}\end{array}$ & & & $\begin{array}{l}0,043 \\
{[7,02]}\end{array}$ & $-3,357$ \\
\hline (4) & $\begin{array}{l}6,335 \\
{[0,36]}\end{array}$ & $\begin{array}{l}-1,215 \\
{[-0,26]}\end{array}$ & & & & & & & $\begin{array}{l}-0,273 \\
{[-0,24]}\end{array}$ & $\begin{array}{l}0,015 \\
{[0,25]}\end{array}$ & & $\begin{array}{l}-4,258 \\
{[-0,59]}\end{array}$ & $\begin{array}{l}0,050 \\
{[8,03]}\end{array}$ & $-4,755$ \\
\hline (5) & $\begin{array}{l}3,277 \\
{[0,17]}\end{array}$ & $\begin{array}{l}-0,894 \\
{[-0,19]}\end{array}$ & & & & & & & $\begin{array}{l}-0,067 \\
{[-0,05]}\end{array}$ & $\begin{array}{l}0,015 \\
{[0,26]}\end{array}$ & $\begin{array}{c}-8,63 \times \mathrm{e}^{\wedge}-8 \\
{[-0,41]}\end{array}$ & & $\begin{array}{l}0,044 \\
{[7,04]}\end{array}$ & $-1,456$ \\
\hline (6) & $\begin{array}{l}6,976 \\
{[0,39]}\end{array}$ & & & & & & $\begin{array}{l}-6,951 \\
{[-0,68]}\end{array}$ & & $\begin{array}{l}-0,349 \\
{[-0,30]}\end{array}$ & $\begin{array}{l}0,009 \\
{[0,15]}\end{array}$ & & & $\begin{array}{l}0,037 \\
{[6,03]}\end{array}$ & $-5,097$ \\
\hline (7) & $\begin{array}{l}8,120 \\
{[0,47]}\end{array}$ & & & & & & $\begin{array}{l}-6,291 \\
{[-0,60]}\end{array}$ & & $\begin{array}{l}-0,420 \\
{[-0,38]}\end{array}$ & $\begin{array}{l}0,009 \\
{[0,16]}\end{array}$ & & $\begin{array}{l}-3,455 \\
{[-0,49]}\end{array}$ & $\begin{array}{l}0,044 \\
{[7,04]}\end{array}$ & $-6,297$ \\
\hline (8) & $\begin{array}{l}5,184 \\
{[0,28]}\end{array}$ & & & & & & $\begin{array}{c}-7,09 \\
{[-0,70]}\end{array}$ & & $\begin{array}{l}-0,203 \\
{[-0,17]}\end{array}$ & $\begin{array}{l}0,009 \\
{[0,16]}\end{array}$ & $\begin{array}{c}-1,09 \times \mathrm{e}^{\wedge}-7 \\
{[-0,51]}\end{array}$ & & $\begin{array}{l}0,037 \\
{[6,05]}\end{array}$ & $-3,131$ \\
\hline (9) & $\begin{array}{l}5,985 \\
{[0,34]}\end{array}$ & & & & $\begin{array}{l}2,848 \\
{[0,63]}\end{array}$ & $\begin{array}{l}-3,901 \\
{[-0,71]}\end{array}$ & & & $\begin{array}{l}-0,255 \\
{[-0,23]}\end{array}$ & $\begin{array}{l}0,014 \\
{[0,25]}\end{array}$ & & & $\begin{array}{c}0,047 \\
{[7,57]}\end{array}$ & $-4,484$ \\
\hline (10) & $\begin{array}{l}7,056 \\
{[0,41]}\end{array}$ & & & & $\begin{array}{l}2,469 \\
{[0,54]}\end{array}$ & $\begin{array}{l}-3,740 \\
{[-0,67]}\end{array}$ & & & $\begin{array}{l}-0,311 \\
{[-0,28]}\end{array}$ & $\begin{array}{l}0,015 \\
{[0,26]}\end{array}$ & & $\begin{array}{l}-3,868 \\
{[-0,54]}\end{array}$ & $\begin{array}{c}0,054 \\
{[8,62]}\end{array}$ & $-5,636$ \\
\hline (11) & $\begin{array}{l}4,289 \\
{[0,23]}\end{array}$ & & & & $\begin{array}{l}2,952 \\
{[0,66]}\end{array}$ & $\begin{array}{l}-3,904 \\
{[-0,72]}\end{array}$ & & & $\begin{array}{l}-0,124 \\
{[-0,10]}\end{array}$ & $\begin{array}{l}0,015 \\
{[0,26]}\end{array}$ & $\begin{array}{c}-8,10 \times \mathrm{e}^{\wedge}-8 \\
{[-0,39]}\end{array}$ & & $\begin{array}{l}0,048 \\
{[7,59]}\end{array}$ & $-2,669$ \\
\hline (12) & $\begin{array}{l}1,604 \\
{[0,28]}\end{array}$ & & & & & & $\begin{array}{l}-6,326 \\
{[-0,55]}\end{array}$ & & & & & & $\begin{array}{l}0,006 \\
{[5,67]}\end{array}$ & $-0,316$ \\
\hline (13) & $\begin{array}{l}1,604 \\
{[0,28]}\end{array}$ & & & & & & & $\begin{array}{l}5,631 \\
{[0,64]}\end{array}$ & & & & & $\begin{array}{l}0,006 \\
{[5,67]}\end{array}$ & $-0,411$ \\
\hline (14) & $\begin{array}{l}-0,750 \\
{[-0,14]}\end{array}$ & $\begin{array}{l}10,393 \\
{[1,47]}\end{array}$ & $\begin{array}{l}-8,953 \\
{[-2,23]}\end{array}$ & & & & & & & & & & $\begin{array}{c}0,014 \\
{[7,41]}\end{array}$ & 1,292 \\
\hline (15) & $\begin{array}{l}-1,210 \\
{[-0,24]}\end{array}$ & $\begin{array}{l}12,235 \\
{[1,42]}\end{array}$ & $\begin{array}{r}-10,139 \\
{[-0,73]}\end{array}$ & $\begin{array}{l}0,252 \\
{[0,04]}\end{array}$ & & & & & & & & & $\begin{array}{l}0,018 \\
{[7,01]}\end{array}$ & 1,849 \\
\hline
\end{tabular}




\section{RISCO SISTÊMICO}

A forte crise financeira recente aumentou sobremaneira o interesse de pesquisadores sobre risco sistêmico. Hansen (2012) reflete esse momento, uma vez que discorre sobre os desafios a serem percorridos, bem como comenta os prós e contras de algumas das medidas de risco sistêmico propostas ultimamente. Originalmente o risco sistêmico tem origem no mercado bancário e, de acordo com ECB (2004), pode ser entendido como o risco que uma instituição bancária não honre suas obrigações dado que outra já não tenha honrado as suas. As implicações podem ser sérios problemas de crédito, liquidez ou confiança nos mercados.

Neste capítulo do estudo, será calculada uma das medidas de risco sistêmico analisadas no estudo citado logo acima, o CoVaR. Mas antes de se adentrar na seara de risco sistêmico propriamente dita, são importantes alguns comentários sobre o VaR, uma medida de risco individual muito popular no mercado financeiro, utilizada para se calcular o risco de mercado de um ativo ou de uma carteira. Com dados históricos e um nível de confiança $(\alpha)$, calcula-se a perda estimada para um intervalo futuro de tempo. Por exemplo, existe $\alpha$ de probabilidade de que no próximo mês ocorra uma perda de pelo menos "VaR reais" na carteira de ativos em questão.

O nível de confiança $(\alpha)$ é equivalente ao quantil $(\tau)$ da distribuição de retornos: ambos são o "corte" em que o VaR é aplicado. O cálculo do VaR sobre uma série de retornos é direto, pois com o retorno estimado e o montante total da carteira chega-se à perda estimada em valores monetários.

Diversos são os incrementos recebidos pelo VaR na tentativa de melhorar sua eficácia. Uma dessas tentativas é estimá-lo de forma condicional. Chernozhukov e Umantsev (2001) analisam diversos modelos de regressão quantílica para estimar o VaR condicional, do preço das ações de uma empresa petrolífera, em função de variáveis econômicas consideradas chave. O conjunto dessas variáveis é composto por: um índice do mercado acionário, um índice acionário do setor de petróleo, defasagens do preço da ação e características do papel, tais como tamanho, book-to-market e liquidez. Os resultados indicaram que os quantis da distribuição de retorno são impactados de 
maneira diferente uns dos outros e de forma não trivial. Outra conclusão interessante é que o VaR condicional produziu melhores resultados que o VaR não-condicional.

\subsection{CoVaR}

Adrian e Brunnermeier (2011) introduzem o conceito de CoVaR, uma medida de propagação de risco entre instituições financeiras. O CoVaR estima o VaR de uma instituição financeira $j$ condicional a uma outra instituição financeira $i$ estar em um mal momento (medido pelo seu VaR). Assim, computa-se o impacto que essa instituição em dificuldades $i$ tem sobre o VaR condicional da instituição de interesse $j$. Uma vantagem dessa metodologia é que o VaR condicional tradicional de uma instituição mede apenas o risco dela, isolada do resto do sistema. Já o CoVaR torna possível que uma instituição financeira seja sistemicamente mais arriscada do que quando considerada isoladamente. Isso ocorre, pois podem existir diversas ligações entre as instituições que as tornariam conjuntamente mais arriscadas do que individualmente, por exemplo uma queda inesperada na produção de um grande fornecedor pode impactar o desempenho de um demandante daquele insumo.

De acordo com Adrian e Brunnermeier (2011) existem duas formas de se estimar o CoVaR: a não condicional e a condicional, ambas em dois estágios. A forma mais simples é a não condicional: primeiramente estima-se o $\operatorname{VaR}^{i}(q)$ de forma tradicional ou ainda por meio de uma regressão quantílica apenas com a constante. A letra $q$ referese ao quantil desejado e o sobrescrito $i$ à instituição financeira em que se condicionará o CoVaR num momento posterior. No segundo estágio estima-se, com regressão quantílica a equação abaixo, sendo a variação dos ativos totais da instituição a variável dependente:

$$
\mathrm{XVIII)} \quad r_{t, q}^{j}=\alpha_{q}^{j \mid i}+\beta_{q}^{j \mid i} r_{t, q}^{i}+\varepsilon_{t, q}^{j \mid i}
$$

$\mathrm{O}$ sobrescrito $j$ remete à firma de interesse em que se estima o CoVaR e $t$ ao tempo. $\mathrm{O}$

valor previsto de XVIII) é definido como: $\operatorname{VaR}_{t, q}^{j \mid r_{t, q}^{i}} \equiv \hat{r}_{t, q}^{j}=\hat{\alpha}_{q}^{j \mid i}+\hat{\beta}_{q}^{j \mid i} r_{t, q}^{i}$, ou seja o 
VaR da instituição $j$ condicional a $r_{t, q}^{i}$. Quando é imposto $r_{t, q}^{i}=\operatorname{VaR}{ }^{i}(q)$, obtém-se o CoVaR de $j$ condicional a $i: \operatorname{CoVaR}_{t, q}^{j \mid i} \equiv \operatorname{VaR}_{t, q}^{j \mid \operatorname{VaR}^{i}(q)}=\hat{\alpha}_{q}^{j \mid i}+\hat{\beta}_{q}^{j \mid i} \operatorname{VaR}_{t, q}^{i}$.

Adrian e Brunnermeier (2011) ainda definem o delta-CoVaR como a diferença entre o $\operatorname{CoVaR}_{t}^{j \mid \operatorname{VaR}_{t}^{i}(q)}(q)$ e o $\operatorname{CoVaR}_{t}^{j \mid \operatorname{VaR}_{t}^{i}(0,5)}(0,5)$, ou seja, é o quanto a instituição $i$ em uma situação de risco (medida pelo $\operatorname{VaR}_{t}^{i}(q)$ ) adiciona de risco à instituição $j$ em relação a uma situação "normal”, da mediana (medida pelo $V_{a} R_{t}^{i}(0,5)$ ). Essa é uma medida de dependência sistêmica de risco entres essas duas instituições, no sentido de $i$ repassando risco para $j$ :

$\mathrm{XIX)} \quad \Delta \operatorname{CoVaR} R_{t}^{j \mid \operatorname{VaR} R_{t}^{i}(q)}(q) \equiv \operatorname{CoVaR}_{t}^{j \mid \operatorname{VaR}_{t}^{i}(q)}(q)-\operatorname{CoVaR}_{t}^{j \mid \operatorname{VaR}_{t}^{i}(0,5)}(0,5)$

A outra forma de se estimar o CoVaR é a condicional. No primeiro estágio o $\operatorname{VaR}^{i}(q)$ é estimado por regressão quantílica, condicional a um vetor $\boldsymbol{M}_{\boldsymbol{t}-\mathbf{1}} 7 \times 1$ de variáveis-estado da economia:

$$
\text { XX) } \quad r_{t, q}^{i}=\alpha_{q}^{i}+\gamma_{\boldsymbol{q}}^{i \prime} \boldsymbol{M}_{\boldsymbol{t}-\mathbf{1}}+\varepsilon_{t, q}^{i}
$$

De acordo com os autores, pertencem a $\boldsymbol{M}_{\boldsymbol{t}-\mathbf{1}}$ : VIX, spread de liquidez, mudança na taxa T-bills de três meses, mudanças na inclinação da yield curve e do spread de crédito, o retorno de mercado do CRSP e o excesso de retorno do setor de real estate em relação ao CRSP. O vetor $\boldsymbol{\gamma}_{\boldsymbol{q}}^{i}$ possui a mesma dimensão de $\boldsymbol{M}_{\boldsymbol{t}-\mathbf{1}}$. O valor previsto resultante do primeiro estágio é definido como $\operatorname{VaR}$ de $i$, no instante $t$, para o quantil $q$ : $\operatorname{VaR}_{t, q}^{i} \equiv \hat{r}_{t, q}^{i}=\hat{\alpha}_{q}^{i}+\widehat{\gamma}_{\boldsymbol{q}}^{i \prime} \boldsymbol{M}_{\boldsymbol{t}-\mathbf{1}}$. Como há o condicionamento no vetor de variáveis macroeconômicas defasadas, esse VaR não é constante no tempo. Por fim, no segundo estágio, estima-se a seguinte regressão quantílica:

XXI) $\quad r_{t, q}^{j}=\lambda_{q}^{j \mid i}+\varphi_{q}^{j \mid i} r_{t, q}^{i}+\boldsymbol{\beta}_{q}^{j \mid i} \boldsymbol{M}_{t-\mathbf{1}}+\varepsilon_{q}^{j \mid i}$

Analogamente ao caso não condicional, o valor previsto de XXI) é dado por: $\operatorname{VaR}_{t, q}^{j \mid r_{t, q}^{i}} \equiv \hat{r}_{t, q}^{j}=\hat{\lambda}_{q}^{j \mid i}+\hat{\varphi}_{q}^{j \mid i} r_{t, q}^{i}+\widehat{\boldsymbol{\beta}}_{q}^{j \mid i \prime} \boldsymbol{M}_{\boldsymbol{t}-\mathbf{1}}$. Ao condicionar $r_{t, q}^{i}=\operatorname{VaR} R_{t, q}^{i}$ obtém-se o 
CoVaR de $j$ condicional a $i: \operatorname{CoVaR}_{t, q}^{j \mid i} \equiv \operatorname{VaR}_{t, q}^{j \mid V a R_{t, q}^{i}}=\hat{\lambda}_{q}^{j \mid i}+\hat{\varphi}_{q}^{j \mid i} \operatorname{VaR}_{t, q}^{i}+\widehat{\boldsymbol{\beta}}_{\boldsymbol{q}}^{j \mid \boldsymbol{i}_{\boldsymbol{\prime}}} \boldsymbol{M}_{\boldsymbol{t}-\mathbf{1}}$. O delta-CoVaR continua a ser dado pela equação XIX).

Para o Brasil, Araújo e Lima (2013) aplicam o CoVaR às instituições financeiras do sistema bancário brasileiro e concluem que os maiores bancos, apesar de individualmente apresentarem os menores riscos, oferecem os maiores riscos sistêmicos.

\subsection{Regressão Quantílica}

A regressão tradicional de mínimos quadrados ordinários (MQO) é um método estatístico que mede o impacto $\left(\beta_{k \times 1}\right)$ de um conjunto de variáveis explicativas (regressores: $\boldsymbol{x}_{n \times k}$ ) sobre uma variável de interesse (regressando: $y_{n \times 1}$ ), por meio das médias, variâncias e covariâncias dessas variáveis.

Por exemplo: seja o modelo genérico descrito em XXII), em que $\varepsilon_{i}$ é o componente não observável e valem as hipóteses usuais para que o estimador seja não viesado.

XXII) $\quad y_{i}=\boldsymbol{x}_{\boldsymbol{i}} \beta+\varepsilon_{i}$

A escolha dos parâmetros estimados $\left(\hat{\beta}_{k \times 1}^{M Q O}\right)$ é feita de modo a minimizar a soma dos quadrados dos resíduos:

$\mathrm{XXIII)} \quad \hat{\beta}_{k \times 1}^{M Q O} \equiv \operatorname{argmin} \sum_{i=1}^{N}\left(y_{i}-\boldsymbol{x}_{i} \beta\right)^{2}$

Com isso é estimada uma média da variável $y$ condicional ao conjunto de regressores $\boldsymbol{x}_{\boldsymbol{i}}$ $\left(E\left[y_{i} \mid \boldsymbol{x}_{\boldsymbol{i}}\right]\right)$. Um fato que afeta significativamente a escolha dos parâmetros estimados é a presença de outliers, que são observações muito destoantes das demais. Esses outliers impactam fortemente a estimação da média condicional, pois seus resíduos são muito maiores que os resíduos das outras observações e a função objetivo utiliza o quadrado 
dos resíduos, acentuando ainda mais essa diferença. Esse mesmo problema pode acontecer com a média não condicional e uma solução plausível é calcular a mediana, uma estatística de ordem, portanto robusta à presença de outliers. Além disso, a mediana é uma medida de tendência central da distribuição, dividindo-a ao meio. Ainda, quanto mais assimétrica for a distribuição, maior será a diferença entre a média e a mediana.

Para o caso da regressão de MQO existe uma alternativa semelhante à mediana, denominada regressão quantílica. A escolha dos parâmetros estimados ocorre a partir da minimização da soma do valor absoluto dos resíduos oriundos do modelo. O estimador $\hat{\beta}_{k \times 1}^{M D A}$ é o de Mínimos Desvios Absolutos (MDA):

$\mathrm{XXIV)} \quad \hat{\beta}_{k \times 1}^{M D A} \equiv \operatorname{argmin} \sum_{i=1}^{N}\left|y_{i}-\boldsymbol{x}_{i} \beta\right|$

Uma definição diretamente ligada às estatísticas de ordem é a de quantil de uma distribuição. Seja uma variável aleatória $(Y)$ que possua uma função de distribuição acumulada tal que:

$\mathrm{XXV}) \quad F(Y)=\operatorname{Prob}(Y \leq y)$

Define-se o $\tau$-ésimo quantil da variável $\mathrm{Y}$, com $0<\tau<1$, como:

$\mathrm{XXVI}) \quad Q(\tau)=\inf \{y: F(y) \geq \tau\}$

Ou seja, o $\tau$-ésimo quantil é definido como o menor $y$ (ínfimo) que satisfaça a relação: $F(y) \geq \tau$. Para o caso específico da mediana, o quantil é aquele que divide a distribuição ao meio, ou seja, $\tau=0,5$.

Koenker e Basset (1978) generalizam o estimador definido em XXIV) para outros quantis da distribuição. Assim, para qualquer quantil $\tau \in(0 ; 1)$ da distribuição condicional da variável dependente, define-se estimador quantílico como aquele que satisfizer: 
$\mathrm{XXVII)} \quad \hat{\beta}_{k \times 1}^{\tau} \equiv \operatorname{argmin}[1-\tau]\left[\sum_{i: y_{i}<x_{i} \beta}\left|y_{i}-\boldsymbol{x}_{i} \beta\right|\right]+\tau\left[\sum_{i: y_{i}>x_{i} \beta}\left|y_{i}-\boldsymbol{x}_{i} \beta\right|\right]$

A diferença entre a função objetivo da regressão de MDA e a função objetivo de uma regressão quantílica qualquer, é que nesta última haverá uma ponderação diferente para os resíduos, de acordo com o quantil $\tau$. Os negativos serão ponderados por $[1-\tau]$, enquanto os positivos por $\tau$.

Se $\tau=0,5$, o caso da mediana, a função objetivo ponderará igualmente os resíduos:

$\mathrm{XXVIII)} \quad \hat{\beta}_{k \times 1}^{0,5} \equiv \operatorname{argmin} \sum_{i=1}^{N}\left|y_{i}-\boldsymbol{x}_{i} \beta\right|=\operatorname{argmin} 0,5\left[\sum_{i: y_{i}<x_{i} \beta}\left|y_{i}-\boldsymbol{x}_{i} \beta\right|\right]+$ $0,5\left[\sum_{i: y_{i}>x_{i} \beta}\left|y_{i}-\boldsymbol{x}_{i} \beta\right|\right]=\hat{\beta}_{k \times 1}^{M D A}$

Dividir a mesma somatória em positivos e negativos não altera seu valor e a última igualdade vem de que uma transformação monotônica não altera o ponto de mínimo de uma função. Portanto, uma regressão de MDA é equivalente a uma regressão quantílica estimada para a mediana.

Koenker (2005) argumenta que o problema descrito em XXVII) pode ser resolvido por algoritmos de programação linear. E tanto sob hipóteses de que os erros são iid, quanto na ausência de hipótese sobre distribuição idêntica, $\hat{\beta}^{\tau}$ converge assintoticamente para uma distribuição normal, cuja média é $\beta^{\tau}$. As variâncias assintóticas ${ }^{9}$ dessa distribuição dependerão da hipótese de iid ou podem ainda ser calculadas via bootstrap, um método de se estimar erros padrão por reamostragem da distribuição empírica.

Existe uma relação entre o VaR e a regressão quantílica. Por exemplo, uma regressão quantílica para $\tau=0,1$ da distribuição dos retornos de uma ação é equivalente à probabilidade $(10 \%)$ de se obter um retorno menor ou igual aquele previsto pelo modelo estimado. Ressaltando que esse $\mathrm{VaR}$ seria condicional às variáveis explicativas da regressão. Um exemplo de estudo que estima VaR de séries financeiras com o método de regressão quantílica é Bianconi e Yoshino (2012b).

\footnotetext{
${ }^{9}$ Koenker e Basset (1978) fornece as distribuições assintóticas para o caso iid.
} 


\subsection{Metodologia}

Chernozhukov e Umantsev (2001) e Adrian e Brunnermeier (2011) estimam o VaR com regressões quantílicas. Com isso, a probabilidade de se obter um retorno menor ou igual ao previsto pela regressão do $\tau$-ésimo quantil é igual a $\tau$.

O segundo trabalho utiliza variáveis macroeconômicas defasadas e, portanto, conhecidas no instante de tempo $t$ para prever o $V a R_{i, t}^{q}$, que é o valor em risco da ação $i$ para o quantil $q$, no instante $t$. Para o mercado financeiro brasileiro não estão disponíveis todas as variáveis semelhantes àquelas usadas por esses autores no mercado norte-americano. Por essa razão, quando disponíveis, serão utilizadas as variáveis existentes para o Brasil e na inexistência delas, as variáveis norte-americanas serão empregadas em seus lugares. Essa não é uma solução perfeita, porém é plausível, porque o mercado dos EUA é de grande relevância para o mundo e, por conseguinte, para o Brasil.

Define-se $\boldsymbol{M}_{\boldsymbol{t}-\mathbf{1}}$ como o vetor $10 \times 1$ que contém as variáveis macroeconômicas, listadas abaixo, de “a)" até “i)". As situadas de "a)" até “e)" são definidos como em Adrian e Brunnermeier (2011), "f)" e "g)" são as contrapartidas brasileiras para seus pares norteamericanos, "h)" é o risco interbancário brasileiro e, finalmente, “i)" e "i)" buscam capturar ligações entre os mercados norte-americano e brasileiro.

a) VIX $\left(v i x_{t-1}\right)$ : a volatilidade implícita das opções sobre o S\&P 500. Representa uma expectativa do mercado sobre a volatilidade para os próximos 30 dias.

b) Excesso de retorno do S\&P 500 em relação a T-bills de 3 meses $\left(r_{S \& P, t-1}^{e}\right)$ : o índice S\&P 500 é o mais representativo índice do mercado acionário norteamericano. Já a T-bills de 3 meses é largamente utilizada como proxy para o ativo livre de risco da economia dos EUA.

c) Mudança da diferença entre os retornos de 10 anos de um título corporativo BAA e de uma treasury de igual maturidade $\left(d_{-}\right.$credit_spread $\left.d_{t-1}\right)$ : mensura alterações no risco de crédito corporativo no prazo de 10 anos. 
d) Mudança da diferença entre os retornos de uma treasury de 10 anos e de uma Tbills de 3 meses $\left(d_{-} y i e l d_{-} s p r e a d_{t-1}\right)$ : mede o risco decorrente de uma eventual deterioração das perspectivas da economia dos EUA.

e) Diferença entre dois retornos consecutivos de uma T-bills de 3 meses, entre $t$ e $t-1\left(d_{-} t\right.$ bill $\left.s_{t-1}\right)$ : mede uma mudança nas taxas T-bills de 3 meses.

f) Excesso de retorno do Ibovespa em relação ao $\operatorname{CDI}\left(r_{m, t-1}^{e}\right)$ : é o índice representativo do mercado de ações do Brasil em relação ao ativo livre de risco.

g) Excesso de retorno do setor de real estate brasileiro em relação ao Ibovespa $\left(r_{-}\right.$estate $\left._{t-1}\right)$ : mede o desempenho do setor de real state em relação à Bolsa.

h) Mudança da diferença entre o CDI e a Selic (d_money_spread $\left.d_{t-1}\right)$ : as alterações capturam variações no risco de solvência do mercado interbancário brasileiro.

i) Retorno contínuo do dólar $\left(\right.$ dolar $\left._{t-1}\right)$ : definido da mesma maneira que os outros retornos contínuos deste estudo. Tem como objetivo servir como uma ponte entre os EUA e o Brasil, do ponto de vista financeiro.

j) Variação percentual da conta capital do Brasil (d\%_conta_k $\left.k_{t-1}\right)$ : deve medir o efeito que a variação da conta capital possui em relação aos riscos das empresas e, também, atuar como ligação entre o Brasil e o resto do mundo, uma vez que os investimentos norte-americanos possuem grande peso no mundo.

A periodicidade das variáveis neste Capítulo é mensal. Nenhuma delas apresenta raiz unitária pelo teste DF-GLS, como pode ser observado pela Tabela 11 localizada no Apêndice. Uma diferença entre este estudo e o de Adrian e Brunnermeier (2011), é que eles usaram como variável dependente uma medida de variação dos ativos totais da instituição financeira. Aqui, a variável dependente é o excesso de retorno das ações.

No Brasil os autores Almeida et al. (2012) estimam o CoVaR não condicional para 16 ações da Bovespa, selecionadas retroativamente a partir da composição vigente do Ibovespa entre maio e agosto de 2011. A periodicidade dessa amostra é diária, cobrindo de janeiro de 1995 a agosto de 2011. Obviamente, muitos dos papéis do Ibovespa em agosto de 2011 não eram sequer listados em 1995. Por essa razão, restaram apenas 16 ações "vencedoras" na amostra daqueles autores. 


\subsubsection{Empresas Participantes}

A Tabela 6 exibe as mesmas 16 ações escolhidas em Almeida et al. (2012) que serão utilizadas neste estudo e algumas de suas estatísticas descritivas. Configura-se como objetivo estimar o CoVaR, tanto o condicional quanto o não condicional no mesmo universo de ações e num período $74 \%$ coincidente com o daqueles autores. Por isso, ao contrário do Capítulo 2, o índice de mercado da bolsa brasileira será apenas o Ibovespa, uma vez que esse foi o índice utilizado por aqueles autores. Uma breve descrição das empresas participantes da amostra é realizada a seguir.

Tabela 6 - Ações Participantes do CoVaR

\begin{tabular}{|c|c|c|c|c|c|}
\hline Empresas & Papel & Média & Mínimo & Máximo & Desvio-Padrão \\
\hline Ambev & AMBV4 & 1,22 & $-28,9$ & 23,23 & 7,61 \\
\hline Banco do Brasil & BBAS3 & 0,72 & $-44,26$ & 27,1 & 11,28 \\
\hline Bradesco & BBDC4 & 0,82 & $-26,9$ & 34,81 & 10,09 \\
\hline Cemig & CMIG4 & 0,62 & $-30,93$ & 33,08 & 9,68 \\
\hline CSN & CSNA3 & 1,32 & $-36,08$ & 42,16 & 12,87 \\
\hline Gerdau & GGBR4 & 1,27 & $-42,6$ & 35,87 & 12,38 \\
\hline Metalúrgica Gerdau & GOAU4 & 1,57 & $-42,62$ & 30,1 & 11,51 \\
\hline Itaúsa & ITSA4 & 1,07 & $-28,99$ & 29,61 & 9,16 \\
\hline Itaú Unibanco & ITUB4 & 0,72 & $-32,44$ & 29,24 & 9,56 \\
\hline Lojas Americanas & LAME4 & 2,03 & $-54,08$ & 86,68 & 16,19 \\
\hline Pão de Açúcar & PCAR4 & 0,19 & $-41,25$ & 29,07 & 9,8 \\
\hline Petrobras & PETR3 & 1,03 & $-39,98$ & 84,32 & 12,02 \\
\hline Petrobras & PETR4 & 0,68 & $-41,99$ & 39,44 & 10,26 \\
\hline Usiminas & USIM5 & 0,74 & -38 & 48,12 & 14,32 \\
\hline Vale & VALE3 & 1,06 & $-23,68$ & 26,05 & 9,53 \\
\hline Vale & VALE5 & 0,83 & $-23,47$ & 24,25 & 9,03 \\
\hline
\end{tabular}

\subsubsection{Ambev}

A Companhia de Cervejas das Américas (Ambev) é a quarta maior cervejaria e integra a maior plataforma de cervejas do mundo, a Anheuser-Busch InBev, além de ser a maior engarrafadora da PepsiCo fora dos EUA. É reconhecida pela excelência em gestão e por um ambiente de trabalho bastante meritocrático ${ }^{10}$.

\footnotetext{
${ }^{10}$ http://www.ambev.com.br/pt-br/a-ambev/institucional/a-ambev
} 


\subsubsection{Banco do Brasil}

Banco público fundado em 1808 pelo príncipe-regente de Portugal Dom João. Foi o primeiro banco do país e está presente há mais de 100 anos na Bolsa de Valores. Ao longo de sua história já emitiu e foi responsável pelo controle da moeda e recentemente incorporou diversas instituições financeiras. Possui a maior carteira de crédito agrícola do país (63,3\% do mercado) e de fundos de investimento (20,8\% do mercado $)^{11}$.

\subsubsection{Bradesco}

Um dos maiores grupos financeiros do Brasil, atuando desde 1943. É a maior operadora de seguros, de previdência complementar e de títulos de capitalização. Possui a maior rede privada de agências bancárias no país ${ }^{12}$.

\subsubsection{Cemig}

Empresa de energia elétrica controlada pelo Governo do Estado de Minas Gerais e a maior empresa integrada (geração, distribuição e concessão) de energia elétrica do país. Nesse Estado é responsável por aproximadamente $96 \%$ da área de concessão, resultando em cerca de 7 milhões de consumidores ${ }^{13}$.

\subsubsection{5 $\quad$ CSN}

Empresa siderúrgica, mineradora e de infra-estrutura fundada em 1941, durante a II Guerra Mundial como empresa pública e a primeira produtora integrada de aço plano do Brasil, fato que viabilizou a implantação de outras indústrias pelo país. Foi privatizada em 1993 e seu aço encontra mercado principalmente nos setores: automotivos, de construção civil, de embalagem e linha branca ${ }^{14}$.

11

http://www.bb.com.br/portalbb/page3,136,3527,0,0,1,8.bb?codigoMenu=204\&codigoNoticia=691\&codig oRet $=1065 \&$ bread $=2$

${ }^{12} \mathrm{http}: / /$ www.bradesco.com.br/html/classic/sobre/index.shtm

${ }^{13} \mathrm{http}: / /$ www.cemig.com.br/pt-br/a_cemig/quem_somos/Paginas/default.aspx

${ }^{14} \mathrm{http}: / / \mathrm{www} . \mathrm{mzweb} . \mathrm{com} . \mathrm{br} / \mathrm{csn} / \mathrm{web} / \mathrm{conteudo} \_$pt.asp?idioma=0\&conta=28\&tipo=1351 


\subsubsection{Gerdau e Metalúrgica Gerdau}

Uma das maiores siderúrgicas brasileiras e também uma empresa com forte presença internacional, principalmente nos EUA. É a maior recicladora de sucata da América Latina e líder na produção de aços longos nas Américas. A Metalúrgica Gerdau é uma holding que controla a Gerdau ${ }^{15}$.

\subsubsection{Itaúsa}

Holding que controla o banco Itaú Unibanco, a empresa de tecnologia da informação e de equipamentos de informática Itautec, a Duratex, a química Elekeiroz, entre outros empreendimentos ${ }^{16}$.

\subsubsection{Itaú Unibanco}

Uma das maiores instituições financeiras do Brasil, resultante da associação entre o Itaú e o Unibanco durante a grave crise de 2008. Suas origens remontam a 1924 e é considerada pela consultoria Interbrand como a marca mais valiosa do Brasil em $2012^{17}$.

\subsubsection{Lojas Americanas}

Tradicional loja de varejo do país, com mais de 80 anos de existência e 740 lojas nas principais cidades brasileiras. Proprietária de sites de comércio eletrônico. Detém grande parte do comércio brasileiro de brinquedos, bombonière, lingerie, CDs e DVDs. É importante frisar que com o aumento da renda e sua melhor distribuição nos últimos anos, o setor varejista apresentou grande crescimento ${ }^{18}$.

\subsubsection{Pão de Açúcar}

Líder do setor varejista no Brasil, presente em 19 estados e no Distrito Federal, com 1.571 lojas. Possui estrutura multiformato capaz de atender às necessidades de consumidores oriundos de diversos níveis sociais e regiões, contando com

\footnotetext{
${ }^{15} \mathrm{http} / / / \mathrm{www}$.gerdau.com.br/sobre-gerdau/perfil-da-empresa.aspx

${ }^{16} \mathrm{http}: / /$ ww13.itau.com.br/itausa/HTML/pt-BR/infofinan/dcc/quemsomos.htm

${ }^{17} \mathrm{http}: / /$ www.itau.com.br/sobre/

${ }^{18} \mathrm{http} / / /$ ri.lasa.com.br/a-empresa/visao-geral-da-empresa
} 
hipermercados, supermercados, lojas de eletroeletrônicos, drogarias e comércio eletrônico ${ }^{19}$.

\subsubsection{Petrobras}

Empresa pública e verticalmente integrada do setor de energia, sendo a maior companhia brasileira por valor de mercado ${ }^{20}$. Presente nos segmentos upstream e downstream da produção de petróleo e gás, além de investir em fontes de energias alternativas e energia elétrica ${ }^{21}$.

\subsubsection{Usiminas}

Grande siderúrgica brasileira, fundada em 1957 e maior produtora de aços planos da América Latina. Também atua nos setores de mineração, distribuição, transformação e galvanização de aços, bens de capital e em toda a cadeia produtiva do aço ${ }^{22}$.

\subsubsection{Vale}

Uma das maiores mineradoras do mundo, criada em 1942 como empresa pública, foi privatizada em 1997. Maior produtora mundial de minério de ferro e a segunda maior de níquel $^{23}$.

A nomenclatura dada por Almeida et al. (2012) ao CoVaR, no que se refere à direção do risco sistêmico será mantida neste estudo para garantir uma maior homogeneidade. As três possíveis direções do risco sistêmico são: das ações individuais para o mercado (risco sistêmico), do mercado para as ações (teste de estresse ou stress test) e de uma ação $i$ para outra $j$ (efeito contágio).

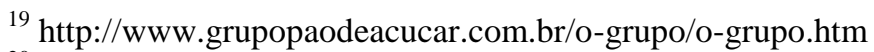

${ }^{20}$ Em agosto de 2012.

${ }^{21} \mathrm{http}: / /$ www.petrobras.com.br/pt/quem-somos/perfil/atividades/

${ }^{22} \mathrm{http}: / /$ www.usiminas.com/irj/portal?NavigationTarget=navurl://ac7c7f39e42caccc8e99fb1dc0d696e8

${ }^{23}$ http://www.vale.com/brasil/PT/aboutvale/across-world/Paginas/default.aspx
} 


\subsubsection{Risco Sistêmico: CoVaR do Mercado Condicional às Ações}

Risco sistêmico é entendido como a diferença entre as contribuições marginais, exercidas sobre o VaR do mercado pelo $\mathrm{VaR}$ de uma ação $i$, comparativamente a essa mesma ação $i$ estar em uma situação mediana. A relevância dessa medida está em saber quais papéis exercem um maior risco sistêmico sobre o mercado, cujo conhecimento permite a adoção de mecanismos de proteção e monitoramento de risco.

Divide-se a estimação condicional em dois estágios: no primeiro estágio estima-se o VaR da ação $i$ condicional a $\boldsymbol{M}_{\boldsymbol{t}-\mathbf{1}}$, para em seguida se estimar o CoVaR do mercado. A seguinte regressão quantílica é estimada no primeiro estágio:

O primeiro estágio estima o VaR condicional de uma ação:

XXIX) $\quad 1^{\circ}$ Estágio: $r_{t, q}^{i}=\alpha_{q}^{i}+\boldsymbol{\beta}_{\boldsymbol{q}}^{i} \boldsymbol{M}_{\boldsymbol{t}-\mathbf{1}}+\varepsilon_{t, q}^{i}$

Cujo valor previsto é definido como $\operatorname{VaR} R_{t, q}^{i} \equiv \hat{r}_{t, q}^{i}=\hat{\alpha}_{q}^{i}+\widehat{\boldsymbol{\beta}}_{\boldsymbol{q}}^{\boldsymbol{i}{ }^{\prime}} \boldsymbol{M}_{\boldsymbol{t}-\mathbf{1}}$.

Já o objetivo do segundo estágio é estimar o CoVaR do mercado (sistema) condicional a $r_{t, q}^{i}$ de uma ação $i$ :

XXX) $\quad 2^{\circ}$ Estágio: $r_{t, q}^{\text {sist }}=\lambda_{q}^{\text {sist } \mid i}+\varphi_{q}^{\text {sist } \mid i} r_{t, q}^{i}+\boldsymbol{\beta}_{\boldsymbol{q}}^{\text {sist } \mid \boldsymbol{i}} \boldsymbol{M}_{\boldsymbol{t}-\mathbf{1}}+\varepsilon_{t, q}^{\text {sist } \mid i}$

O valor previsto de XXX) para o sistema é dado por: $\operatorname{VaR}_{t, q}^{s i s t \mid r_{t, q}^{i}} \equiv \hat{r}_{t, q}^{s i s t}=\hat{\lambda}_{q}^{s i s t \mid i}+$ $\hat{\varphi}_{q}^{\text {sist } \mid i} r_{t, q}^{i}+\widehat{\boldsymbol{\beta}}_{\boldsymbol{q}}^{\text {sist } \mid \boldsymbol{i}_{1}} \boldsymbol{M}_{\boldsymbol{t}-\mathbf{1}}$. Como visto anteriormente na seção 3.1, condicionar ao evento $r_{t, q}^{i}=\operatorname{VaR} R_{t, q}^{i} \quad$ é $\quad$ calcular $\quad$ o $\quad$ CoVaR: $\quad \operatorname{CoVaR}_{t, q}^{s i s t \mid i} \equiv \operatorname{VaR}_{t, q}^{\text {sist } \mid V a R_{t, q}^{i}}=\hat{\lambda}_{q}^{s i s t \mid i}+$ $\hat{\varphi}_{q}^{s i s t \mid i} \operatorname{VaR}_{t, q}^{i}+\widehat{\boldsymbol{\beta}}_{q}^{\text {sist } \mid i,} \boldsymbol{M}_{\boldsymbol{t}-\mathbf{1}}$.

Contudo, comparar previsões feitas em diferentes distribuições condicionais de retorno não é apropriado. A solução para isso é o $\Delta \operatorname{CoV} a R_{t, q}^{s i s t \mid i}$, que pode ser interpretado como uma medida de distância entre o quantil $q$ e a mediana da distribuição condicional, tornando possível a comparação entre as diferentes ações. Ainda, de acordo com Adrian 
e Brunnermeier (2011), o delta-CoVaR pode ser visto também como a contribuição marginal que cada ativo faz ao risco sistêmico do mercado, numa situação de risco $q$ em relação à uma situação mediana. $\mathrm{O} \Delta \operatorname{CoV} a R_{t, q}^{s i s t \mid i}$ é a medida de risco sistêmico, definida pela diferença entre $\operatorname{CoVaR}_{t, q}^{\text {sist } \mid i}$ e $\operatorname{CoVaR} R_{t, 0,5}^{\text {sist } \mid i}$ :

$$
\text { XXXI) } \quad \Delta \operatorname{CoVaR} R_{t, q}^{s i s t \mid i}=\operatorname{CoVaR} R_{t, q}^{\text {sist } \mid i}-\operatorname{CoVaR}_{t, 0,5}^{\text {sist } \mid i}
$$

As regressões serão estimadas para $q=0,05$ e para a mediana, sempre com o objetivo de tornar possível a comparação com os resultados de Almeida et al. (2012). Nesta seção foi descrito somente a metodologia condicional para o cálculo do CoVaR. Já a não condicional pode ser encontrada na seção 3.1 ou ainda quando $\boldsymbol{\beta}_{\boldsymbol{q}}^{\boldsymbol{i}} \boldsymbol{M}_{\boldsymbol{t}-\mathbf{1}}$ é suprimido do primeiro e do segundo estágio. Essa consideração vale também para as seções 3.3.3 e 3.3 .4 a seguir.

\subsubsection{Stress Test: CoVaR das Ações Condicional ao Mercado}

$\mathrm{O}$ objetivo do stress test é estimar o $\mathrm{VaR}$ do mercado condicional às variáveis macroeconômicas $\boldsymbol{M}_{t-1}$ no primeiro estágio para, num segundo momento, computar seu impacto sobre o VaR de cada uma das 16 ações. Essa medida captura o quão exposto está o papel $i$ a um evento ruim do mercado.

XXXII) $\quad 1^{\mathrm{o}}$ Estágio: $r_{t, q}^{\text {sist }}=\alpha_{q}^{\text {sist }}+\boldsymbol{\beta}_{\boldsymbol{q}}^{\text {sist' }} \boldsymbol{M}_{\boldsymbol{t}-\mathbf{1}}+\varepsilon_{t, q}^{\text {sist }}$

Define-se $\operatorname{VaR}_{t, q}^{\text {sist }}$ como o valor em risco previsto para a série de retornos do mercado em cada mês $t$ e num dado quantil $q: \operatorname{VaR}_{t, q}^{s i s t} \equiv \hat{r}_{t, q}^{\text {sist }}=\hat{\alpha}_{t, q}^{\text {sist }}+\widehat{\boldsymbol{\beta}}_{\boldsymbol{t}, \boldsymbol{q}}^{\text {sist' }} \boldsymbol{M}_{\boldsymbol{t - 1} \mathbf{1}}$.

No segundo estágio, a seguinte regressão quantílica é estimada para cada uma das 16 ações:

XXXIII) $\quad 2^{\circ}$ Estágio: $r_{t, q}^{i}=\lambda_{q}^{i}+\varphi_{q}^{i \mid s i s t} r_{t, q}^{\text {sist }}+\boldsymbol{\beta}_{\boldsymbol{q}}^{i \mid \text { sist }}{ }^{{ }_{1}} \boldsymbol{M}_{\boldsymbol{t}-\mathbf{1}}+\varepsilon_{q}^{i \mid s i s t}$ 


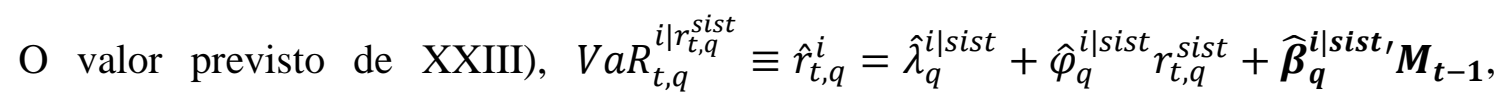
quando condicionado em $r_{t, q}^{\text {sist }}=\operatorname{VaR}_{t, q}^{\text {sist }}$ é definido como: $\quad \operatorname{CoVaR}_{t, q}^{i \mid s i s t} \equiv$ $\operatorname{VaR}_{t, q}^{i \mid V a R_{t, q}^{\text {sist }}}=\hat{\lambda}_{q}^{i \mid s i s t}+\hat{\varphi}_{q}^{i \mid s i s t} \operatorname{VaR}_{t, q}^{\text {sist }}+\widehat{\boldsymbol{\beta}}_{\boldsymbol{q}}^{i \mid \text { sist }}{ }^{\boldsymbol{M}_{\boldsymbol{t}-\mathbf{1}}}$, ou seja, o valor em risco de uma ação $i$ condicional ao valor em risco do mercado $\left(\operatorname{VaR}_{t, q}^{\text {sist }}\right)$.

Pelas mesmas razões e com idêntica interpretação da seção anterior, é possível obter o delta-CoVaR $\left(\Delta \operatorname{CoVaR}_{t, q}^{i \mid s i s t}\right)$, a diferença entre o $\operatorname{CoVaR}_{t, q}^{i \mid s i s t}$ para um quantil $q$ qualquer e o $\operatorname{CoV} a R_{t, 0,5}^{i \mid s i s t}$ em relação à mediana. A essa contribuição marginal de risco que o mercado faz para a ação $i$ é dado o nome de stress test.

XXXIV) $\quad \Delta \operatorname{CoVaR} R_{t, q}^{i \mid s i s t}=\operatorname{CoVaR} R_{t, q}^{i \mid s i s t}-\operatorname{CoVaR} R_{t, 0,5}^{i \mid s i s t}$

\subsubsection{Efeito Contágio: CoVaR de $\boldsymbol{j}$ condicional ao CoVaR de $\boldsymbol{i}$}

O efeito-contágio mede as inter-relações entre as 16 ações utilizadas por Almeida et al. (2012). Com todas as combinações possíveis, chega-se numa matriz-contágio de ordem $16 \times 16$, em que as diagonais são nulas, porque seria o efeito sistêmico de uma ação $i$ sobre ela própria. De posse dessa matriz, documenta-se quais papéis são mais influenciados e por quem o são, um resultado importante da ótica do monitoramento de risco de uma carteira.

O primeiro estágio consiste na estimação do VaR da ação $i$ condicionada ao vetor $\boldsymbol{M}_{\boldsymbol{t}-\mathbf{1}}$, tal qual a equação XXIX). Já no segundo estágio estima-se por regressões quantílica a seguinte equação:

XXXV) $\quad 2^{\circ}$ Estágio: $r_{t, q}^{j}=\lambda_{q}^{j \mid i}+\varphi_{q}^{j \mid i} r_{t, q}^{i}+\boldsymbol{\beta}_{q}^{j \mid i \boldsymbol{i}} \boldsymbol{M}_{\boldsymbol{t}-\mathbf{1}}+\varepsilon_{q}^{j \mid i}$

O valor previsto de XXXV) é definido como o VaR da ação $j$ condicional ao retorno da ação $i: V_{a} R_{t, q}^{j \mid r_{t, q}^{i}} \equiv \hat{r}_{t, q}^{j}=\hat{\lambda}_{q}^{j \mid i}+\hat{\varphi}_{q}^{j \mid i} r_{t, q}^{i}+\widehat{\boldsymbol{\beta}}_{q}^{j \mid i,} \boldsymbol{M}_{\boldsymbol{t}-\mathbf{1}}$. Impondo $r_{t, q}^{i}=\operatorname{VaR} R_{t, q}^{i}$ obtém-se o CoVaR da ação $j$ condicional a $i$. Portanto: $\operatorname{CoVaR}_{t, q}^{j \mid i} \equiv \operatorname{VaR}_{t, q}^{j \mid \operatorname{VaR} R_{t, q}^{i}}=\hat{\lambda}_{q}^{j \mid i}+$ 
$\hat{\varphi}_{q}^{j \mid i} \operatorname{VaR}_{t, q}^{i}+\widehat{\boldsymbol{\beta}}_{\boldsymbol{q}}^{j \mid i{ }_{1}} \boldsymbol{M}_{\boldsymbol{t}-\mathbf{1}}$. Finalmente, define-se o efeito contágio de $i$ sobre $j$ como o delta-CoVaR $\left(\triangle \operatorname{CoVaR} R_{t, q}^{j \mid i}\right)$ :

$\mathrm{XXXVI)} \quad \Delta \operatorname{CoVaR} R_{t, q}^{j \mid i}=\operatorname{CoVaR}_{t, q}^{j \mid i}-\operatorname{CoVaR}_{t, 0,5}^{j \mid i}$

\subsection{Resultados}

Nesta seção são apresentados os resultados referentes ao CoVaR, proposto por Adrian e Brunnermeier (2011), que utiliza as variáveis-estado $\boldsymbol{M}_{\boldsymbol{t}-\mathbf{1}}$ (condicional) em sua estimação e também a estimação não condicional. Por fim, os números obtidos são comparados com os de Almeida et al. (2012).

\subsubsection{Risco Sistêmico}

Na Tabela 7 encontram-se os resultados do risco sistêmico de cada uma das dezesseis ações sobre o Ibovespa. Primeiramente na estimação condicional, a maior contribuição marginal, medida pelo delta-CoVaR, é dada pela GOAU4 e a menor pela ação preferencial da Vale (VALE5). Agora focalizando a não condicional, temos que a maior transmissão de risco ocorre com o papel BBDC4 e a menor na preferencial do Pão de Açúcar (PCAR4). A correlação entre essas duas metodologias é de 0,41, o que não é estatisticamente diferente de zero. Por sua vez, Almeida et al. (2012) encontraram na PETR4 a maior contribuição marginal para o risco sistêmico e explicam-na pelo fato da Petrobras possuir o maior volume de negociação na BM\&FBovespa e também por essa empresa ser fortemente influenciada por decisões governamentais. Já a ação que menos influencia o Ibovespa também é PCAR4. Por meio das colunas 3 e 6, percebe-se a grande disparidade existente entre os números dos dois trabalhos, implicando uma correlação de apenas 0,23 e também não estatisticamente diferente de zero. Duas possíveis explicações para essa grande diferença são a periodicidade diferente das duas bases de dados (lá diária e aqui mensal) e a base de dados deste estudo representar $74 \%$ do período total daquele estudo. 
Tabela 7 - Risco Sistêmico

\begin{tabular}{|c|c|c|c|c|c|}
\hline Ações & $\begin{array}{c}\text { Risco } \\
\text { Sistêmico } \\
\text { Condicional }\end{array}$ & $\begin{array}{c}\text { Risco } \\
\text { Sistêmico } \\
\text { Não- } \\
\text { Condicional }\end{array}$ & $\begin{array}{c}\text { Ações } \\
\text { Classificadas pelo } \\
\text { Risco Sistêmico } \\
\text { Condicional }\end{array}$ & $\begin{array}{c}\text { Ações } \\
\text { Classificadas pelo } \\
\text { Risco Sistêmico } \\
\text { Não-Condicional }\end{array}$ & $\begin{array}{c}\text { Ações Classificadas } \\
\text { pelo Risco Sistêmico } \\
\text { de Almeida } \text { et al. } \\
\text { (2012) }\end{array}$ \\
\hline & & & \multicolumn{3}{|c|}{ Do Risco Maior para o Menor } \\
\hline AMBV4 & $-16,43$ & $-17,80$ & $1^{\circ} \mathrm{GOAU} 4$ & $1^{\circ} \mathrm{BBDC} 4$ & $1^{\circ}$ PETR4 $(-2,75)$ \\
\hline BBAS3 & $-18,26$ & $-18,22$ & $2^{\circ}$ CMIG4 & $2^{\circ}$ USIM5 & $2^{\circ}$ VALE5 $(-2,48)$ \\
\hline BBDC4 & $-18,04$ & $-21,81$ & $3^{\circ}$ ITUB4 & $3^{\circ}$ ITUB4 & $3^{\circ}$ BBAS3 $(-2,37)$ \\
\hline CMIG4 & $-19,62$ & $-18,37$ & $4^{\circ}$ ITSA4 & $4^{\circ}$ GGBR4 & $4^{\circ}$ GGBR4 $(-2,36)$ \\
\hline CSNA3 & $-18,31$ & $-17,62$ & $5^{\circ}$ PETR3 & $5^{\circ} \mathrm{CMIG} 4$ & $5^{\circ}$ GOAU4 $(-2,3)$ \\
\hline GGBR4 & $-18,37$ & $-18,51$ & $6^{\circ}$ GGBR4 & $6^{\circ} \mathrm{GOAU} 4$ & $6^{\circ}$ CMIG4 $(-2,29)$ \\
\hline GOAU4 & $-20,55$ & $-18,37$ & $7^{\circ}$ CSNA3 & $7^{\circ} \mathrm{BBAS} 3$ & $7^{\circ}$ CSNA3 $(-2,28)$ \\
\hline ITSA4 & $-18,84$ & $-17,35$ & $8^{\circ}$ BBAS3 & $8^{\circ}$ LAME4 & $8^{\circ}$ USIM5 $(-2,27)$ \\
\hline ITUB4 & $-19,57$ & $-19,67$ & $9^{\circ} \mathrm{BBDC} 4$ & $9^{\circ} \mathrm{AMBV} 4$ & $9^{\circ} \mathrm{BBDC} 4(-2,12)$ \\
\hline LAME4 & $-16,90$ & $-17,83$ & $10^{\circ}$ PETR4 & $10^{\circ} \mathrm{CSNA} 3$ & $10^{\circ}$ ITSA4 $(-2,03)$ \\
\hline PCAR4 & $-14,82$ & $-14,43$ & $11^{\circ}$ USIM5 & $11^{\circ}$ VALE5 & $11^{\circ}$ PETR3 $(-1,99)$ \\
\hline PETR3 & $-18,72$ & $-16,83$ & $12^{\circ}$ LAME4 & $12^{\circ}$ ITSA4 & $12^{\circ}$ AMBV4 $(-1,95)$ \\
\hline PETR4 & $-17,78$ & $-16,27$ & $13^{\circ} \mathrm{AMBV} 4$ & $13^{\circ}$ VALE3 & $13^{\circ}$ LAME4 $(-1,81)$ \\
\hline USIM5 & $-17,64$ & $-20,40$ & $14^{\circ}$ PCAR4 & $14^{\circ}$ PETR3 & $14^{\circ}$ ITUB4 $(-1,72)$ \\
\hline VALE3 & $-14,60$ & $-16,98$ & $15^{\circ}$ VALE3 & $15^{\circ}$ PETR4 & $15^{\circ}$ VALE3 $(-1,64)$ \\
\hline VALE5 & $-13,95$ & $-17,62$ & $16^{\circ}$ VALE5 & $16^{\circ}$ PCAR4 & $16^{\circ}$ PCAR4 $(-1,43)$ \\
\hline \multicolumn{6}{|c|}{ Correlações } \\
\hline \multicolumn{6}{|c|}{ Correlação (Stress Test Condicional; Stress Test Não-Condicional) = 0,41 $(0,11)$} \\
\hline \multicolumn{6}{|c|}{ Correlação (Stress Test Não-Cond.; Stress Test Não-Cond. de Almeida et al. $(2012))=0,23(0,40)$} \\
\hline \multicolumn{6}{|c|}{ Correlação (Stress Test Cond.; Stress Test Não-Cond. de Almeida et al. $(2012))=0,30(0,26)$} \\
\hline
\end{tabular}

*P-valor entre parênteses

\subsubsection{Teste de Estresse}

O teste de estresse ou stress test é obtido pela contribuição marginal do mercado em uma situação de risco influenciando uma determinada ação. A Tabela 8 mostra quais são os papéis mais afetados por um distress no Ibovespa. Na estimação condicional a ação que sofre maior influência de um estresse no Ibovespa é a LAME4, ao passo que AMBV4 sofre a menor influência. Na metodologia não condicional o papel mais influenciado é novamente o preferencial das Lojas Americanas. A correlação entre as duas medidas é de 0,93 e estatisticamente diferente de zero, sendo interessante que as três ações mais afetadas são as mesmas nas duas formas de cômputo ( $4^{\mathrm{a}}$ e $5^{\mathrm{a}}$ colunas). 
Mais uma vez as similaridades entre os resultados não condicionais deste estudo com os de Almeida et al. (2012) são bastante baixas, com uma correlação de apenas 0,23. Um resultado convergente nos dois artigos é a colocação de AMBV4 como o papel menos influenciado pelo sistema nas três classificações. Outro ponto em comum diz respeito à ação preferencial classe A da Usiminas, USIM5 sendo a mais afetada em Almeida et al. (2012) e a segunda mais nas duas metodologias deste estudo.

Tabela 8 - Stress Test

\begin{tabular}{|c|c|c|c|c|c|}
\hline Ações & $\begin{array}{c}\text { Stress Test } \\
\text { Condicional }\end{array}$ & $\begin{array}{c}\text { Stress Test } \\
\text { Não- } \\
\text { Condicional }\end{array}$ & $\begin{array}{c}\text { Ações } \\
\text { classificadas } \\
\text { pelo Stress } \\
\text { Test } \\
\text { Condicional }\end{array}$ & $\begin{array}{c}\text { Ações } \\
\text { Classificadas } \\
\text { pelo Stress Test } \\
\text { Não- } \\
\text { Condicional }\end{array}$ & $\begin{array}{c}\text { Ações Classificadas } \\
\text { pelo Stress Test Não- } \\
\text { Condicional de Almeida } \\
\text { et al. (2012) }\end{array}$ \\
\hline & & & \multicolumn{3}{|c|}{ Do Risco Maior para o Menor } \\
\hline AMBV4 & $-13,56$ & $-13,35$ & $1^{\circ}$ LAME4 & $1^{\circ}$ LAME4 & $1^{\circ}$ USIM5 $(-3,38)$ \\
\hline BBAS3 & $-28,24$ & $-27,29$ & $2^{\circ}$ USIM5 & $2^{\circ}$ USIM5 & $2^{\circ}$ PETR4 $(-3,37)$ \\
\hline BBDC4 & $-22,37$ & $-23,79$ & $3^{\circ}$ GGBR4 & $3^{\circ}$ GGBR4 & $3^{\circ}$ PETR3 $(-3,31)$ \\
\hline CMIG4 & $-22,67$ & $-23,13$ & $4^{\circ}$ CSNA3 & $4^{\circ} \mathrm{GOAU} 4$ & $4^{\circ} \mathrm{CMIG} 4(-3,14)$ \\
\hline CSNA3 & $-28,78$ & $-25,84$ & $5^{\circ} \mathrm{GOAU} 4$ & $5^{\circ} \mathrm{BBAS3}$ & $5^{\circ}$ BBDC4 $(-2,88)$ \\
\hline GGBR4 & $-31,15$ & $-29,85$ & $6^{\circ} \mathrm{BBAS3}$ & $6^{\circ}$ CSNA3 & $6^{\circ}$ CSNA3 $(-2,77)$ \\
\hline GOAU4 & $-28,71$ & $-28,50$ & $7^{\circ}$ ITUB4 & $7^{\circ}$ PETR4 & $7^{\circ}$ ITUB4 $(-2,76)$ \\
\hline ITSA4 & $-21,45$ & $-21,19$ & $8^{\circ}$ PCAR4 & $8^{\circ}$ ITUB4 & $8^{\circ}$ VALE5 $(-2,75)$ \\
\hline ITUB4 & $-27,05$ & $-24,05$ & $9^{\circ}$ PETR4 & $9^{\circ} \mathrm{BBDC} 4$ & $9^{\circ}$ GOAU4 $(-2,72)$ \\
\hline LAME4 & $-34,40$ & $-39,42$ & $10^{\circ} \mathrm{CMIG} 4$ & $10^{\circ}$ PETR3 & $10^{\circ}$ GGBR4 $(-2,70)$ \\
\hline PCAR4 & $-25,94$ & $-21,00$ & $11^{\circ} \mathrm{BBDC} 4$ & $11^{\circ} \mathrm{CMIG} 4$ & $11^{\circ}$ ITSA4 $(-2,70)$ \\
\hline PETR3 & $-21,80$ & $-23,21$ & $12^{\circ}$ PETR3 & $12^{\circ}$ ITSA4 & $12^{\circ}$ BBAS3 $(-2,51)$ \\
\hline PETR4 & $-23,13$ & $-24,19$ & $13^{\circ}$ ITSA4 & $13^{\circ}$ PCAR4 & $13^{\circ}$ VALE3 $(-2,40)$ \\
\hline USIM5 & $-31,82$ & $-34,57$ & $14^{\circ}$ VALE3 & $14^{\circ}$ VALE3 & $14^{\circ}$ LAME4 $(-2,14)$ \\
\hline VALE3 & $-18,99$ & $-19,42$ & $15^{\circ}$ VALE5 & $15^{\circ}$ VALE5 & $15^{\circ}$ PCAR4 $(-1,82)$ \\
\hline VALE5 & $-16,97$ & $-17,02$ & $16^{\circ} \mathrm{AMBV} 4$ & $16^{\circ} \mathrm{AMBV} 4$ & $16^{\circ}$ AMBV4 $(-1,81)$ \\
\hline \multicolumn{6}{|c|}{ Correlações } \\
\hline \multicolumn{6}{|c|}{ Correlação (Stress Test Condicional; Stress Test Não-Condicional) = 0,93 $(0,00)$} \\
\hline \multicolumn{6}{|c|}{ Correlação (Stress Test Não-Cond.; Stress Test Não-Cond. de Almeida et al. $(2012))=0,23(0,39)$} \\
\hline \multicolumn{6}{|c|}{ Correlação (Stress Test Cond.; Stress Test Não-Cond. de Almeida et al. $(2012))=0,13(0,64)$} \\
\hline
\end{tabular}




\subsubsection{Efeito Contágio}

A última possibilidade de aplicação da metodologia CoVaR é obtida condicionando o VaR de uma ação $j$ ao VaR de uma ação $i\left(\Delta \operatorname{CoVaR} R_{t, q}^{j \mid i}\right)$. As Tabela 9 e 10 apresentam a matriz de efeitos contágio elaborada de forma, respectivamente, condicional e não condicional para os papéis utilizados por Almeida et al. (2012) e comparável à Tabela 5 daquele artigo. Como já mencionado anteriormente, o principal objetivo da matriz de efeito contágio é identificar as ações que mais transmitem riscos às demais e, também, aquelas que mais são influenciadas pelas demais.

A análise coluna a coluna informa a contribuição marginal feita por cada um dos papéis $i$, em situações de distress financeiro, sobre seus pares $j$. Já a análise linha a linha mostra as várias influências sofridas por uma ação $j$ pelos seus pares $i$. Primeiramente com a Tabela 9 que exibe as estimativas condicionais, a ação que mais exerceu influência sobre as demais, controlando pelas variáveis macroeconômicas defasadas, foi a ITSA4. Essa conclusão é obtida pelo maior somatório das colunas. Já o papel que menos influencia seus pares, obtido pelo menor somatório das colunas, é VALE5. Na outra direção, o ativo mais influenciado pelos demais (obtido pelo maior somatório das linhas) foi LAME4. Já AMBV4 é o menos exposto às contribuições marginais de risco de seus pares.

As estimativas não condicionais são apresentadas na Tabela 10. $\mathrm{O}$ papel que mais influencia seus pares é USIM5 e a que menos exerce influência é PETR3. Alternativamente a ação que mais recebe contribuições de risco das outras é LAME4, ao passo que a de menor recepção é novamente a AMBV4.

Almeida et al. (2012) encontraram PETR4 como ação que mais contribuía para o aumento de risco sistêmico das demais e de menor influência LAME4. PETR4 é também o ativo mais influenciado pelos demais e a AMBV4 o menos influenciado. Neste estudo confirmam-se apenas os resultados referentes a AMBV4. Os demais resultados não se conformam com os de Almeida et al. (2012) e como indicativo disso, tem-se que a correlação existente entre a última linhas deste e daquele artigo é de 0,34 e a correlação entre a última coluna dos dois estudos é de apenas 0,17 , nenhuma estatisticamente diferente de zero. Ressaltando somente, que para o cálculo dessas 
correlações foram usados os números da Tabela 10, por se tratar dos resultados não condicionais, da mesma forma que acontece com Almeida et al. (2012). 
Tabela 9 - Matriz de Efeito Contágio Condicional

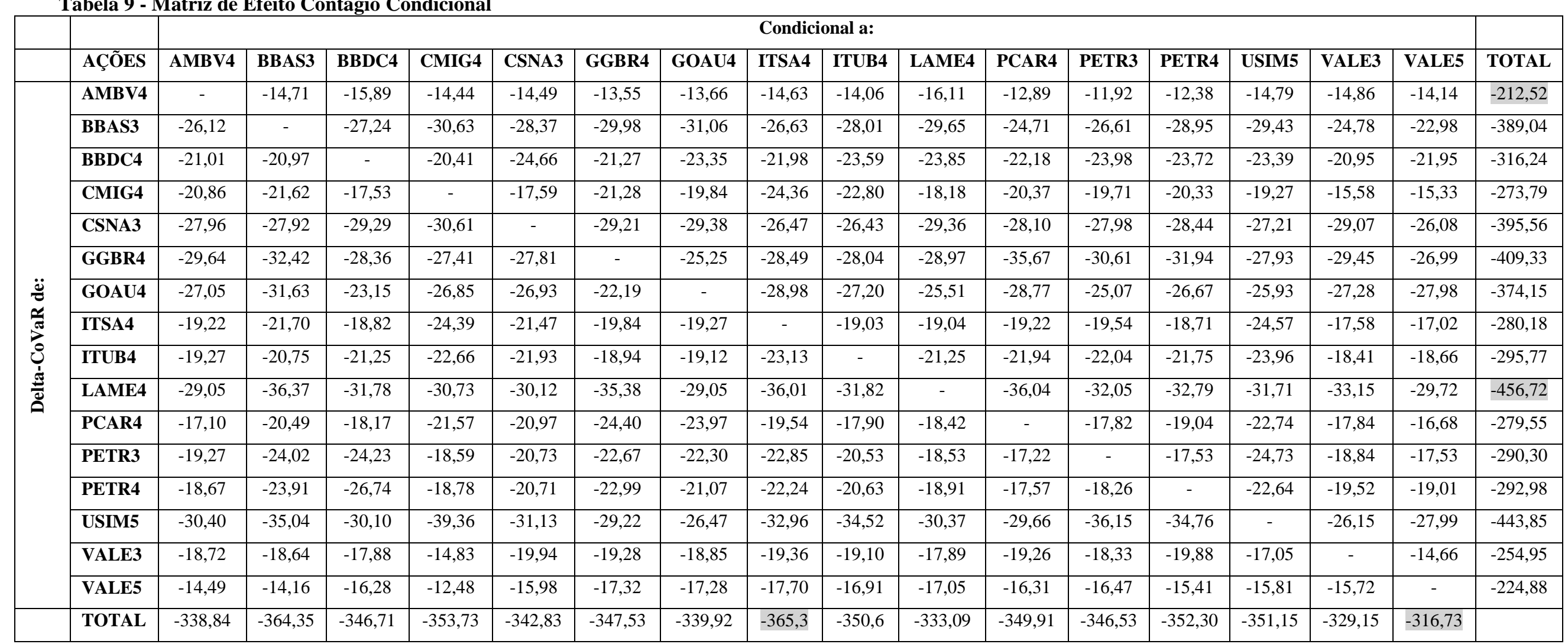


Tabela 10 - Matriz de Efeito Contágio Não Condicional

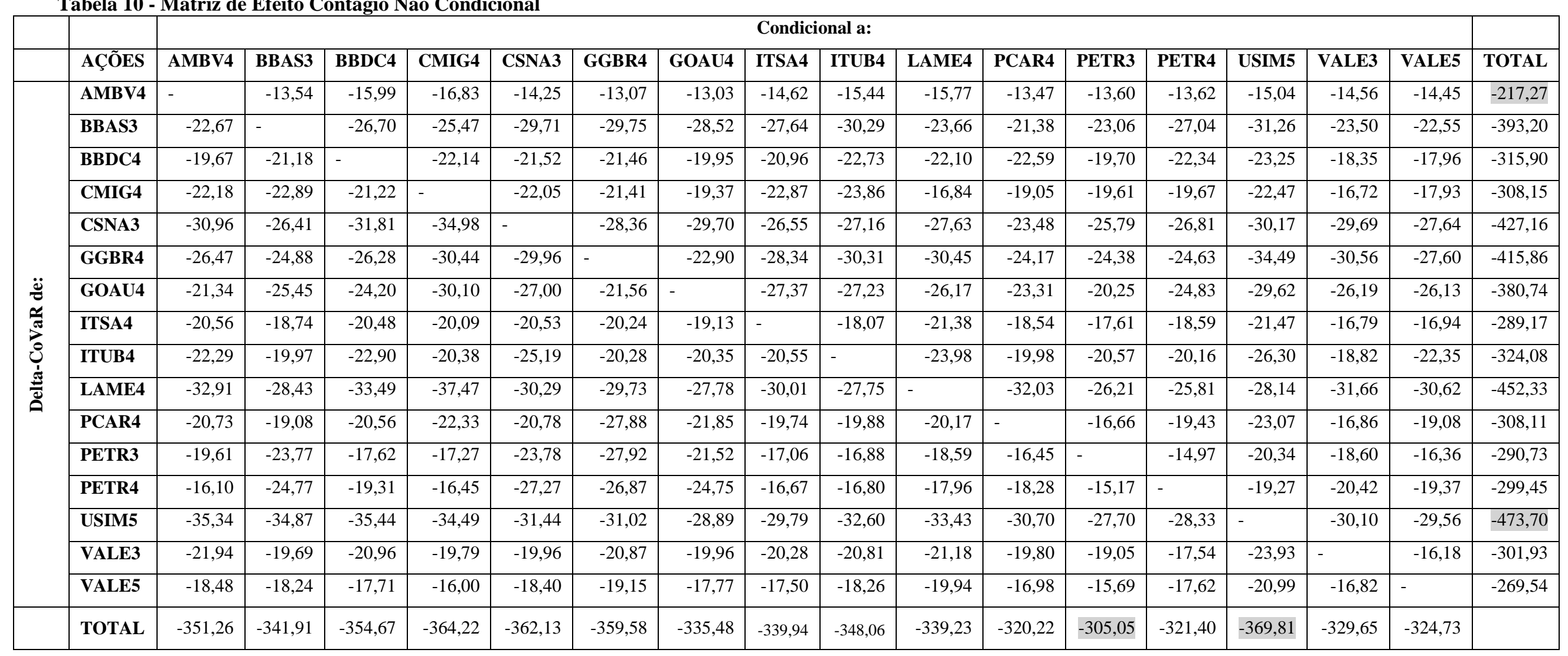




\section{CONCLUSÕES}

Diante dos resultados obtidos pelo estudo, conclui-se que o modelo de risco downside proposto por Ang et al. (2006) não é adequado para o Brasil durante o período estudado (janeiro de 1999 a julho de 2012). As carteiras formadas a partir do beta downside e do beta downside relativo não apresentaram os padrões esperados pelo modelo, uma vez que os portfólios de ações mais expostas a esse risco assimétrico obtiveram retornos inferiores àqueles dos portfólios menos expostos, ainda que não estatisticamente significantes. O beta upside mostrou-se um desconto, o que era esperado, mas apenas devido a sua alta correlação com o beta tradicional.

Rejeita-se o modelo CAPM devido às não linearidades no beta tradicional, sendo o termo quadrático estatisticamente significante. Com sua inclusão pode-se dizer que os retornos das ações são positivamente relacionados ao beta, mas de maneira decrescente. A partir de $\beta_{i, t}$ igual a 0,642 a relação entre o retorno das ações e o beta-CAPM torna-se negativa. De forma geral, as regressões à Fama-MacBeth confirmaram os padrões enunciados pelas carteiras: irrelevância do beta tradicional e das medidas assimétricas de risco. Sem significância estatística, observou-se que ações de firmas pequenas, ações com baixa liquidez e aquelas com alto B-M pagariam um prêmio de risco.

Com respeito às estimações do $\mathrm{CoVaR}$, conclui-se que as diferenças entre os resultados das metodologias condicional e não condicional são maiores no risco sistêmico (transmissão sentido ação para o mercado), com uma correlação de 0,41 entre as duas medidas. Por sua vez no stress test (transmissão sentido mercado para ações) a correlação entre as duas formas de se calcular o CoVaR é bastante alta e estatisticamente diferente de zero: 0,93. Comparando o resultado das medidas não condicionais obtidos por este estudo com Almeida et al. (2012) chega-se a uma correlação de 0,23 para o risco sistêmico e também para o teste de estresse. Acredita-se que essa baixa correlação se deva principalmente à distinta periodicidade da amostra daquele artigo (diária) e também ao período da amostra não ser 100\% coincidentes. 


\section{REFERÊNCIAS}

ACHARYA, Viral V.; PEDERSEN, Lasse Heje. Asset Pricing with Liquidity Risk. Journal of Financial Economics. v.77, n.2, p.375-410, August 2005.

ADRIAN, Tobias; BRUNNERMEIER, Markus K. CoVaR. NBER, Working Paper 17454, October 2011.

ALMEIDA, Aléssio Tony Cavalcanti de et al. Medidas de Risco e Matriz de Contágio: Uma Aplicação do CoVaR para o Mercado Financeiro Brasileiro. Revista Brasileira de Finanças. v.10, n.4, p.551-584, December 2012.

AMIHUD, Yakov. Illiquidity and Stock Returns: Cross-Section and Time-Series Effects. Journal of Financial Markets. v.5, n.1, p.31-56, January 2002.

ANG, Andrew et al. Downside Risk. The Review of Financial Studies. v.19, n.4, p.1191-1239, March 2006.

ARAÚJO, Gustavo Silva; LEÃO, Sérgio. Risco Sistêmico no Mercado Brasileiro Uma Abordagem pelo Método CoVaR. Trabalhos para Discussão - BCB. Working Paper 307, Julho 2013.

BANZ, Rolf W. The Relationship Between Return and Market Value of Common Stocks. Journal of Financial Economics. v.9, n.1, p.3-18, March 1981.

BAWA, Vijay S.; LINDENBERG, Eric B. Capital Market Equilibrium in a MeanLower Partial Moment Framework. Journal of Financial Economics. v.5, n.2, p.189200, November 1977.

BIANCONI, Marcelo; YOSHINO, Joe Akira. Firm Market Performance and Volatility in a National Real Estate Sector. International Review of Economics and Finance. v.22, n.1, p.230-252, April 2012a.

- Worldwide Commodities Sector Market-to-Book and Return on Equity Valuation. SSRN. Acesso em http://papers.ssrn.com/sol3/papers.cfm?abstract_id=2166006.

BLACK, Fischer. Capital Market Equilibrium with Restricted Borrowing. The Journal of Business. v.45, n.3, p.444-455, July 1972.

CHERNOZHUKOV, Victor; UMANTSEV, Len. Conditional Value-at-Risk: Aspects of Modelling and Estimation. Empirical Economics. v.26, n.1, p.271-292, SpringerVerlag 2001. 
ESTRADA, Javier. Systematic Risk in Emerging Markets: the D-CAPM. Emerging Markets Review. v.3, n.4, p.365-379, December 2002.

EUROPEAN CENTRAL BANK - ECB. Annual Report 2004. February 2005.

FAMA, Eugene F.; FRENCH, Kenneth R. The Cross-Section of Expected Stock Returns. The Journal of Finance. v.47, n.2, p.427-465, June 1992.

Common Risk Factors in Stock and Bond Returns. Journal of Financial Economics. v.33, n.1, p.3-56, February 1993.

FAMA, Eugene F.; MACBETH, James D. Risk, Return and Equilibrium: Empirical Tests. Journal of Political Economy. v.81, n.3, p.607-636, May 1973.

FORTUNATO, Graziela Xavier et al. Custo de Capital Próprio em Mercados Emergentes: Uma Abordagem Empírica no Brasil com o Downside Risk. Revista de Administração Mackenzie. v.11, n.1, p. 92-116, Janeiro 2010.

GARCIA, René; BONOMO, Marco. Tests of Conditional Asset Pricing Models in the Brazilian Stock Market. Journal of International Money and Finance. v. 20, n.1, p.71-90, February 2001.

GIOVANNETTI, Bruno Cara. Essays on Asset Pricing and Downside Risk. Nova Iorque, 2011. PhD Thesis (Doctor of Philosophy) - Graduate School of Arts and Sciences, Columbia University.

HANSEN, Lars Peter. Challenges in Identifying and Measuring Systemic Risk. NBER, Working Paper 18505, November 2012.

IMPROTA, João Paulo de B. Momentum and Reversal Effects in Brazil. São Paulo, 2012. Dissertação de Mestrado - Instituto de Pesquisas Econômicas, Universidade de São Paulo.

KOENKER, Roger. Quantile Regression. 1.ed.Nova Iorque: Cambridge University Press, 2005.

KOENKER, Roger; BASSET, Gilbert. Regression Quantiles. Econometrica. v.46, n.1, p.33-50, January 1978.

KYLE, Albert S. Continuous Auction and Insider Trading. Econometrica. v.53, n.6, p.1315-1335, November 1985. 
LINTNER, John. The Valuation of Risk Assets and the Selection of Risky Investments in Stock Portfolios and Capital Budgets. The Review of Economics and Statistics. v.47, n.1, p.13-37, February 1965.

MACHADO, Márcio André Veras; MEDEIROS, Otávio Ribeiro de. Modelos de Precificação de Ativos e o Efeito Liquidez: Evidências Empíricas no Mercado Acionário Brasileiro. Revista Brasileira de Finanças. v.9, n.3, p. 383-412, Setembro 2011.

MARKOWITZ, Harry. Portfolio Selection. The Journal of Finance. v.7, n.1, p.77-91, March 1952.

MEHRA, Rajnish; PRESCOTT, Edward C. The Equity Premium: A Puzzle. Journal of Monetary Economics. v.15, n.2, p.145-161, March 1985.

ROSTAGNO, Luciano Martin et al. Previsibilidade de Retorno das Ações na Bovespa: Um Teste Envolvendo o Modelo de Fator de Retorno Esperado. Revista Brasileira de Finanças. v.2, n.2, p. 183-206, Abril 2005.

ROUTLEDGE, Bryan R.; ZIN, Stanley E. Generalized Disapointment Aversion and Asset Prices. The Journal of Finance. v.65, n.4, p.1303-1332, August 2010.

SHARPE, William F. Capital Asset Prices:A Theory of Market Equilibrium under Conditions of Risk. The Journal of Finance. v.19, n.3, p.425-445, September 1964.

SARR, Abdourahmane; LYBEK, Tonny. Measuring Liquidity in Financial Markets. IMF, Working Paper 02/232, December 2002. 


\section{APÊNDICES}

Na Tabela 11 são apresentados os resultados do teste DF-GLS para raiz unitária das séries utilizadas nos modelos $\mathrm{CoVaR}$. A última coluna conclui que não há raiz unitária em nenhuma delas.

Tabela 11 - Testes de Raiz Unitária para as Variáveis Macroeconômicas Defasadas

\begin{tabular}{|c|c|c|c|c|c|c|}
\hline Variável & $\begin{array}{l}\text { Lag } \\
\text { (SC) }\end{array}$ & $\begin{array}{c}\text { DF-GLS } \\
\text { tau }\end{array}$ & $\begin{array}{c}\text { Valor } \\
\text { Crítico } 1 \%\end{array}$ & $\begin{array}{c}\text { Valor } \\
\text { Crítico } 5 \%\end{array}$ & $\begin{array}{c}\text { Valor } \\
\text { Crítico } 10 \%\end{array}$ & Conclusão \\
\hline$v_{i x}$ & 1 & $-3,62$ & $-3,51$ & $-2,96$ & $-2,67$ & Não há RU \\
\hline$r_{-}$estate ${ }_{t-1}$ & 2 & $-4,84$ & $-3,51$ & $-2,95$ & $-2,66$ & Não há RU ${ }^{* * * *}$ \\
\hline$r_{m, t-1}^{e}$ & 1 & $-7,21$ & $-3,51$ & $-2,96$ & $-2,67$ & Não há RU ${ }^{* * *}$ \\
\hline$U S \$_{t-1}$ & 1 & $-6,60$ & $-3,51$ & $-2,96$ & $-2,67$ & Não há RU ${ }^{* * * *}$ \\
\hline$r_{S \& P, t-1}^{e}$ & 1 & $-8,38$ & $-3,51$ & $-2,96$ & $-2,67$ & Não há RU ${ }^{* * * *}$ \\
\hline$d_{-} m o n e y \_s p d_{t-1}$ & 3 & $-2,98$ & $-3,51$ & $-2,94$ & $-2,65$ & Não há RU** \\
\hline$d_{-}$credit_spd $d_{t-1}$ & 1 & $-7,09$ & $-3,51$ & $-2,96$ & $-2,67$ & Não há RU ${ }^{* * * *}$ \\
\hline$d \_y i e l d \_s p d_{t-1}$ & 1 & $-7,64$ & $-3,51$ & $-2,96$ & $-2,67$ & Não há RU ${ }^{* * *}$ \\
\hline$d_{-}$tbills $s_{t-1}$ & 2 & $-3,95$ & $-3,51$ & $-2,95$ & $-2,66$ & Não há RU ${ }^{* * *}$ \\
\hline$d \% \_c o n t a \_k_{t-1}$ & 1 & $-8,17$ & $-3,51$ & $-2,96$ & $-2,67$ & Não há RU ${ }^{* * * *}$ \\
\hline
\end{tabular}

Não há Raiz Unitária (RU) a um nível de significância de $1 \%$. ${ }^{* * *}$ Não há RU a um nível de significância de 5\%. *Não há RU a um nível de significância de $10 \%$.

A Tabela 12 é a contrapartida da Tabela 2, mas com os retornos contemporâneos às medidas de risco, como em Ang et al. (2006). Já mencionado no corpo do texto que essa alteração não contribui para o sucesso do modelo de risco downside, além de inviabilizar uma possível aplicação dos resultados do modelo ao dia-a-dia do mercado.

Nas tabelas seguintes são apresentados os resultados referentes às rentabilidades obtidas pelas carteiras formadas a partir das medidas de riscos, para diferentes níveis de liquidez (com a medida de liquidez DM). 
Tabela 12 - Portfólios com Retornos em 60 Meses Anualizados

PAINEL A: Portfólios formados pelo $\beta_{i, t}$

\begin{tabular}{|c|c|c|c|c|c|c|c|c|c|c|c|}
\hline Portfólios & $\begin{array}{l}\text { 1: } \beta_{p, t} \\
\text { baixo }\end{array}$ & 2 & 3 & 4 & 5 & 6 & 7 & 8 & 9 & $\begin{array}{l}10: \beta_{p, t} \\
\text { alto }\end{array}$ & $\begin{array}{l}\text { Alto menos } \\
\text { baixo (Estat. t) }\end{array}$ \\
\hline$r_{p, t}^{e}$ & 5,93 & 4,83 & 4,82 & 6,23 & 5,13 & 5,46 & 5,35 & 4,84 & 2,83 & 0,75 & $-5,18(-4,37)$ \\
\hline $\boldsymbol{\beta}_{p, t}$ & $-0,12$ & 0,17 & 0,32 & 0,44 & 0,57 & 0,69 & 0,83 & 0,97 & 1,16 & 1,53 & 1,66 \\
\hline $\boldsymbol{\beta}_{i, t}^{+}$ & $-0,17$ & 0,15 & 0,29 & 0,39 & 0,52 & 0,64 & 0,75 & 0,92 & 1,07 & 1,40 & 1,57 \\
\hline$\beta_{p, t}^{-}$ & $-0,10$ & 0,18 & 0,34 & 0,47 & 0,59 & 0,72 & 0,87 & 1,00 & 1,21 & 1,61 & 1,71 \\
\hline $\boldsymbol{\beta}_{i, t}^{-}-\beta_{i, t}$ & 0,03 & 0,01 & 0,02 & 0,03 & 0,02 & 0,03 & 0,04 & 0,03 & 0,05 & 0,08 & 0,06 \\
\hline \multicolumn{12}{|c|}{ PAINEL B: Portfólios formados pelo $\beta_{i, t}^{-}$} \\
\hline Portfólios & $\begin{array}{l}\text { 1: } \beta_{p, t} \\
\text { baixo }\end{array}$ & 2 & 3 & 4 & 5 & 6 & 7 & 8 & 9 & $\begin{array}{l}10: \beta_{p, t} \\
\text { alto }\end{array}$ & $\begin{array}{l}\text { Alto menos } \\
\text { baixo (Estat. t) }\end{array}$ \\
\hline$r_{p, t}^{e}$ & 4,15 & 4,72 & 5,25 & 6,81 & 7,19 & 6,42 & 4,75 & 3,81 & 2,39 & 0,68 & $-3,48(-7,36)$ \\
\hline$\beta_{p, t}$ & $-0,08$ & 0,19 & 0,34 & 0,45 & 0,57 & 0,69 & 0,82 & 0,96 & 1,14 & 1,48 & 1,55 \\
\hline $\boldsymbol{\beta}_{i, t}^{+}$ & 0,02 & 0,23 & 0,36 & 0,43 & 0,54 & 0,63 & 0,74 & 0,85 & 0,99 & 1,17 & 1,15 \\
\hline $\boldsymbol{\beta}_{p, t}^{-}$ & $-0,14$ & 0,16 & 0,31 & 0,45 & 0,59 & 0,72 & 0,86 & 1,03 & 1,24 & 1,68 & 1,82 \\
\hline $\boldsymbol{\beta}_{i, t}^{-}-\boldsymbol{\beta}_{i, t}$ & $-0,07$ & $-0,03$ & $-0,02$ & 0,00 & 0,02 & 0,03 & 0,05 & 0,07 & 0,09 & 0,20 & 0,27 \\
\hline \multicolumn{12}{|c|}{ PAINEL C: Portfólios formados pelo $\beta_{i, t}^{+}$} \\
\hline Portfólios & $\begin{array}{l}\text { 1: } \beta_{p, t} \\
\text { baixo }\end{array}$ & 2 & 3 & 4 & 5 & 6 & & 8 & 9 & $\begin{array}{l}10: \beta_{p, t} \\
\text { alto }\end{array}$ & $\begin{array}{l}\text { Alto menos } \\
\text { baixo (Estat. t) }\end{array}$ \\
\hline$r_{p, t}^{e}$ & 6,99 & 4,23 & 4,94 & 4,70 & 5,18 & 5,65 & 4,93 & 3,90 & 3,78 & 1,84 & $-5,15(-3,88)$ \\
\hline $\boldsymbol{\beta}_{p, t}$ & $-0,01$ & 0,22 & 0,34 & 0,45 & 0,58 & 0,69 &, 80 & 0,94 & 1,12 & 1,42 & 1,43 \\
\hline$\beta_{i, t}^{+}$ & $-0,27$ & 0,09 & 0,25 & 0,38 & 0,50 & 0,63 & $\overline{, 78}$ & 0,94 & 1,15 & 1,52 & 1,80 \\
\hline $\boldsymbol{\beta}_{p, t}^{-}$ & 0,18 & 0,31 & 0,40 & 0,49 & 0,63 & 0,72 & 0,80 & 0,94 & 1,09 & 1,35 & 1,17 \\
\hline $\boldsymbol{\beta}_{i, t}^{-}-\boldsymbol{\beta}_{i, t}$ & 0,18 & 0,09 & 0,06 & 0,04 & 0,05 & 0,03 &, 00 & $-0,01$ & $-0,03$ & $-0,07$ & $-0,25$ \\
\hline \multicolumn{12}{|c|}{ PAINEL D: Portfólios formados pelo $\beta_{i, t}^{-}-\beta_{i, t}$} \\
\hline Portfólios & $\begin{array}{l}\text { 1: } \beta_{p, t} \\
\text { baixo }\end{array}$ & 2 & 3 & 4 & 5 & 6 & 7 & 8 & 9 & $\begin{array}{l}10: \beta_{p, t} \\
\text { alto }\end{array}$ & $\begin{array}{l}\text { Alto menos } \\
\text { baixo (Estat. t) }\end{array}$ \\
\hline$r_{p, t}^{e}$ & 3,58 & 5,28 & 6,29 & 7,17 & 6,49 & 4,79 & 3,55 & 3,67 & 3,42 & 1,91 & $-1,67(-1,03)$ \\
\hline $\boldsymbol{\beta}_{p, t}$ & 0,65 & 0,56 & 0,58 & 0,63 & 0,63 & 0,62 & 0,64 & 0,66 & 0,74 & 0,83 & 0,17 \\
\hline $\boldsymbol{\beta}_{i, t}^{+}$ & 1,02 & 0,74 & 0,68 & 0,67 & 0,62 & 0,55 & 0,52 & 0,47 & 0,45 & 0,27 & $-0,75$ \\
\hline$\beta_{p, t}^{-}$ & 0,39 & 0,44 & 0,52 & 0,61 & 0,64 & 0,66 & 0,72 & 0,78 & 0,93 & 1,21 & 0,82 \\
\hline $\boldsymbol{\beta}_{i, t}^{-}-\beta_{i, t}$ & $-0,26$ & $-0,12$ & $-0,07$ & $-0,03$ & 0,01 & 0,04 & 0,08 & 0,12 & 0,19 & 0,38 & 0,64 \\
\hline
\end{tabular}


Tabela 13 - Portfólios Formados pelo Beta Downside com Retornos Mês à Frente Anualizados, em Diferentes Cortes de Liquidez

\begin{tabular}{|c|c|c|c|c|c|c|c|c|c|c|c|}
\hline \multicolumn{12}{|c|}{ PAINEL A: Média do Excesso de Retorno } \\
\hline Portfólios & $\begin{array}{l}\text { 1: } \beta_{p, t} \\
\text { baixo }\end{array}$ & 2 & 3 & 4 & 5 & 6 & 7 & 8 & 9 & $\begin{array}{l}10: \beta_{p, t} \\
\text { alto }\end{array}$ & $\begin{array}{l}\text { Alto menos } \\
\text { baixo (Estat. t) }\end{array}$ \\
\hline 10\%+Líq. & $-1,01$ & $-6,23$ & $-1,61$ & 3,95 & 1,20 & 1,02 & 2,39 & $-0,36$ & $-11,16$ & $-10,17$ & $-9,16(-0,86)$ \\
\hline $25 \%+L i ́ q$. & 4,21 & $-2,54$ & 3,37 & 1,93 & 6,61 & 2,88 & 3,44 & 0,22 & $-0,66$ & $-14,37$ & $-18,57(-2,22)$ \\
\hline 40\%+Líq. & 3,99 & 7,93 & 5,87 & 2,65 & 1,55 & 7,78 & 1,90 & $-2,42$ & 2,55 & $-10,98$ & $-14,97(-2,02)$ \\
\hline $\mathbf{5 0} \%+$ Líq. & 0,68 & 8,07 & 10,45 & 2,54 & 4,69 & 0,37 & 4,66 & $-3,46$ & 2,23 & $-10,70$ & $-11,38(-1,58)$ \\
\hline 60\% + Líq. & 2,01 & 1,68 & 8,55 & 8,44 & 0,76 & 1,96 & 3,33 & $-1,42$ & 2,18 & $-6,69$ & $-8,70(-1,18)$ \\
\hline 75\% + Líq. & 1,72 & 1,49 & 6,84 & 8,05 & 3,24 & 2,50 & 3,46 & 1,18 & $-2,73$ & $-0,97$ & $-2,69(-0,38)$ \\
\hline 90\%+Líq. & 10,32 & 3,79 & 2,18 & 9,03 & 8,29 & 2,57 & 2,93 & 1,85 & $-1,61$ & $-1,38$ & $-11,70(-1,55)$ \\
\hline Todas & 2,96 & 2,50 & $-2,48$ & 3,78 & 7,07 & 1,86 & 2,29 & 0,08 & $-3,03$ & $-0,28$ & $-3,23(-0,45)$ \\
\hline \multicolumn{12}{|c|}{ PAINEL B: Média dos Betas $\left(\beta_{p, t}\right)$} \\
\hline Portfólios & $\begin{array}{l}\text { 1: } \beta_{p, t} \\
\text { baixo }\end{array}$ & 2 & 3 & 4 & 5 & 6 & 7 & 8 & 9 & $\begin{array}{l}10: \beta_{p, t} \\
\text { alto }\end{array}$ & $\begin{array}{l}\text { Alto menos } \\
\text { baixo }\end{array}$ \\
\hline 10\% + Líq. & 0,36 & 0,55 & 0,66 & 0,79 & 0,94 & 1,08 & 1,18 & 1,29 & 1,39 & 1,71 & 1,36 \\
\hline $25 \%+$ Líq. & 0,30 & 0,48 & 0,61 & 0,74 & 0,86 & 0,95 & 1,07 & 1,21 & 1,35 & 1,65 & 1,35 \\
\hline 40\%+Líq. & 0,23 & 0,43 & 0,57 & 0,69 & 0,80 & 0,91 & 1,01 & 1,17 & 1,32 & 1,61 & 1,39 \\
\hline $\mathbf{5 0} \%+$ Líq. & 0,18 & 0,41 & 0,54 & 0,65 & 0,76 & 0,87 & 0,97 & 1,12 & 1,28 & 1,59 & 1,40 \\
\hline 60\% + Líq. & 0,13 & 0,37 & 0,50 & 0,62 & 0,72 & 0,83 & 0,94 & 1,08 & 1,25 & 1,56 & 1,43 \\
\hline 75\% + Líq. & 0,04 & 0,30 & 0,43 & 0,56 & 0,66 & 0,77 & 0,89 & 1,03 & 1,21 & 1,53 & 1,48 \\
\hline 90\% + Líq. & $-0,04$ & 0,23 & 0,37 & 0,49 & 0,61 & 0,72 & 0,85 & 0,99 & 1,17 & 1,50 & 1,53 \\
\hline Todas & $-0,08$ & 0,19 & 0,34 & 0,45 & 0,57 & 0,69 & 0,82 & 0,96 & 1,14 & 1,47 & 1,55 \\
\hline \multicolumn{12}{|c|}{ PAINEL C: Médias dos Betas Downside $\left(\beta_{i, t}^{-}\right)$} \\
\hline Portfólios & $\begin{array}{l}\text { 1: } \beta_{p, t} \\
\text { baixo }\end{array}$ & 2 & 3 & 4 & 5 & 6 & 7 & 8 & 9 & $\begin{array}{l}10: \beta_{p, t} \\
\text { alto }\end{array}$ & $\begin{array}{l}\text { Alto menos } \\
\text { baixo }\end{array}$ \\
\hline 10\% + Líq. & 0,29 & 0,48 & 0,63 & 0,77 & 0,92 & 1,06 & 1,16 & 1,29 & 1,43 & 1,84 & 1,55 \\
\hline $25 \%+L i ́ q$. & 0,23 & 0,45 & 0,59 & 0,73 & 0,85 & 0,97 & 1,09 & 1,23 & 1,38 & 1,82 & 1,59 \\
\hline 40\% + Líq. & 0,17 & 0,41 & 0,55 & 0,68 & 0,81 & 0,93 & 1,06 & 1,20 & 1,37 & 1,80 & 1,63 \\
\hline $50 \%+$ Líq. & 0,13 & 0,38 & 0,52 & 0,65 & 0,77 & 0,89 & 1,02 & 1,17 & 1,35 & 1,77 & 1,64 \\
\hline 60\% + Líq. & 0,08 & 0,34 & 0,49 & 0,62 & 0,74 & 0,86 & 0,99 & 1,14 & 1,33 & 1,75 & 1,67 \\
\hline 75\% + Líq. & $-0,01$ & 0,27 & 0,42 & 0,56 & 0,68 & 0,80 & 0,94 & 1,09 & 1,29 & 1,73 & 1,73 \\
\hline 90\% + Líq. & $-0,10$ & 0,21 & 0,36 & 0,50 & 0,63 & 0,76 & 0,90 & 1,06 & 1,26 & 1,70 & 1,81 \\
\hline Todas & $-0,15$ & 0,16 & 0,31 & 0,45 & 0,58 & 0,72 & 0,86 & 1,03 & 1,23 & 1,68 & 1,82 \\
\hline
\end{tabular}


cont. Tabela 13 - Portfólios Formados pelo Beta Downside com Retornos Mês à Frente Anualizados, em Diferentes Cortes de Liquidez

PAINEL D: Médias dos Betas Upside $\left(\beta_{i, t}^{+}\right)$

\begin{tabular}{|c|c|c|c|c|c|c|c|c|c|c|c|}
\hline \multicolumn{12}{|c|}{ PAINEL D: Médias dos Betas Upside $\left(\beta_{i, t}^{+}\right)$} \\
\hline Portfólios & $\begin{array}{l}\text { 1: } \beta_{p, t} \\
\text { baixo }\end{array}$ & 2 & 3 & 4 & 5 & 6 & 7 & 8 & 9 & $\begin{array}{l}10: \beta_{p, t} \\
\text { alto }\end{array}$ & $\begin{array}{l}\text { Alto menos } \\
\text { baixo }\end{array}$ \\
\hline 10\% + Líq. & 0,45 & 0,65 & 0,70 & 0,82 & 0,96 & 1,12 & 1,21 & 1,28 & 1,33 & 1,55 & 1,10 \\
\hline $25 \%+$ Líq. & 0,38 & 0,53 & 0,63 & 0,75 & 0,86 & 0,92 & 1,04 & 1,18 & 1,30 & 1,41 & 1,02 \\
\hline 40\% + Líq. & 0,30 & 0,47 & 0,60 & 0,70 & 0,79 & 0,87 & 0,94 & 1,11 & 1,23 & 1,33 & 1,03 \\
\hline $\mathbf{5 0} \%+$ Líq. & 0,26 & 0,44 & 0,56 & 0,65 & 0,74 & 0,84 & 0,89 & 1,04 & 1,18 & 1,31 & 1,05 \\
\hline 60\%+Líq. & 0,20 & 0,41 & 0,50 & 0,61 & 0,69 & 0,78 & 0,86 & 0,99 & 1,14 & 1,28 & 1,08 \\
\hline 75\% + Líq. & 0,11 & 0,33 & 0,43 & 0,55 & 0,63 & 0,71 & 0,80 & 0,93 & 1,08 & 1,23 & 1,11 \\
\hline 90\% + Líq. & 0,05 & 0,27 & 0,38 & 0,48 & 0,57 & 0,66 & 0,77 & 0,88 & 1,03 & 1,19 & 1,13 \\
\hline Todas & 0,02 & 0,23 & 0,36 & 0,43 & 0,54 & 0,63 & 0,74 & 0,85 & 0,99 & 1,17 & 1,15 \\
\hline \multicolumn{12}{|c|}{ PAINEL E: Médias dos Betas Downside Relativos $\left(\beta_{i, t}^{-}-\beta_{i, t}\right)$} \\
\hline Portfólios & $\begin{array}{l}\text { 1: } \beta_{p, t} \\
\text { baixo }\end{array}$ & 2 & 3 & 4 & 5 & 6 & 7 & 8 & 9 & $\begin{array}{l}10: \beta_{p, t} \\
\text { alto }\end{array}$ & $\begin{array}{l}\text { Alto menos } \\
\text { baixo }\end{array}$ \\
\hline 10\% + Líq. & $-0,07$ & $-0,07$ & $-0,03$ & $-0,02$ & $-0,02$ & $-0,03$ & $-0,02$ & 0,00 & 0,04 & 0,12 & 0,19 \\
\hline $\mathbf{2 5} \%+$ Líq. & $-0,06$ & $-0,03$ & $-0,01$ & $-0,01$ & $-0,01$ & 0,02 & 0,02 & 0,02 & 0,04 & 0,17 & 0,23 \\
\hline $\mathbf{4 0} \%+$ Líq. & $-0,05$ & $-0,03$ & $-0,02$ & $-0,01$ & 0,00 & 0,02 & 0,05 & 0,03 & 0,05 & 0,19 & 0,24 \\
\hline $\mathbf{5 0} \%+$ Líq. & $-0,05$ & $-0,03$ & $-0,02$ & 0,00 & 0,01 & 0,02 & 0,05 & 0,05 & 0,07 & 0,19 & 0,24 \\
\hline 60\% + Líq. & $-0,05$ & $-0,03$ & $-0,01$ & 0,00 & 0,02 & 0,03 & 0,05 & 0,06 & 0,07 & 0,19 & 0,24 \\
\hline 75\% + Líq. & $-0,05$ & $-0,03$ & 0,00 & 0,00 & 0,02 & 0,03 & 0,05 & 0,06 & 0,08 & 0,20 & 0,25 \\
\hline 90\% + Líq. & $-0,07$ & $-0,03$ & $-0,01$ & 0,00 & 0,02 & 0,04 & 0,05 & 0,07 & 0,09 & 0,21 & 0,27 \\
\hline Todas & $-0,07$ & $-0,03$ & $-0,02$ & 0,00 & 0,02 & 0,03 & 0,05 & 0,07 & 0,09 & 0,20 & 0,27 \\
\hline
\end{tabular}


Tabela 14 - Portfólios Formados pelo Beta Upside, com Retornos Mês à Frente Anualizados, em Diferentes Cortes de Liquidez

\begin{tabular}{|c|c|c|c|c|c|c|c|c|c|c|c|}
\hline \multicolumn{12}{|c|}{ PAINEL A: Média do Excesso de Retorno } \\
\hline Portfólios & $\begin{array}{l}\text { 1: } \beta_{p, t} \\
\text { baixo }\end{array}$ & 2 & 3 & 4 & 5 & 6 & 7 & 8 & 9 & $\begin{array}{l}\text { 10: } \beta_{p, t} \\
\text { alto }\end{array}$ & $\begin{array}{l}\text { Alto menos } \\
\text { baixo (Estat. t) }\end{array}$ \\
\hline 10\% + Líq. & $-8,06$ & $-0,37$ & 1,57 & $\begin{array}{c}- \\
11,20\end{array}$ & 7,79 & $-1,67$ & 1,61 & 3,88 & $-1,79$ & $-13,17$ & $-5,12(-0,58)$ \\
\hline $25 \%+$ Líq. & $-0,77$ & 0,97 & 5,85 & 8,12 & 1,54 & 1,38 & 3,24 & $-0,32$ & $-3,84$ & $-11,35$ & $-10,58(-1,30)$ \\
\hline 40\%+ Líq. & 5,22 & 5,64 & 0,72 & 7,46 & 4,42 & 0,11 & 3,30 & 6,27 & $-0,55$ & $-12,01$ & $-17,22(-2,24)$ \\
\hline $\mathbf{5 0} \%+$ Líq. & 0,88 & 7,65 & 4,54 & 5,49 & 5,12 & 2,93 & 0,95 & 4,77 & $-1,22$ & $-11,27$ & $-12,15(-1,57)$ \\
\hline 60\% + Líq. & $-1,50$ & 8,96 & 3,02 & 2,59 & 4,37 & 4,79 & 1,91 & 6,46 & $-0,86$ & $-9,07$ & $-7,57(-1,04)$ \\
\hline 75\% + Líq. & 0,90 & 2,41 & 6,43 & 1,94 & 5,51 & 3,68 & 3,21 & 4,73 & 2,02 & $-6,01$ & $-6,91(-1,06)$ \\
\hline 90\%+Líq. & 9,25 & 1,71 & 7,70 & 4,42 & 2,89 & 5,53 & 4,60 & 3,79 & 2,40 & $-4,16$ & $-13,41(-1,99)$ \\
\hline Todas & 2,82 & $-2,50$ & 2,68 & 2,59 & $-0,78$ & 6,10 & 4,36 & 1,67 & 3,07 & $-5,15$ & $-7,97(-0,74)$ \\
\hline \multicolumn{12}{|c|}{ PAINEL B: Média dos Betas $\left(\beta_{p, t}\right)$} \\
\hline Portfólios & $\begin{array}{l}\text { 1: } \beta_{p, t} \\
\text { baixo }\end{array}$ & 2 & 3 & 4 & 5 & 6 & 7 & 8 & 9 & $\begin{array}{l}10: \beta_{p, t} \\
\text { alto }\end{array}$ & $\begin{array}{l}\text { Alto menos } \\
\text { baixo }\end{array}$ \\
\hline 10\% + Líq. & 0,40 & 0,55 & 0,65 & 0,79 & 0,95 & 1,11 & 1,19 & 1,27 & 1,39 & 1,65 & 1,25 \\
\hline 25\% + Líq. & 0,32 & 0,52 & 0,63 & 0,73 & 0,85 & 0,99 & 1,09 & 1,18 & 1,33 & 1,59 & 1,27 \\
\hline 40\% + Líq. & 0,25 & 0,47 & 0,60 & 0,71 & 0,78 & 0,92 & 1,03 & 1,14 & 1,30 & 1,55 & 1,30 \\
\hline $\mathbf{5 0} \%+$ Líq. & 0,22 & 0,44 & 0,56 & 0,68 & 0,75 & 0,86 & 0,98 & 1,10 & 1,26 & 1,53 & 1,31 \\
\hline 60\% + Líq. & 0,18 & 0,39 & 0,52 & 0,63 & 0,72 & 0,81 & 0,94 & 1,07 & 1,22 & 1,52 & 1,33 \\
\hline 75\% + Líq. & 0,19 & 0,38 & 0,49 & 0,59 & 0,70 & 0,78 & 0,88 & 1,01 & 1,17 & 1,39 & 1,20 \\
\hline 90\% + Líq. & 0,04 & 0,25 & 0,38 & 0,50 & 0,62 & 0,71 & 0,83 & 0,98 & 1,15 & 1,45 & 1,41 \\
\hline Todas & $-0,01$ & 0,22 & 0,34 & 0,45 & 0,58 & 0,69 & 0,79 & 0,94 & 1,12 & 1,42 & 1,43 \\
\hline \multicolumn{12}{|c|}{ PAINEL C: Médias dos Betas Downside $\left(\beta_{i, t}^{-}\right)$} \\
\hline Portfólios & $\begin{array}{l}\text { 1: } \beta_{p, t} \\
\text { baixo }\end{array}$ & 2 & 3 & 4 & 5 & 6 & 7 & 8 & 9 & $\begin{array}{l}10: \beta_{p, t} \\
\text { alto }\end{array}$ & $\begin{array}{l}\text { Alto menos } \\
\text { baixo }\end{array}$ \\
\hline 10\% + Líq. & 0,45 & 0,54 & 0,62 & 0,78 & 0,94 & 1,09 & 1,18 & 1,25 & 1,38 & 1,65 & 1,20 \\
\hline $25 \%+$ Líq. & 0,39 & 0,57 & 0,66 & 0,73 & 0,87 & 1,01 & 1,10 & 1,16 & 1,31 & 1,57 & 1,19 \\
\hline 40\% + Líq. & 0,35 & 0,52 & 0,65 & 0,75 & 0,78 & 0,93 & 1,04 & 1,14 & 1,29 & 1,53 & 1,18 \\
\hline $\mathbf{5 0} \%+$ Líq. & 0,34 & 0,50 & 0,63 & 0,73 & 0,78 & 0,87 & 0,98 & 1,10 & 1,25 & 1,49 & 1,16 \\
\hline 60\% + Líq. & 0,32 & 0,46 & 0,59 & 0,69 & 0,76 & 0,82 & 0,94 & 1,07 & 1,21 & 1,48 & 1,15 \\
\hline 75\% + Líq. & 0,27 & 0,39 & 0,51 & 0,63 & 0,72 & 0,77 & 0,89 & 1,01 & 1,17 & 1,43 & 1,16 \\
\hline 90\%+Líq. & 0,22 & 0,34 & 0,45 & 0,55 & 0,66 & 0,74 & 0,83 & 0,97 & 1,13 & 1,39 & 1,17 \\
\hline Todas & 0,17 & 0,31 & 0,40 & 0,49 & 0,63 & 0,72 & 0,80 & 0,93 & 1,09 & 1,35 & 1,17 \\
\hline
\end{tabular}


cont. Tabela 14 - Portfólios Formados pelo Beta Upside, com Retornos Mês à Frente Anualizados, em Diferentes Cortes de Liquidez

PAINEL D: Médias dos Betas Upside $\left(\beta_{i, t}^{+}\right)$

\begin{tabular}{|c|c|c|c|c|c|c|c|c|c|c|c|}
\hline \multicolumn{12}{|c|}{ PAINEL D: Médias dos Betas Upside $\left(\beta_{i, t}^{+}\right)$} \\
\hline Portfólios & $\begin{array}{l}\text { 1: } \beta_{p, t} \\
\text { baixo }\end{array}$ & 2 & 3 & 4 & 5 & 6 & 7 & 8 & 9 & $\begin{array}{l}10: \beta_{p, t} \\
\text { alto }\end{array}$ & $\begin{array}{l}\text { Alto menos } \\
\text { baixo }\end{array}$ \\
\hline $10 \%+$ Líq. & 0,32 & 0,56 & 0,70 & 0,82 & 0,98 & 1,13 & 1,21 & 1,30 & 1,41 & 1,65 & 1,33 \\
\hline $25 \%+L i ́ q$. & 0,22 & 0,44 & 0,58 & 0,71 & 0,83 & 0,95 & 1,07 & 1,20 & 1,35 & 1,63 & 1,41 \\
\hline 40\% + Líq. & 0,12 & 0,38 & 0,51 & 0,64 & 0,76 & 0,89 & 1,01 & 1,14 & 1,30 & 1,59 & 1,47 \\
\hline $\mathbf{5 0} \%+$ Líq. & 0,05 & 0,34 & 0,46 & 0,59 & 0,71 & 0,84 & $\overline{0,96}$ & 1,10 & 1,27 & 1,58 & 1,54 \\
\hline 60\% + Líq. & $-0,03$ & 0,28 & 0,42 & 0,54 & 0,66 & 0,79 & 0,92 & 1,07 & 1,24 & 1,57 & 1,60 \\
\hline 75\% + Líq. & $-0,13$ & 0,20 & 0,35 & 0,47 & 0,59 & 0,72 & 0,86 & 1,01 & 1,20 & 1,55 & 1,68 \\
\hline 90\%+Líq. & $-0,23$ & 0,13 & 0,29 & 0,42 & 0,54 & 0,67 & 0,81 & 0,97 & 1,17 & 1,53 & 1,76 \\
\hline Todas & $-0,28$ & 0,09 & 0,25 & 0,38 & 0,50 & 0,63 & 0,78 & 0,94 & 1,15 & 1,52 & 1,80 \\
\hline \multicolumn{12}{|c|}{ PAINEL E: Médias dos Betas Downside Relativos $\left(\beta_{i, t}^{-}-\beta_{i, t}\right)$} \\
\hline Portfólios & $\begin{array}{l}\text { 1: } \beta_{p, t} \\
\text { baixo }\end{array}$ & 2 & 3 & 4 & 5 & 6 & 7 & 8 & 9 & $\begin{array}{l}10: \beta_{p, t} \\
\text { alto }\end{array}$ & $\begin{array}{l}\text { Alto menos } \\
\text { baixo }\end{array}$ \\
\hline 10\% + Líq. & 0,05 & 0,01 & $-0,03$ & $-0,01$ & $-0,01$ & $-0,01$ & $-0,01$ & $-0,02$ & $-0,01$ & 0,01 & $-0,04$ \\
\hline $25 \%+$ Líq. & 0,07 & 0,05 & 0,03 & 0,00 & 0,01 & 0,02 & 0,01 & $-0,02$ & $-0,01$ & $-0,02$ & $\begin{array}{l}-0,09 \\
\end{array}$ \\
\hline 40\%+Líq. & 0,09 & 0,06 & 0,05 & 0,04 & 0,00 & 0,01 & 0,01 & 0,00 & $-0,01$ & $-0,03$ & $-0,12$ \\
\hline $\mathbf{5 0} \%+$ Líq. & 0,12 & 0,07 & 0,06 & 0,06 & 0,02 & 0,01 & 0,00 & $-0,01$ & $-0,01$ & $-0,04$ & $-0,15$ \\
\hline 60\% + Líq. & 0,14 & 0,07 & 0,07 & 0,06 & 0,04 & 0,01 & 0,01 & 0,00 & $-0,02$ & $-0,04$ & $-0,18$ \\
\hline 75\% + Líq. & 0,16 & 0,08 & 0,06 & 0,06 & 0,05 & 0,02 & 0,01 & 0,00 & $-0,02$ & $-0,05$ & $-0,21$ \\
\hline 90\% + Líq. & 0,18 & 0,08 & 0,06 & 0,05 & 0,05 & 0,03 & 0,00 & 0,00 & $-0,02$ & $-0,06$ & $-0,24$ \\
\hline Todas & 0,18 & 0,09 & 0,06 & 0,04 & 0,05 & 0,03 & 0,00 & $-0,01$ & $-0,03$ & $-0,07$ & $-0,25$ \\
\hline
\end{tabular}


Tabela 15 - Portfólios Formados pelo Beta, com Retornos Mês à Frente Anualizados, em Diferentes Cortes de Liquidez

\begin{tabular}{|c|c|c|c|c|c|c|c|c|c|c|c|}
\hline \multicolumn{12}{|c|}{ PAINEL A: Média do Excesso de Retorno } \\
\hline Portfólios & $\begin{array}{l}\text { 1: } \beta_{p, t} \\
\text { baixo }\end{array}$ & 2 & 3 & 4 & 5 & 6 & 7 & 8 & 9 & $\begin{array}{l}\text { 10: } \beta_{p, t} \\
\text { alto }\end{array}$ & $\begin{array}{l}\text { Alto menos } \\
\text { baixo (Estat. t) }\end{array}$ \\
\hline 10\% + Líq. & $-9,20$ & $-0,82$ & 9,79 & $-2,78$ & $-5,05$ & 2,69 & 0,73 & 1,31 & $-4,94$ & $-13,16$ & $-3,96(-0,41)$ \\
\hline 25\% + Líq. & $-0,33$ & 2,05 & $-0,49$ & 10,25 & 4,21 & 5,59 & 0,77 & $-4,80$ & 1,47 & $-13,65$ & $-13,32(-1,65)$ \\
\hline 40\% + Líq. & 5,12 & 7,38 & 4,08 & 0,76 & 7,45 & 3,69 & 4,41 & $-0,14$ & $-1,44$ & $-10,64$ & $-15,77(-2,09)$ \\
\hline $\mathbf{5 0} \%+$ Líq. & 2,09 & 7,99 & 1,13 & 8,08 & 2,36 & 5,19 & 5,61 & 0,57 & $-3,29$ & $-10,18$ & $-12,26(-1,57)$ \\
\hline 60\% + Líq. & 1,20 & 2,67 & 3,37 & 7,12 & 4,55 & 4,40 & 3,93 & 2,09 & $-0,29$ & $-8,11$ & $-9,30(-1,25)$ \\
\hline 75\% + Líq. & $-0,80$ & 1,23 & 6,58 & 5,46 & 2,07 & 5,37 & 4,35 & 5,46 & $-0,21$ & $-4,55$ & $-3,76(-0,55)$ \\
\hline 90\% + Líq. & 9,39 & 2,45 & 4,24 & 6,07 & 6,73 & 6,03 & 1,86 & 3,21 & 2,61 & $-4,56$ & $-13,95(-2,01)$ \\
\hline Todas & 2,67 & 0,54 & $-1,96$ & 3,62 & 5,32 & 4,47 & 0,37 & 3,18 & $-0,72$ & $-2,65$ & $-5,32(-0,74)$ \\
\hline \multicolumn{12}{|c|}{ PAINEL B: Média dos Betas $\left(\beta_{p, t}\right)$} \\
\hline Portfólios & $\begin{array}{l}\text { 1: } \beta_{p, t} \\
\text { baixo }\end{array}$ & 2 & 3 & 4 & 5 & 6 & 7 & 8 & 9 & $\begin{array}{l}\text { 10: } \beta_{p, t} \\
\text { alto }\end{array}$ & $\begin{array}{l}\text { Alto menos } \\
\text { baixo }\end{array}$ \\
\hline 10\% + Líq. & 0,34 & 0,53 & 0,65 & 0,79 & 0,95 & 1,09 & 1,18 & 1,29 & 1,40 & 1,73 & 1,38 \\
\hline $25 \%+$ Líq. & 0,27 & 0,48 & 0,60 & 0,72 & 0,85 & 0,97 & 1,08 & 1,20 & 1,36 & 1,68 & 1,42 \\
\hline 40\%+Líq. & 0,19 & 0,43 & 0,56 & 0,68 & 0,79 & 0,91 & 1,03 & 1,17 & 1,32 & 1,66 & 1,46 \\
\hline $\mathbf{5 0} \%+$ Líq. & 0,15 & 0,39 & 0,52 & 0,65 & 0,75 & 0,87 & 0,99 & 1,13 & 1,29 & 1,63 & 1,48 \\
\hline 60\%+Líq. & 0,09 & 0,36 & 0,48 & 0,61 & 0,72 & 0,83 & 0,95 & 1,09 & 1,27 & 1,61 & 1,52 \\
\hline 75\% + Líq. & 0,00 & 0,28 & 0,42 & 0,54 & 0,66 & 0,77 & 0,90 & 1,04 & 1,23 & 1,58 & 1,57 \\
\hline 90\%+Líq. & $-0,08$ & 0,21 & 0,36 & 0,48 & 0,61 & 0,73 & 0,86 & 1,00 & 1,19 & 1,55 & 1,63 \\
\hline Todas & $-0,12$ & 0,17 & 0,31 & 0,44 & 0,56 & 0,69 & 0,82 & 0,97 & 1,16 & 1,53 & 1,65 \\
\hline \multicolumn{12}{|c|}{ PAINEL C: Médias dos Betas Downside $\left(\beta_{i, t}^{-}\right)$} \\
\hline Portfólios & $\begin{array}{l}\text { 1: } \beta_{p, t} \\
\text { baixo }\end{array}$ & 2 & 3 & 4 & 5 & 6 & 7 & 8 & 9 & $\begin{array}{l}\text { 10: } \beta_{p, t} \\
\text { alto }\end{array}$ & $\begin{array}{l}\text { Alto menos } \\
\text { baixo }\end{array}$ \\
\hline 10\% + Líq. & 0,31 & 0,50 & 0,63 & 0,77 & 0,92 & 1,06 & 1,15 & 1,30 & 1,41 & 1,82 & 1,51 \\
\hline $25 \%+$ Líq. & 0,26 & 0,46 & 0,60 & 0,74 & 0,86 & 0,97 & 1,07 & 1,23 & 1,37 & 1,79 & 1,53 \\
\hline 40\%+Líq. & 0,20 & 0,43 & 0,57 & 0,69 & 0,82 & 0,92 & 1,04 & 1,20 & 1,36 & 1,77 & 1,57 \\
\hline $\mathbf{5 0} \%+$ Líq. & 0,17 & 0,40 & 0,54 & 0,65 & 0,78 & 0,89 & 1,01 & 1,16 & 1,33 & 1,73 & 1,56 \\
\hline 60\% + Líq. & 0,12 & 0,37 & 0,50 & 0,63 & 0,75 & 0,86 & 0,98 & 1,13 & 1,32 & 1,70 & 1,58 \\
\hline 75\% + Líq. & 0,03 & 0,30 & 0,44 & 0,57 & 0,68 & 0,81 & 0,93 & 1,07 & 1,28 & 1,67 & 1,63 \\
\hline 90\% + Líq. & $-0,05$ & 0,23 & 0,38 & 0,51 & 0,62 & 0,77 & 0,90 & 1,04 & 1,25 & 1,64 & 1,69 \\
\hline Todas & $-0,10$ & 0,18 & 0,34 & 0,47 & 0,59 & 0,72 & 0,86 & 1,00 & 1,21 & 1,61 & 1,71 \\
\hline
\end{tabular}


cont. Tabela 15 - Portfólios Formados pelo Beta, com Retornos Mês à Frente Anualizados, em Diferentes Cortes de Liquidez

PAINEL D: Médias dos Betas Upside $\left(\beta_{i, t}^{+}\right)$

\begin{tabular}{|c|c|c|c|c|c|c|c|c|c|c|c|}
\hline \multicolumn{12}{|c|}{ PAINEL D: Médias dos Betas Upside $\left(\beta_{i, t}^{+}\right)$} \\
\hline Portfólios & $\begin{array}{l}\text { 1: } \beta_{p, t} \\
\text { baixo }\end{array}$ & 2 & 3 & 4 & 5 & 6 & 7 & 8 & 9 & $\begin{array}{l}\text { 10: } \beta_{p, t} \\
\text { alto }\end{array}$ & $\begin{array}{l}\text { Alto menos } \\
\text { baixo }\end{array}$ \\
\hline 10\% + Líq. & 0,39 & 0,58 & 0,68 & 0,82 & 0,98 & 1,14 & 1,22 & 1,27 & 1,38 & 1,61 & 1,22 \\
\hline 25\% + Líq. & 0,27 & 0,50 & 0,59 & 0,71 & 0,84 & 0,97 & 1,08 & 1,16 & 1,34 & 1,53 & 1,26 \\
\hline 40\%+Líq. & 0,18 & 0,42 & 0,54 & 0,67 & 0,76 & 0,89 & 1,01 & 1,12 & 1,27 & 1,49 & 1,31 \\
\hline $\mathbf{5 0} \%+$ Líq. & 0,12 & 0,38 & 0,50 & 0,63 & 0,71 & 0,83 & 0,95 & 1,08 & 1,22 & 1,49 & 1,37 \\
\hline 60\% + Líq. & 0,06 & 0,33 & 0,45 & 0,57 & 0,67 & 0,78 & 0,90 & 1,04 & 1,18 & 1,48 & 1,42 \\
\hline 75\% + Líq. & $-0,04$ & 0,25 & 0,38 & 0,49 & 0,61 & 0,71 & 0,84 & 0,99 & 1,13 & 1,44 & 1,48 \\
\hline 90\%+Líq. & $-0,12$ & 0,19 & 0,32 & 0,43 & 0,57 & 0,66 & 0,79 & 0,94 & 1,10 & 1,42 & 1,54 \\
\hline Todas & $-0,17$ & 0,15 & 0,28 & 0,39 & 0,52 & 0,64 & 0,75 & 0,92 & 1,07 & 1,40 & 1,57 \\
\hline \multicolumn{12}{|c|}{ PAINEL E: Médias dos Betas Downside Relativos $\left(\beta_{i, t}^{-}-\beta_{i, t}\right)$} \\
\hline Portfólios & $\begin{array}{l}\text { 1: } \beta_{p, t} \\
\text { baixo }\end{array}$ & 2 & 3 & 4 & 5 & 6 & 7 & 8 & 9 & $\begin{array}{l}\text { 10: } \beta_{p, t} \\
\text { alto }\end{array}$ & $\begin{array}{l}\text { Alto menos } \\
\text { baixo }\end{array}$ \\
\hline 10\%+Líq. & $-0,03$ & $-0,03$ & $-0,02$ & $-0,02$ & $-0,02$ & $-0,03$ & $-0,03$ & 0,01 & 0,01 & 0,10 & 0,13 \\
\hline $25 \%+L i ́ q$. & 0,00 & $-0,02$ & 0,01 & 0,01 & 0,01 & 0,00 & $-0,01$ & 0,03 & 0,01 & 0,11 & 0,11 \\
\hline 40\% + Líq. & 0,01 & 0,00 & 0,01 & 0,01 & 0,02 & 0,01 & 0,01 & 0,03 & 0,03 & 0,11 & 0,10 \\
\hline $\mathbf{5 0} \%+$ Líq. & 0,02 & 0,01 & 0,02 & 0,01 & 0,02 & 0,02 & 0,02 & 0,03 & 0,04 & 0,10 & 0,08 \\
\hline 60\% + Líq. & 0,02 & 0,02 & 0,02 & 0,02 & 0,03 & 0,03 & 0,03 & 0,03 & 0,05 & 0,09 & 0,06 \\
\hline 75\% + Líq. & 0,03 & 0,02 & 0,02 & 0,03 & 0,02 & 0,04 & 0,04 & 0,03 & 0,05 & 0,09 & 0,06 \\
\hline 90\% + Líq. & 0,03 & 0,02 & 0,02 & 0,03 & 0,02 & 0,04 & 0,04 & 0,04 & 0,05 & 0,09 & 0,06 \\
\hline Todas & 0,03 & 0,01 & 0,02 & 0,03 & 0,02 & 0,03 & 0,04 & 0,03 & 0,05 & 0,08 & 0,06 \\
\hline
\end{tabular}


Tabela 16 - Portfólios Formados pelo Beta Downside Relativo, com Retornos Mês à Frente Anualizados, em Diferentes Cortes de Liquidez

\begin{tabular}{|c|c|c|c|c|c|c|c|c|c|c|c|}
\hline \multicolumn{12}{|c|}{ PAINEL A: Média do Excesso de Retorno } \\
\hline Portfólios & $\begin{array}{l}\text { 1: } \beta_{p, t} \\
\text { baixo }\end{array}$ & 2 & 3 & 4 & 5 & 6 & 7 & 8 & 9 & $\begin{array}{l}\text { 10: } \beta_{p, t} \\
\text { alto }\end{array}$ & $\begin{array}{l}\text { Alto menos } \\
\text { baixo (Estat. t) }\end{array}$ \\
\hline 10\% + Líq. & $-2,65$ & 1,73 & 0,99 & $-5,76$ & 9,79 & 1,26 & 1,67 & $-8,46$ & $-9,61$ & $-10,73$ & $-8,09(-0,78)$ \\
\hline $25 \%+$ Líq. & $-1,59$ & 1,82 & $-0,66$ & 4,26 & 3,71 & 2,65 & 0,40 & 6,26 & $-8,49$ & $-3,85$ & $-2,26(-0,32)$ \\
\hline 40\% + Líq. & $-2,54$ & 8,61 & 1,25 & 0,96 & 9,25 & 5,90 & 1,47 & 0,86 & 0,10 & $-4,96$ & $-2,41(-0,38)$ \\
\hline $\mathbf{5 0} \%+$ Líq. & $-3,90$ & 7,53 & 4,16 & 0,76 & 7,02 & 2,90 & 4,12 & $-1,02$ & 5,63 & $-7,31$ & $-3,41(-0,56)$ \\
\hline 60\%+Líq. & $-1,30$ & 5,57 & 1,97 & 1,37 & 6,71 & 0,07 & 3,17 & 0,39 & 4,68 & $-1,73$ & $-0,43(-0,07)$ \\
\hline 75\% + Líq. & $-2,73$ & 5,62 & 1,09 & 5,65 & 5,61 & 2,23 & 0,10 & 2,24 & 5,87 & $-0,92$ & $1,81(0,30)$ \\
\hline 90\%+Líq. & 1,18 & 8,37 & 2,77 & 3,93 & 7,48 & 2,44 & 3,57 & 4,03 & 5,99 & $-1,83$ & $-3,02(-0,51)$ \\
\hline Todas & $-0,81$ & 5,02 & 3,10 & $-0,71$ & 6,45 & $-1,20$ & 0,00 & 3,04 & 3,29 & $-3,34$ & $-2,53(-0,45)$ \\
\hline \multicolumn{12}{|c|}{ PAINEL B: Média dos Betas $\left(\beta_{p, t}\right)$} \\
\hline Portfólios & $\begin{array}{l}\text { 1: } \beta_{p, t} \\
\text { baixo }\end{array}$ & 2 & 3 & 4 & 5 & 6 & 7 & 8 & 9 & $\begin{array}{l}\text { 10: } \beta_{p, t} \\
\text { alto }\end{array}$ & $\begin{array}{l}\text { Alto menos } \\
\text { baixo }\end{array}$ \\
\hline 10\% + Líq. & 0,89 & 0,82 & 0,89 & 0,95 & 1,05 & 1,02 & 1,05 & 0,99 & 1,03 & 1,23 & 0,33 \\
\hline $25 \%+$ Líq. & 0,89 & 0,82 & 0,86 & 0,93 & 0,92 & 0,88 & 0,80 & 0,85 & 1,01 & 1,23 & 0,34 \\
\hline 40\% + Líq. & 0,84 & 0,77 & 0,81 & 0,85 & 0,86 & 0,79 & 0,80 & 0,87 & 0,98 & 1,16 & 0,32 \\
\hline $\mathbf{5 0} \%+$ Líq. & 0,83 & 0,74 & 0,79 & 0,81 & 0,80 & 0,75 & 0,80 & 0,84 & 0,93 & 1,08 & 0,24 \\
\hline 60\%+Líq. & 0,81 & 0,71 & 0,74 & 0,78 & 0,75 & 0,73 & 0,77 & 0,80 & 0,89 & 1,00 & 0,19 \\
\hline 75\% + Líq. & 0,75 & 0,65 & 0,67 & 0,73 & 0,69 & 0,69 & 0,71 & 0,75 & 0,83 & 0,93 & 0,18 \\
\hline 90\%+Líq. & 0,67 & 0,60 & 0,62 & 0,67 & 0,67 & 0,66 & 0,68 & 0,69 & 0,77 & 0,86 & 0,18 \\
\hline Todas & 0,65 & 0,56 & 0,58 & 0,63 & 0,63 & 0,62 & 0,64 & 0,66 & 0,74 & 0,82 & 0,17 \\
\hline \multicolumn{12}{|c|}{ PAINEL C: Médias dos Betas Downside $\left(\beta_{i, t}^{-}\right)$} \\
\hline Portfólios & $\begin{array}{l}\text { 1: } \beta_{p, t} \\
\text { baixo }\end{array}$ & 2 & 3 & 4 & 5 & 6 & 7 & 8 & 9 & $\begin{array}{l}\text { 10: } \beta_{p, t} \\
\text { alto }\end{array}$ & $\begin{array}{l}\text { Alto menos } \\
\text { baixo }\end{array}$ \\
\hline 10\%+Líq. & 0,71 & 0,71 & 0,82 & 0,91 & 1,03 & 1,01 & 1,06 & 1,04 & 1,13 & 1,44 & 0,73 \\
\hline 25\% + Líq. & 0,70 & 0,72 & 0,80 & 0,89 & 0,91 & 0,90 & 0,84 & 0,94 & 1,14 & 1,50 & 0,80 \\
\hline 40\% + Líq. & 0,64 & 0,67 & 0,75 & 0,82 & 0,86 & 0,82 & 0,86 & 0,97 & 1,14 & 1,45 & 0,81 \\
\hline $\mathbf{5 0} \%+$ Líq. & 0,62 & 0,64 & 0,73 & 0,79 & 0,80 & 0,79 & 0,87 & 0,95 & 1,10 & 1,39 & 0,77 \\
\hline 60\%+Líq. & 0,59 & 0,60 & 0,68 & 0,76 & 0,76 & 0,77 & 0,85 & 0,92 & 1,06 & 1,34 & 0,74 \\
\hline 75\% + Líq. & 0,52 & 0,54 & 0,61 & 0,70 & 0,70 & 0,74 & 0,79 & 0,87 & 1,01 & 1,29 & 0,77 \\
\hline 90\% + Líq. & 0,43 & 0,48 & 0,56 & 0,65 & 0,67 & 0,70 & 0,76 & 0,82 & 0,97 & 1,24 & 0,81 \\
\hline Todas & 0,39 & 0,44 & 0,52 & 0,61 & 0,64 & 0,66 & 0,72 & 0,78 & 0,93 & 1,20 & 0,81 \\
\hline
\end{tabular}


cont. Tabela 16 - Portfólios Formados pelo Beta Downside Relativo, com Retornos Mês à Frente Anualizados, em Diferentes Cortes de Liquidez

\begin{tabular}{|c|c|c|c|c|c|c|c|c|c|c|c|}
\hline & & & & $I N E L$ & : Méd & $\operatorname{dos} B$ & tas Ups & $\boldsymbol{e}\left(\boldsymbol{\beta}_{i, t}^{+}\right.$ & & & \\
\hline Portfólios & $\begin{array}{l}\text { 1: } \beta_{p, t} \\
\text { baixo }\end{array}$ & 2 & 3 & 4 & 5 & 6 & 7 & 8 & 9 & $\begin{array}{l}\text { 10: } \beta_{p, t} \\
\text { alto }\end{array}$ & $\begin{array}{l}\text { Alto menos } \\
\text { baixo }\end{array}$ \\
\hline 10\% + Líq. & 1,16 & 0,97 & 0,99 & 1,02 & 1,09 & 1,03 & 1,03 & 0,93 & 0,90 & 0,92 & $-0,24$ \\
\hline $25 \%+$ Líq. & 1,17 & 0,97 & 0,95 & 0,97 & 0,93 & 0,86 & 0,73 & 0,73 & 0,81 & 0,84 & $-0,32$ \\
\hline 40\% + Líq. & 1,13 & 0,93 & 0,90 & 0,89 & 0,85 & 0,74 & 0,70 & 0,71 & 0,75 & 0,73 & $-0,40$ \\
\hline $\mathbf{5 0} \%+$ Líq. & 1,13 & 0,90 & 0,87 & 0,85 & 0,78 & 0,70 & 0,69 & 0,67 & 0,68 & 0,62 & $-0,52$ \\
\hline 60\% + Líq. & 1,12 & 0,86 & 0,82 & 0,81 & 0,73 & 0,67 & 0,66 & 0,63 & 0,62 & 0,52 & $-0,60$ \\
\hline 75\% + Líq. & 1,07 & 0,81 & 0,76 & 0,76 & 0,67 & 0,62 & 0,59 & 0,56 & 0,55 & 0,40 & $-0,67$ \\
\hline 90\% + Líq. & 1,02 & 0,77 & 0,71 & 0,70 & 0,65 & 0,59 & 0,56 & 0,50 & 0,49 & 0,30 & $-0,72$ \\
\hline Todas & 1,02 & 0,73 & 0,68 & 0,67 & 0,62 & 0,55 & 0,52 & 0,47 & 0,45 & 0,27 & $-0,75$ \\
\hline Portfólios & $\begin{array}{l}\text { 1: } \beta_{p, t} \\
\text { baixo }\end{array}$ & 2 & 3 & 4 & 5 & 6 & 7 & 8 & 9 & $\begin{array}{l}\text { 10: } \beta_{p, t} \\
\text { alto }\end{array}$ & $\begin{array}{l}\text { Alto menos } \\
\text { baixo }\end{array}$ \\
\hline 10\% + Líq. & $-0,19$ & $-0,10$ & $-0,07$ & $-0,04$ & $-0,02$ & $-0,01$ & 0,01 & 0,05 & 0,09 & 0,21 & 0,40 \\
\hline 25\% + Líq. & $-0,19$ & $-0,11$ & $-0,06$ & $-0,03$ & $-0,01$ & 0,02 & 0,05 & 0,08 & 0,14 & 0,26 & 0,46 \\
\hline 40\% + Líq. & $-0,20$ & $-0,11$ & $-0,06$ & $-0,03$ & 0,00 & 0,03 & 0,06 & 0,10 & 0,16 & 0,29 & 0,50 \\
\hline $\mathbf{5 0} \%+$ Líq. & $-0,22$ & $-0,11$ & $-0,06$ & $-0,03$ & 0,00 & 0,04 & 0,07 & 0,11 & 0,17 & 0,31 & 0,53 \\
\hline 60\% + Líq. & $-0,22$ & $-0,11$ & $-0,06$ & $-0,02$ & 0,01 & 0,04 & 0,07 & 0,12 & 0,18 & 0,33 & 0,55 \\
\hline 75\% + Líq. & $-0,23$ & $-0,11$ & $-0,06$ & $-0,02$ & 0,01 & 0,04 & 0,08 & 0,12 & 0,19 & 0,36 & 0,59 \\
\hline 90\%+Líq. & $-0,25$ & $-0,12$ & $-0,06$ & $-0,03$ & 0,01 & 0,04 & 0,08 & 0,12 & 0,19 & 0,38 & 0,63 \\
\hline Todas & $-0,26$ & $-0,13$ & $-0,07$ & $-0,03$ & 0,01 & 0,04 & 0,08 & 0,12 & 0,19 & 0,38 & 0,64 \\
\hline
\end{tabular}

